Illinois State University

ISU ReD: Research and eData

Theses and Dissertations

$9-12-2013$

\title{
Homophonic Translation, Appositional Writing, And The Monster
}

Ryan Landry Clark

Illinois State University, ryanlandryclark@gmail.com

Follow this and additional works at: https://ir.library.illinoisstate.edu/etd

Part of the Curriculum and Instruction Commons, Educational Methods Commons, English Language and Literature Commons, and the Ethics and Political Philosophy Commons

\section{Recommended Citation}

Clark, Ryan Landry, "Homophonic Translation, Appositional Writing, And The Monster" (2013). Theses and Dissertations. 34.

https://ir.library.illinoisstate.edu/etd/34

This Dissertation is brought to you for free and open access by ISU ReD: Research and eData. It has been accepted for inclusion in Theses and Dissertations by an authorized administrator of ISU ReD: Research and eData. For more information, please contact ISUReD@ilstu.edu. 


\title{
HOMOPHONIC TRANSLATION, APPOSITIONAL WRITING,
}

\section{AND THE MONSTER}

\author{
Ryan L. Clark
}

235 Pages

December 2013

This dissertation features a combination of critical and creative work exploring the ethics of appropriative writing and the reparative potential of homophonic translation. The opening essay examines the ethics of appropriation-based poetry and introduces the concept of what I call "appositional writing," a term to describe ethically-minded works of poetry that make use of appropriative writing methods. The next three parts of this dissertation are each appositional writing projects that make use of homophonic translation as the primary method of composition. "Arizona State Bill 1070: An Act" is a homophonic translation of the anti-immigration bill of the same name. In this work, I investigate at various points the idea of borders, the necessity of migration, the politics of race and language, and xenophobia. "How I Pitched the First Curve" is a sequence of ten different homophonic translations of an article written by William Arthur "Candy" Cummings that describes Cummings' invention of the curveball in the early days of organized baseball. With each translation, I examine various social issues that are as deeply rooted within the game of baseball as they are in American culture. In "Is Ryan Clark a Monster?" I interrogate my own potential for domination and violence by 
delving into personal trauma, incorporating homophonic translations of text message responses from friends and family to the question "Is Ryan Clark a monster?". This dissertation concludes with a pedagogical essay discussing the potential benefits of teaching appropriative writing in an introductory-level creative writing course. Throughout this dissertation I hope to show that as authors increasingly turn to appropriative writing methods and incorporate found language into their work, it is important to examine the various ethical risks involved with the act of appropriation, both in our respective writing communities and in our classrooms. 
HOMOPHONIC TRANSLATION, APPOSITIONAL WRITING, AND THE MONSTER

RYAN L. CLARK

A Dissertation Submitted in Partial

Fulfillment of the Requirements

for the Degree of

DOCTOR OF PHILOSOPHY

Department of English

ILLINOIS STATE UNIVERSITY 
Copyright 2013 Ryan L. Clark 
HOMOPHONIC TRANSLATION, APPOSITIONAL WRITING, AND THE MONSTER

RYAN L. CLARK

COMMITTEE MEMBERS:

Gabriel Gudding, Chair

Duriel E. Harris

Kass Fleischer 


\section{ACKNOWLEDGMENTS}

As solitary as writing often feels, I have received outstanding encouragement, feedback, direction, and support during and leading up to my work with this dissertation. I would like to first express my sincerest gratitude to my committee: Gabriel Gudding, whose support and guidance extend far beyond merely providing me with a wealth of feedback on my work or introducing me to moral philosophy or watching my cat when I've been out of town; Duriel E. Harris, whose encouragement for me to confront all aspects of my humanness, joy and tragedy alike, set in motion a process of maturation in my writing and in myself for which I will be forever grateful; and Kass Fleischer, whose Experimental Autobiography course and whose directness in the classroom helped me to be more direct and forthcoming with myself in my writing. I would also like to thank Michelle Naka Pierce, without whom I would neither have pursued a career as a teacher nor would I have stumbled across and then fallen in love with homophonic translation. The mentorship of Kirstin Zona has been a highlight of my time at Illinois State, and for that I am quite grateful. I could not have made it through this dissertation or the doctoral program without Shailen Mishra and Jamison Lee, with whom I have commiserated, formed writing contracts, and found a great deal of stress relief.

I appreciate the text messaging assistance of those who responded to my query, "Is 
Ryan Clark a monster?", including some whom I have already thanked and also Gina Cooke, Alan Lin, Jane Carman, Nicholas A. DeBoer, Steven and Susan Clark, Travis Macdonald, Jen Marie Macdonald, Nate Jordan, Travis Cebula, Christopher Edwards, Rebecca George, Jonathan Morris, Adrienne Dodt, Quintus Havis, Kimberly Castañon, Merissa Nathan Gerson, Pankaj Challa, Susana Rodriguez, Jordan Cox, Brendan Hamilton, and Jarret Noll.

Some portions of the creative work featured in this dissertation have previously been published in the following journals: Seven Corners, which published an excerpt from “Arizona State Bill 1070: An Act”; Similar Peaks Poetry, which published "Top of the First" from "How I Pitched the First Curve"; Smoking Glue Gun, which published an excerpt from “Arizona State Bill 1070: An Act”; and Tenderloin, which published material from "Is Ryan Clark a Monster?". To each of these journals and their editors I express my gratitude.

Finally, I want to thank Melanie Goss, who is the greatest friend and source of support that I have ever known.

R.L.C. 


\section{CONTENTS}

\section{CHAPTER}

I. APPOSITIONAL POETICS: TOWARD AN ETHICS OF

Contextualizing the Ethics of Appropriative Writing:

The Dissolution of the Subject

Moving Toward the Appositional

The Risk of Arrogance in Appropriation

The Risk of Asymmetrical Power Relations

The Risk of Exceeding Reasonable Responsibility

A Detailed Discussion of an Appositional Text:

M. NourbeSe Philip's Zong!

Homophonic Translation as Appositional (re)Writing

"Arizona State Bill 1070: An Act"

"How I Pitched the First Curve"

"Is Ryan Clark a Monster?"

The Appositional Project

II. ARIZONA STATE BILL 1070: AN ACT 50

III. HOW I PITCHED THE FIRST CURVE 100

IV. IS RYAN CLARK A MONSTER? 173

V. APPROPRIATION AS INTRODUCTION 


\section{CHAPTER I}

\section{APPOSITIONAL POETICS:}

\section{TOWARD AN ETHICS OF APPROPRIATIVE WRITING}

On April 27, 2010, poet Kenneth Goldsmith declared on the Poetry Foundation's Harriet blog that "Conceptual Writing is a-ethical and wouldn't dare make the presumption that it has the power to affect the world for better or worse. Conceptual Poetry makes nothing happen. Conceptual Writing is the Switzerland of poetry. We're stuck in neutral. We believe in the moral weightlessness of art" ("If I were to raise my children," n.p.). This was, in part, a response to a small number of poets, including Mark Nowak and Martin Earl, who had recently posted on the blog about documentary poetics, a field of poetry which, like Conceptual Writing, often appropriates language from source materials in order to craft new creative work. Nowak, in particular, had criticized Goldsmith's previous descriptions of language as simply material to be filtered and appropriated; in citing his own research of coal mining disasters, Nowak claimed, "I have found this language to be anything but a debased, temporary "mere material"” ("25 miners," n.p.). With this debate, the question of the role of ethics in poetry (and the role of poetry in ethics) has found a new battleground: the explosion of appropriation-based writing practices in recent years that has coincided, in part, with the rise of the digital 
age. How are we to view this act of appropriation in the context of ethics? Or should we remain neutral on the subject, as Goldsmith suggests?

One of the key factors in this discussion is undoubtedly the question of exactly what becomes of text when it is removed from its original context and placed into the new context of an appropriative work. Does it, for example, become completely unmoored from its original context? As Goldsmith tends to argue, ${ }^{1}$ this is exactly what happens. While this line of thought certainly extends from the Modernist idea that texts are not anchored to a particular culture or time, the internet, with its ease of sharing, linking to, or outright copying and pasting of text, has helped to foster the notion that context is something that can be left behind, replaced, and wholly reconceptualized; the

${ }^{1}$ Goldsmith's stance on what becomes of appropriated text may be cloudier than I suggest, as he seems to express competing views. On April 5, 2010, Goldsmith wrote on the Harriet blog, "Language has become a provisional space, temporary and debased, mere material to be shoveled, reshaped, hoarded and molded into whatever form is convenient, only to be discarded just as quickly.” Later that month, on April 27, 2010, Goldsmith wrote on the Harriet blog in a separate post, "All language is pre-encoded with political, historical, and social DNA. We feel that writers try too hard to construct meaning when words are already so loaded, so meaningful.” Perhaps the earlier comment was the result of Goldsmith being flippant. Or perhaps the latter comment was an attempt to save face after Mark Nowak provided the example of testimony from survivors of coal mining accidents as being more than "mere material.” Nowak's blogpost (“25 miners killed in West Virginia coal mine blast") was posted on the Harriet blog on April 6, 2010. 
belief that such appropriation is a-ethical exists as an extension of this same premise, because the internet is itself neither ethical nor unethical (in the sense that it is a tool that can be used for good or for ill), and Conceptual Writing attempts to mirror workings of the internet. However, I find that this argument suffers from what I call the Fallacy of Unmoored Digital Text, or more simply the Unmooring Fallacy, for while a text's source may quite easily become clouded through a process of cycling through tweets, shared links, and endless copying and pasting, this does not negate the fact that an origin does exist, and that the origin is of a specific practical and cultural context. The internet may provide the illusion of a text unmoored from its context, but this is never completely so.

As Nowak, Earl, and others have argued, despite the ease of textual transport provided by digital technology, a text ${ }^{2}$ cannot be removed from its context, as written language and spoken utterance (as well as any communication through sign language or other methods) arises out of specific cultural settings. As William Burroughs once said of a cut-up page of Arthur Rimbaud's poetry, the new cut-up line remains Rimbaud's line; the new images, though reconfigured, remain Rimbaud's images (Burroughs and Gysin 4). If one were to appropriate language from the grieving widow of a coal miner, the language retains a link to its origin. This origin can either be brought forth as paratextual material in the form of a footnote or author's note, in which case the original context helps to create (or recreate) new meaning, or else the origin can be ignored by the writer with no link provided for the reader; regarding this latter case I would argue, as I make

${ }^{2} \mathrm{~A}$ "text" in this case may be as small as a phrase or line, or as large as a book or an overheard conversation. I simply mean it to stand for any appropriated language. 
clear later on, that this is an irresponsible move on the part of the author featuring a lack of considerateness not only for the original context but for the trauma of the grieving widow. In this way it quickly becomes evident that it matters where language comes from, and it matters how language is used. It matters when one chooses to perform erasure upon the recorded testimony of an African American slave, for example, because the action reinscribes centuries of domination and suppression. It is ethically significant in the light of bitter arguments between creationists and evolutionists when poet Marci Nelligan splices text from the Old Testament with text from The Origin of Species in an attempt to create poetry. It matters because such work can provide, even in small ways, models for treating others in the world, ranging from a considerate negotiation of differences to silencing voices through violence. As such, it is important to consider how one might work with appropriated text in considerate and ethically careful ways.

In examining the ethical implications of appropriative writing, I will contextualize this discussion by first demonstrating how the increase in the use of appropriative writing methods and the dissolution of the authorial subject in literary theory developed as movements parallel to one another; after then discussing the politicization of appropriative methods via the work of Guy DeBord and the Situationist Collective, which later spawned the phenomena of culture jamming, I will proceed to examine further the more recent digitalization of text and the accompanying explosion of appropriative writing practices through Conceptual Writing and a renewed interest in Documentary Poetry. The historicizing of the intersections between appropriative writing, literary theory, and ethics is an important step toward a fuller understanding of exactly how the 
Unmooring Fallacy came into being, as well as why Nowak and others maintain that appropriative writing can have profound moral and ethical implications.

From here, I will provide a detailed explanation of what I have termed "appositional writing," which is the intentional use of source texts to create new literary art that is ethically purposeful. By "appositional" I hope to draw upon the term's reference to placing things in close contact, which I believe to be an apt depiction of what appropriative writing does, namely putting different voices and texts in close proximity with one another. Further, appositional writing seeks to actively foster a climate of trust ${ }^{3}$ within and/or across communities by pro-socially writing with or against existing discourse, in the form of written text or uttered language, with a strong emphasis on care and repair along existing points of rupture within and/or across such communities. One particularly effective example of appositional writing, which will later be analyzed at

3 "Climate of trust" is a term used by Annette C. Baier to refer to the ability of people, living in a state of mutual vulnerability, to comfortably trust one another. Moral virtue is founded upon strengthening and contributing to this climate of trust, as opposed to damaging the climate of trust by mistreating others. Baier's emphasis on mutual vulnerability is key here, as a damaged climate of trust is harmful to all. Toward this end, she adamantly rejects "a sharp distinction between what concerns others and what concerns self" ("Demoralization, Trust, and the Virtues," 184). While this is not to say that a trust network cannot itself be corrupt (see: Nazi Germany, the Jim Crow South, and countless other examples), such a corrupt network would exist in a weak climate of trust, in which case mistrusting those who would dominate is ethically noble. 
length, is M. NourbeSe Philip's Zong!, a self-proclaimed work of "anti-narrative" written in response to the 1781 Zong Massacre. While Philip's work could also rightly be called oppositional, the type of work that Erica Hunt discusses at length in her essay "Notes for an Oppositional Poetics," I believe that apposition in this case could be viewed as a specific form of opposition, one that adopts appropriative methods in an attempt to write against and through an existing text. Zong!, then, is an example of opposition through apposition. ${ }^{4}$ As I illustrate the central tenets of appositional writing, I will explain three risks that may lead such a project to become ethically problematic, or even outright damaging to the overall climate of trust; I refer to these risks as the Risk of Arrogance in Appropriation (which can also be thought of as the Risk of Exceeding Permissions), the Risk of Asymmetrical Power Relations, and the Risk of Exceeding Reasonable Responsibility. Appositional writing runs the risk of damaging the climate of trust by assuming more than what one might reasonably expect to claim as one's own.

${ }^{4}$ The difference between opposition and apposition in this context is arguably too minor to warrant a new term to differentiate between them, and concerns have been raised that "appositional writing" undercuts the complexity and importance of oppositional writing. Despite their similarities, I believe that apposition functions in a way that is specific to appropriative writing projects and therefore it is important to thoroughly discuss the specific concerns regarding the ethics and efficacy of such projects. The distinctness of the appositional approach regarding the use of source texts demands its own separate discussion, even if the need for a separate term for this collection of writing projects is debatable. 
Asymmetrical power relations along sociopolitical lines between author and source material may magnify this issue. The case of Raymond McDaniel's Saltwater Empire, a book of poetry partially constructed out of first-person narratives from survivors of Hurricane Katrina, will serve as an example of an ethically problematic work of appropriative writing that fails to adequately consider these risks. McDaniel's book provides ample opportunity to examine exactly why and how a consideration of ethics, as well as the risks involved in an ethically ambitious project, becomes necessary in the development of an appropriation-based writing project. Finally, I will explain how homophonic translation, when reconceptualized as a method of re-sounding, is a particularly useful tool for appositional writing, as it is able to employ a text's own phonological excess as reparative material; toward this end I will cite three of my own writing projects as examples.

I hope that by re-centering the discussion of the ethical implications of appropriative writing more firmly within the field of moral philosophy, as opposed to remaining exclusively within the field of poetics or literary theory, we might begin to more seriously analyze what is at stake when text is repurposed. When Robin S. Dillon in her essay "Kant on Arrogance and Self-Respect" writes about primary arrogance as a presumed entitlement to more than what one should reasonably expect to be allotted, this raises a question to those of us who frequently appropriate source materials to create our 
art. Should $\mathrm{we}^{5}$ presume an entitlement to text? Or should we take a more nuanced approach? I believe that the latter is a far more palatable and ethically careful view, and I will turn to a variety of moral philosophers who offer significant points of discussion that help us to navigate through this question in morally responsible ways.

5 The "we" that I use throughout this essay is problematic due to the various social and cultural differences that exist between myself and other people in the world. The work of moral philosophers Alison Jaggar and Marilyn Friedman offer some insight into how to navigate a discussion of ethics across such differences. In her essay “Globalizing Feminist Ethics" Jaggar attempts "to develop an account of practical moral reason that shows how respect for cultural difference may be combined with claims to postconventional moral objectivity" (233), ultimately settling on a need for advocacy and dialogue over pushing prescriptive moral codes onto people from different cultures. Likewise, Friedman attempts to navigate the question of how exactly one is able to evaluate different moral viewpoints, suggesting that, whenever possible, one "should be prepared...to accept openness toward all new views at the early stages of encountering them," before deciding whether to trust or distrust such views. Friedman notes that views espousing scorn and hatred are perhaps less trustworthy beyond this early stage of consideration. The work of Jaggar and Friedman offer an interesting jumping off point for further discussion, but surely an examination of how to account for different viewpoints across cultures and identities is an immense project that cannot be fully covered here. 


\section{Contextualizing the Ethics of Appropriative Writing: The Dissolution of the Subject ${ }^{6}$}

By 1967, when Roland Barthes declared that "the birth of the reader must be at the cost of the death of the Author" (1470), William Burroughs and Brion Gysin had already begun experimenting with cut-ups. Tom Phillips, feeling inspired after reading an interview with Burroughs in the Paris Review in 1965, had started experimenting with the method himself; the following year, in 1966, he began work on his groundbreaking book of visual art-based erasure, A Humument, which was eventually published for the first time in 1970 (Introduction to A Humument n.p). And while various forms of appropriation have been used throughout literary history, perhaps most notably by T.S. Eliot, Marianne Moore, and other Modernist writers, the project of subject-dissolution (or, more specifically, the dissolution of the writer as a remarkable subject) coupled with the visionary work of Burroughs, Gysin, and Phillips was part of a collective signaling of a renewed sense of agency in the reader as creator, which itself followed Heidegger's claim that art, and not the artist, is the origin of a work of art (Heidegger 165). The site of the text's creation shifted from author to participatory reader, and the "tissue of

\footnotetext{
${ }^{6}$ While there are numerous ways that one might contextualize appropriative
} writing, due to the various thinkers, writers, artists, and performers who have taken part in or have theorized appropriative writing and other artistic acts of appropriation, I am choosing to foreground what I believe to be the particular traditions from which Conceptual Writing generally seems to originate. Also relevant to a deeper discussion of the ethics of appropriative writing are the artistic traditions of graffiti, sampling, and the remix, as well as various folk and oral traditions. 
quotations drawn from the innumerable centers of culture" (Barthes 1468) came to refer not only to any text's inherent intertextuality, but also to gestures of textual appropriation. The cut-up, for example, could be seen as an instance in which the source text was not read in typical left-right, top-down fashion, but in an order determined by the readercreator; in this sense, a cut-up might be seen as one person's reading of a text that is then mapped and shared. For that matter, any work of appropriative writing could be described in this manner: as a reading that has been pinned to the page, a shared, collaborative entity created by author and reader. As Deleuze and Guattari made clear, there is no subject; "there are only collective assemblages of enunciation" (18).

In addition to the announcement of "the birth of the reader," Julia Kristeva's concept of intertextuality, a logical progression from Barthes' claim that each text exists as a "tissue of quotations," is essential to the understanding of the ethical function of appropriative writing. She writes, "[A]ny text is constructed as a mosaic of quotations; any text is the absorption and transformation of another. The notion of intertextuality replaces that of intersubjectivity, and poetic language is read as at least double" (Kristeva 37). Texts, like people, exist in a state of relation to one another, one in which "[e]very new text inserts itself into history...becomes an absorption of, a reply to, or a transformation of preceding texts" (Brophy 79).

Influence is inevitable, a natural part of the creation of the new, but in appropriative writing this influence is made explicit; it calls attention to the fact of influence, though it does so embracingly, a far cry from Harold Bloom's Anxiety of Influence, which portrays influence as a source of anxiety that each poet must overcome 
in order to be considered "strong" and original. In viewing appropriative writing as an ethical engagement, we might consider how shedding light on the inevitability of influence has the potential to tear down both the illusion of isolation and also the Industrial Revolution-era notion of the author as a misunderstood genius, "who created only what was within him, regardless of the world and in defiance of a public whose only right was to accept him on his own terms or not at all" (Hobsbawm 261). Such realization of influence brought to the fore through appropriation, by highlighting this ever-present relationship with other people in the world, makes it possible to reconceptualize an author's ethical responsibility as we shift our understanding away from the authorial subject as a mere creator of texts and toward the act of writing itself as an engagement with others. Strange as it is to have to say in today's world, in that writing is an engagement with others it should be bound by the same kinds of moral obligations. The author is of course no longer considered isolated, but is also, contrary to Goldsmith, inevitably connected and morally beholden to others in the world.

In seeking "total participation" in the production of art and culture, Guy Debord, in his "Situationist Manifesto," first published in 1960, proclaims, "Against unilateral art, Situationist culture will be an art of dialogue, an art of interaction. [...] At a higher stage, everyone will become an artist, i.e., inseparably a producer-consumer of total culture creation" (350). Debord and the Situationists sought to transform the passive reception of culture's monologue into an active, co-constructed dialogue wherein the consumer becomes empowered as a producer. It is here where appropriative writing takes a political turn. Craig Dworkin refers to Debord's notion of "a radical reading embodied in writing" 
in an effort to explain the Situationist term détournement relative to appropriative writing

(11). Détournement, which comes from the French verb détourner (to 'deflect'), was used by the Situationists to refer to a repurposing of ready-made cultural output, most typically taking the form of language. "Taking what is given and improving upon it," writes Dworkin, "détournement unsettles hierarchies by initiating a dialogue in a formerly monologic setting and inscribing multiple authors and multiple sites for the generation of meaning" (13).

That meaning becomes participatory is not revolutionary or necessarily ethical in itself; it requires an intentional movement toward the ethical, and this is exactly what makes the Situationists so significant, as they specifically sought to turn capitalist discourse, such as advertisements, against the very system from which it was derived. Slogans would become repurposed as anti-capitalist critique, a symbolic rejection of the status quo. Out of this Situationist tradition, culture jamming (with its origins in the 1980s) seeks to transform media messages to expose and comment on their underlying ideologies and power structures. The magazine Ad Busters, in particular, has become well-known for this kind of activist work, famously détourning an image of Joe Camel into "Joe Chemo" as commentary on the advertisement of cigarettes. Jennifer A. Sandlin and Jennifer L. Milam write that "culture jamming is based on the idea of resisting the dominant ideology of consumerism and re-creating commercial culture in order to transform society" (325). Likewise, Carrie Lambert-Beatty writes that "[c]ulture jamming purposefully confuses cultural expression and political activism, mirroring a world in which culture and power, image and reality are inextricably intertwined" (101). It is clear 
that language and power, text and reality are inextricably intertwined as well, although it is less clear exactly to what extent this form of resistance and re-creation can actually prove socially transformative. Culture jamming, like the work of the Situationists before, has shown itself to be a politically efficacious blend of protest and art, but it remains specifically combative, and as a result, it proves quite limited; combat provides no opportunity for more nuanced kinds of moral repair, such as providing advocacy or witness to those who are largely ignored by mass media and commercial culture, such as the homeless or the mentally ill. A constant "writing against" provides valuable opportunities for social critique, but it lacks the ability to foster a more fully formed moral agent and a climate of care, repair, and mutuality.

While culture jamming has gained a foothold in the field of cultural and political activism, it has only been since the internet-inspired increase in appropriative writing practices that a similar form of détournement-based ethical engagement and activism has found its way, in earnest, into the field of creative writing. Poets such as Mark Nowak, Janet Holmes, Susan Howe, and M. NourbeSe Philip have written books founded on the ability of appropriative writing to take a text and détourn it not only for the purpose of cultural and political commentary, but to provide support and care and to promote empathy for populations who have been exploited, subjugated, or otherwise wronged. Nowak's work in documentary poetics is especially significant. This is not purely about protest, but about seeking to understand, coming to terms with, and pointing explicitly to the various forms of injustice that are perpetuated through language. This move toward empowerment, as opposed to simply combativeness, is an identifying feature of this kind 
of appropriative poetry, and it is the heart of appositional writing. Still, it must be said that this work makes up only a small portion of recent appropriative writing projects.

Much of the reason for this is due to the fact that the Conceptual Writing movement of Kenneth Goldsmith and others contributed greatly to the popularizing of appropriative writing methods in recent years. While appropriative writing practices continued throughout the 1970 s, ' 80 s, and '90s, the rise of the digital age around the turn of the century helped to spawn renewed interest in poets working with source texts. "While home computers have been around for three decades and people have been cutting and pasting all that time," writes Goldsmith, "it's the sheer penetration and saturation of broadband that makes the harvesting of masses of language easy and tempting" (Uncreative Writing 5). The ease of appropriation, then, encourages "writers to take their cues from the workings of technology and the Web as ways of constructing literature" (2); in this way, Goldsmith and other Conceptual writers, such as Craig Dworkin, have adopted the extension of digital technology into American culture as their kairotic moment. It would seem that appropriative writing, in Goldsmith's conceptualization, cannot be disentangled from our conceptualization of the internet. As he says, "Today, digital media has set the stage for a literary revolution" (Uncreative Writing 15); the internet, and its workings, will show us the way.

Considering that so much of Conceptual Writing's self-justification stems from this idea that the rise of digital technologies necessitates the reevaluation of creative writing as a practice and Creative Writing as a field, it is important to examine the internet in the context of how it has been theorized as an ethical tool for 
acknowledgment. Michael J. Hyde in 2006 claimed that "the act of acknowledging is a communicative behavior that grants attention to others and thereby makes room for them in our lives" (1). By recognizing and affirming the existence of others, acknowledgement is able to serve an ethical purpose in the world. Hyde also recognizes and addresses the harmful effects of negative acknowledgement, noting that acknowledgement in itself is not an ethical act, but is rather a tool with which one is able to use for good or ill. The internet, for example, provides users with an opportunity to acknowledge and engage with people with whom they would otherwise not be able to interact, leading to the formation of entire communities that exist exclusively in an online space. "No technology in the history of humankind (with the exception of language itself)," Hyde continues, "allows for and facilitates acknowledgment more than the personal computer" (224). This stands in contrast to Goldsmith's emphasis on language as "mere material," which seems to downplay or even ignore the network of acknowledgment between the users of language.

Conceptual Writing emphasizes the process of selecting and recontextualizing, which is itself a form of acknowledgement affirming the existence of ready-made text (and also an intertextual engagement with the network of authors behind such texts, although Goldsmith has ignored this part of the equation), and yet this, inexplicably, is the reason Goldsmith claims that this form of crafting art is "a-ethical." Due to the deemphasizing of traditional primary vehicles for moral content within the poem, namely the act of reading the words themselves, one might be inclined to agree with Goldsmith's claim. However, this formulation ignores, among other things, the rhetorical effects of 
appropriation demonstrated by Hyde's analysis. If Conceptual Writing takes as its guiding principle the workings of the internet, then the ethics of appropriation cannot be ignored. Whether acknowledgment makes someone feel appreciated, or whether it provides someone with a devastating blow, or whether it simply creates a space for someone in the world by recognizing her presence, there are often moral consequences. This principle is as relevant to people's language as it is to the people themselves, as our language represents us, stands in for us as our communicated (and communicating) versions of ourselves.

Hyde's analysis of the practice of acknowledgment as a "life-giving gift" provides us a way to understand what it means, rhetorically and ethically, to redefine writing as the recontextualization - rather than the creation - of text. Such an understanding pushes creative writing practices to mirror the workings of digital technology. If digital technology is an impetus for this shift in our understanding of literary art, we could then understand how the practice of appropriative writing operates as a tool which "allows for and facilitates acknowledgment" not merely of other texts, but other people and other experiences of being-in-the-world.

In writing about the relation between Conceptual Writing and the internet, Stephen Voyce brings our attention to the commons, the notion of the internet as a shared space. Heavily intertwined with the commons is the software programming term "open source," which Voyce describes as particularly relevant to our conception of appropriative writing in the digital age: 
Software programmers first introduced the term open source to describe a model of peer production in which users are free to access, modify, and collaborate on software code. [...] Applied to literature, the term evocatively brings into focus a number of issues relating to authorship and intertextuality, "intellectual property" and the public domain, poetic license and collective artistic production. One might speak of an open source poetics or commons-based poetics based on a decentralized and nonproprietary model of shared cultural codes, networks of dissemination, and collaborative authorship. (407)

Voyce goes on to argue that the cultural commons, the space of artistic exchange and "communal construction," must be defended in order to disturb "the boundaries we assign to the private and the public, the owned and the shared, the closed and the open" (424-25). This, he claims, is an intrinsic function of appropriative writing: to challenge the reader to ask, "how do we define the public domain, why should we protect it, and how might we expand it?" (424-25).

The value of this conception of an "open source poetics," in regard to the ethics of appropriative writing, is that by disturbing these boundaries, we are also bringing ourselves closer together with others. When one person invents a new internet meme and hundreds of other people create their own takes on that meme, there is a web of engagement, from the more immediate collaboration between meme-creator and memeadapter, to the wider intertextuality occurring from one version of the meme to the next. A meme invites the user to engage, to create their own take on the meme; this is the same 
invitation that is offered to the reader in a work of appropriative writing. One erasure encourages another, and another.

But this pattern of collaborative participation fostered by the premise of open source poetics falls short of providing a model for ethical engagement, simply because it does not require a writer to hold the intention of ethical engagement. There is of course a degree of benefit to certain collaborative activities, but collaboration on its own is by no means inherently ethical or even prosocial. The shootings at Columbine were a collaboration; the Holocaust was also a collaborative effort, which is not to forget the various regimes who collaborated with the Nazis. It is not enough to write collaboratively by bringing multiple voices into one's creative work; one must do so with ethical intention. And yet, reliance on good intentions is itself highly problematic. In his attempt to lay out a virtue theory of art, Peter Goldie stresses that ethical intention alone is not sufficient. Given that we "accept the importance of intentions in evaluating ethical action," he explains, "there is the second shared difficulty, of saying precisely what intentions count as being the right or appropriate ones" (Goldie 378). Goldie rightly calls attention to the idea that certain intentions are more ethical than others. I propose that the more ethical intentions are those that aim toward care and repair of a climate of trust and away from the domination and exploitation of others, as domination and exploitation only serve to weaken and corrupt a climate of trust. Further, because harm may still result even from these kinds of good intentions, one must also seek to be considerate of the potential effects of appropriation. This means that even an author who goes into an appropriative writing project with highly ethical intentions must still consider various factors that may 
result in unintended negative consequences, particularly the potential for the act of appropriation to damage the vulnerable trust network that exists between the appropriated text, the appropriating author, and the readership who engages the work. In the following section I will attempt to lay out precisely what factors should be considered and how they should be navigated if one is to pursue an ethically-intentioned appropriative writing project, to which I have given the term appositional writing.

\section{Moving Toward the Appositional}

As a term for the kind of writing that employs the use of source texts to intentionally address ethical and social concerns, appositional writing foregrounds juxtaposition and the act of bringing texts and voices into close proximity; it is the addition or application of one voice or text to another. Most of all, this form of writing compares favorably to the process of "appositional growth," which is a medical term referring to the addition of new layers of tissue on top of pre-existing layers, causing the tissue (typically made up of rigid material, such as bone) to increase in thickness and become stronger. Appositional writing, like appositional growth, may be seen as a reparative procedure, except that instead of biological tissue, it is the climate of trust that becomes strengthened; and rather than being utilized only in response to injury or illness, appositional writing is not a periodic medical treatment but a sustained project of apposition that seeks to foster the climate of trust with a continual emphasis on care. While appositional writing by definition requires ethical intentions, this does not mean that writing lacking intentionality of care and repair cannot be ethically impactful; 
likewise, the intentions of care and repair do not necessarily culminate in an ethically impactful text that fosters a climate of trust.

Baier's central thesis in her essay "Demoralization, Trust, and the Virtues" is founded upon the notion of mutual vulnerability and the power we hold over one another, "for good or ill," as well as the idea that moral virtues regulate precisely how we ought to treat one another such that a climate of trust can be maintained (177). She names thoughtfulness and considerateness as two particularly important virtues in this context. "The considerate person," Baier writes, "is appropriately aware of how her attitudes and actions affect those around her, and if necessary she alters them so as not to cause fear, hurt, annoyance, insult, or disappointment in others....If she has more power over the other than that one has over her, she will not flaunt it or use it ruthlessly for her own ends" (178). It is important to note the influence of power here, as we tend to be at our most vulnerable when someone has a great deal of power over us. We trust close friends with humiliating secrets about ourselves and trust that they will not use this knowledge to attack or embarrass us. We might allow a close friend or family member to borrow our car so they might run an important errand, trusting that they will not drive recklessly or simply drive off with the car never to be heard from again. The process of exposing our vulnerability to one another and not taking advantage of this vulnerability is particularly conducive to fostering a climate of trust; conversely, taking advantage of someone at their most vulnerable might completely destroy it.

In the larger, more communal sense, treating others respectfully and equitably helps strengthen a climate of trust, whereas mistreating or seeking to dominate or oppress 
others will no doubt weaken a climate of trust, as the mistreated become less trusting and those who mistreat them become less trustworthy. Thus, a society that tends toward equality will feature a stronger climate of trust than one that tends toward inequality. When a climate of trust becomes so weakened as to be fraught with inequality and oppression, when trusting those in power becomes little more than accepting institutionalized oppression, the trust network within that society has proven itself to be corrupt. According to Baier, "When the trust relationship itself is corrupt and perpetuates brutality, tyranny, or injustice, trusting may be silly self-exposure, and disappointing and betraying trust, including encouraged trust, may not be merely morally permissible but morally praiseworthy" (“Trust and Antitrust,” 253). ${ }^{7}$

Aimé Césaire's "Discourse on Colonialism” addresses exactly this sort of scenario playing out in the 20th century (and to this day) through European and American colonization of Africa, Asia, and elsewhere. When Césaire writes "that a nation which

${ }^{7}$ It is important to note that Baier's conceptualization of trust is quite distinct from the male-dominated history of moral philosophy, which can be seen as an ethics of justice that emphasizes obligation to social contracts. Baier and other feminist moral philosophers focus more on an ethics founded on relationships, love, and care. For Baier, than, it is not enough to simply uphold social contracts (not stealing from your neighbor, for example), but rather one should also seek to be generous and caring toward others. Cheshire Calhoun's essay entitled "Common Decency" offers a detailed analysis of how Ebenezer Scrooge may uphold his social contracts, but his lack of care and common decency marks him as a villainous character in need of moral guidance. 
colonizes, that a civilization which justifies colonization - and therefore force - is already a sick civilization, a civilization which is morally diseased" (39), we can also see how this sickness parallels the corrupt trust relationships at play. In circumstances such as these, "it may take fortitude to display distrust and heroism to disappoint the trust of the powerful," and yet this kind of distrust is morally just and indeed valuable to repairing that which has proved itself corrupt (Baier, "Trust and Antitrust," 259). Mistrust, in this case, can become not only necessary for survival, but also an important step toward establishing more equitable relations within or across societies, and thereby strengthening the climate of trust with an emphasis on care. Mistrust, at least initially, can help jumpstart this process of repair.

Poets have been theorizing about the intersections between poetry and relations of power for many years, aiming to find ways that poetry might aid in this important repair work, but it is the work of two poets in particular that I believe laid much of the groundwork for conceptualizing what it is to write with political or ethical intent. In seeking to write against the discourse of domination, Bruce Andrews' "Poetry as Explanation, Poetry as Praxis" and Erica Hunt's "Notes for an Oppositional Poetics" provide valuable signposts for any poet interested in writing with an eye toward social justice. Andrews is primarily concerned with "rewriting the social body" through a writing that "counter-occludes, or counter-disguises" and makes explicit the workings of society, including both historical and current relations of power, in an attempt to demonstrate its constructed nature (28-29). Poetry, in other words, becomes an explanation of how structures of power exert control through language, as well as a 
practice of demonstrating language as something that can never truly be controlled.

Making these processes, including language itself, visible as ongoing social constructions, as opposed to naturalized behaviors and static institutions, he argues, is a necessary precursor to reconstructing or rewriting society and social relations. This is a radical writing that "rewrites its material - in this case: the raw materials of a society, a collection of practices \& disavowals, governed by discourse" (29). If these practices are inscribed and naturalized in large part through language, then language would seem to need to play a role in transforming society toward a series of more equitable relations and practices. Even if poetry fails to ignite social change in a meaningful way, language can still help to make explicit the myriad vehicles of domination so that we might be made more aware of its workings.

Hunt affirms this when she writes how "Dominant forms of discourse...use convention and label to bind and organize us." We are limited by such discourse, "and we are simultaneously bearers of the codes of containment" (199-200). In order to break away, she claims, we must write against the dominant discourse, because although this alone cannot transform society, oppositional writing "enhances our capacity to strategically read our condition more critically and creatively," by making injustice explicit, so that we might interrupt the discourse of domination and craft something new and potentially healing in its wake (212). Such opposition is akin to the way in which mistrust can help to reveal those in power to be untrustworthy, creating room for the work of repair to begin strengthening the climate of trust as part of a move toward justice. 
It is not an accident that "appositional" differs from "oppositional" by a single letter, as Hunt's concept of oppositional poetics was highly influential in my initial conceptions of how appropriative writing can be conducive to the composition of ethically motivated writing projects. In an ethically-motivated work of erasure, for example, one can literally interrupt the discourse of domination by striking through the language, blurring it out, or using black-out or white-out methods. In this way one is able to scramble the message - not to encode it, but to free it of its old code, to replace injustice with a critical awareness and a gesture of care.

The move from opposition to apposition is in some ways a lateral one. Both are concerned with ways that writing might be able to interrupt the dominant discourse and foster increased social justice in its wake. On the surface it may even appear that the only thing that appositional writing does differently is adopt appropriative writing techniques as its preferred mode of composition. However, the use of appropriative writing methods allow for a particular kind of oppositional work (think: opposition via apposition), in which the discourse of domination itself is deformed, rearranged, translated, cut-up, or erased. This textual manipulation becomes a literal repair of the very language that advocates and exemplifies oppression, a repair which allows for the author to write herself into the text, to create room for other voices and narratives and ways of being in the world, to create room for possibility where there had previously been only a shutting down, a closing off of possibility. From the point of oppositional break, which is the cutting away from and disruption of the discourse of domination, an author can create room for advocacy (including advocacy for those who have been unjustly vilified or 
discredited by the discourse of domination), for justice, and self-narration out of the mess of disrepair. All of these are important steps within the appositional movement toward repair.

While similar in purpose to oppositional work, appositional writing seeks similar goals through different processes. There is indeed much overlap between the oppositional and appositional. M. NourbeSe Philip's Zong!, for instance, is clearly an oppositional text, but I would argue that it is also appositional due to its use of appropriative methods to compose the work. Meanwhile, a poem constructed as a collage of voices in praise of a cease-fire during an armed conflict may not specifically be oppositional, but it is appositional for its use of appropriative methods coupled with its ethical engagement with the world. Appositional work, largely due to its adopting appropriative writing methods, must deal with a slightly different and specific set of challenges from oppositional work. Most significantly, while apposition is able to turn the dominant discourse against itself, it must also maintain a heightened awareness of the various ethical concerns that arise due to the act of appropriation, or else risk reinscribing patterns of domination.

A more detailed explanation of the ethical model provided by appositional writing could not be considered sound by the standards of moral philosophy without first mapping out these various ethical risks involved. Heeding Baier's warning, any appositional writing project must maintain particular attention to the nuances of considerateness, especially in regard to questions of power. I will here examine three risks that one should consider before engaging an ethical project of appropriation, namely 
what I call the Risk of Arrogance in Appropriation (or the Risk of Exceeding

Permissions), the Risk of Asymmetrical Power Relations, and the Risk of Exceeding

Reasonable Responsibility.

\section{The Risk of Arrogance in Appropriation}

First, it is important to point out that appropriation historically has been used in the context of domination. Land, language, culture, goods, and even people have long been appropriated by dominant cultures as a result of what Robin S. Dillon refers to as "primary arrogance," a form of arrogance that she quotes the O.E.D. as meaning "the taking of too much upon oneself as one's right; the assertion of unwarrantable claims in respect of one's own importance; undue assumption of dignity, authority, or knowledge" (198). The United States and Europe have for centuries appropriated land, people, and resources because those in power felt that such land, people, and resources were entitled to their nation as resources. "I want it" makes a smooth transition into "I am entitled to it." There is a risk, then, for one who appropriates a text to replicate this action. At the very least, it begs the question, who is entitled to text? Those in positions of privilege, such as middle-class white males (myself, included), are surely more likely to assume this entitlement, even possibly as if it were a given. But what about those who have been (and are still) discouraged from such basic forms of social participation as voting? or marriage? Assuming entitlement to appropriate a text without recognizing it as entitlement therefore moves beyond a simple lack of self-awareness; such a writer falls in danger of reinscribing appropriation as an act of domination grounded in arrogance. 
Appropriative writing cannot help but also raise the issue of legal permissions. ${ }^{8}$ While, admittedly, some writers do make an effort to obtain such legal permissions prior to their appropriation of a text, many do not feel a need to request permissions prior to the publication of their small press book of appropriation-based poetry. The unlikelihood of legal prosecution due to the relative obscurity of the book does not change the moral weight of the action (or failure to act), but of course it does play a role in the pursuit of such a project, and the lack of any real legal obstacle might also play a role in a writer's failure to take into consideration the larger ethical implications of appropriating a particular text. If there is no risk of legal penalty, it is perhaps easier to overlook the potential for any other kind of risk involved, such as the risk of arrogance in appropriation.

It is especially useful here to consider the case of Raymond McDaniel's Saltwater Empire, a book that serves as a poetic investigation into the social, ecological, and geographical landscape of the Gulf Coast region of the American South (which McDaniel refers to as the "saltwater empire"). This book also features a poem interwoven throughout the book called "Convention Centers of the New World," which was constructed by appropriating first-person narratives from survivors of Hurricane Katrina

${ }^{8}$ Jonathan Safran Foer, for example, had his publisher obtain permission from Bruno Schulz's estate prior to the publication of Foer's Tree of Codes, an erasure-based novel cut out of Schulz's The Street of Crocodiles. Foer, a best-selling author, would likely not have been in a position to avoid this step without incurring legal penalty. 
in New Orleans. In small print within the acknowledgements section of the copyright page, McDaniel writes the following:

The text of the "Convention Centers of the New World" poems is drawn from interviews conducted by volunteers for Alive in Truth: the New Orleans Disaster Oral History \& Memory Project, which records life histories of people from New Orleans, Louisiana, and nearby areas who were affected by Hurricane Katrina. I have assembled the poems by recombining several of these histories, and I offer my deepest gratitude to the interviewees and to the project organizers and volunteers. For more information about Alive in Truth, including opportunities to donate to the organization so that it can continue to preserve the voices of the Gulf Coast, please visit their website at www.aliveintruth.org. (Saltwater Empire, Copyright Page)

While McDaniel expresses gratitude and even directs his readers toward making contributions to Alive in Truth, he never actually contacted the organization, or its founder Abe Louise Young, or any of the survivors whose testimony he transformed into poetry, to request permission to appropriate the archived narratives for use in his book.

On August 19, 2010, the Harriet Blog published an essay by Abe Louise Young about McDaniel's failure to request permission for these materials. While Young herself had vaguely considered turning these collected narratives into poetry, she explains that the narrators themselves disapproved of the idea, and so Young decided to scrap it. More importantly, she makes it clear in this essay that Young made specific commitments to the 
narrators in order to ensure a level of support, advocacy, and protection for their stories and themselves as storytellers. Young, in fact, considered this to be a necessary precursor to making these narratives publicly available on the website McDaniel refers to in his acknowledgments, and she explicitly assured the narrators that their stories would not be employed for commercial use. Young's consideration of the narrators' needs and wishes concerning their stories prevented her from pursuing her own appropriative writing project, as she recognized that to do so would betray the trust the narrators placed in her efforts to gather and make available their stories for the purpose of allowing their voices and experiences to be heard. By understanding the need for considerateness, Young avoided the risk of arrogance in appropriation.

McDaniel similarly wanted to provide an opportunity to make these stories heard, and while he appears to have been well intentioned and ethically purposeful, his failure in the lack of consideration for the effects of appropriation caused his actions to be ethically damaging to the larger climate of trust. The narrators, who had been promised that their stories would not be used in ways to which they had not agreed, had trusted in Young and in the organization Alive in Truth, and yet McDaniel has appropriated their narratives and not only published them for commercial use, but he has also stripped the stories of names and context, interweaving them together as if they were interchangeable strings of text. So despite McDaniel's self proclaimed good intentions, as he says, "the gap between intent and effect stretches wide" ("The Voices of Hurricane Katrina, part II" n.p.).

As Dillon suggests, power relations play a role in determining whose actions are deemed to be arrogant. McDaniel as a white male thus can be said to follow the cultural- 
historical pattern of empowered whites appropriating from disempowered African Americans. This context matters, as Dillon makes evident:

[I]t is inevitable that the attempts of subordinated people to unsubordinate themselves will appear to dominant people to be arrogant...[because] in claiming the authority for themselves to redefine their status and worth, those struggling for liberation are usurping the authority of the dominant norms and values. From the perspective of the dominant norms, their claims are unwarranted, hence arrogant; but to the extent that their claims are in fact rationally justified, they are not arrogant. (210)

So perhaps if subordinated people were to appropriate text in an attempt to write against the dominant discourse that subordinates them, then this, too, would be rationally justified and therefore not arrogant. But of course such questions must always be considered as contextually dependent.

\section{The Risk of Asymmetrical Power Relations}

Translation scholar Lawrence Venuti, in advocating for "an ethics of difference" within the field of translation studies, explains how “asymmetries, inequities, relations of domination and dependence exist in every act of translating, of putting the translated in the service of the translating culture" (4). While Venuti is obviously concerned with translating across languages and cultures, I believe that one could just as well replace "translating" with "appropriation" and "translated" with "appropriated" and arrive at a no less reasonable conclusion. In each case, there are multiple subjectivities in play, multiple subject positions, and very real relations of power. Once again, what is required is not 
merely considerateness but an ethical due diligence toward assessing potential effects. For Venuti, this might lead him to "foreignize" a translation so that such differences are not lost, ignored, or transformed into the image of the translating culture. In appropriative writing, however, it becomes less clear how one is able to navigate without reinscribing patterns of domination. In this section, I intend to highlight this risk, while suggesting possible avenues for moving forward with the use of appropriative writing methods with an emphasis on self-awareness, including an acute awareness as to the consequences of the act of appropriation.

In continuing to examine the case of Saltwater Empire, it is too simplistic, and even perhaps even unfair, to cast McDaniel as an author who is in a privileged, empowered social position, and who appropriates language from the supremely disempowered narrators who had survived Hurricane Katrina only to be vilified across mainstream media as looters and criminals, rendered powerless in a situation that was particularly racially charged. However, the act of appropriation along racial lines, especially when the appropriator is a white male and the author of the appropriated text is African American, runs the risk of simply reinscribing centuries of racial oppression. The effects of white privilege, which can be related to the issue of primary arrogance perhaps manifesting as the notion that one's good intentions are enough, can lead one to believe that consequences do not need to be considered, that what is not illegal to take as one's own is fair game.

In light of this example, I would like to propose the following general statement about the ethics of appropriative writing. In analyzing the power relations at play in an 
act of appropriative writing, it is important to consider four primary elements: 1) the appropriating author; 2) the appropriated author; 3) the appropriative text; 4) the appropriated text. Is the appropriating author in a position of dominance or a position of subordination? What about the appropriated author? Is the appropriative text critiquing an appropriated text of the dominant discourse? Or is the appropriative text an erasure of a marginal text written by an author from a traditionally silenced population? These relations are obviously quite significant, and also very fluid. What is key, above all, certainly must be an intention toward fairness and away from domination, but also highly significant in considering an act of appropriative writing is a concerted effort toward selfawareness and considerateness, including an awareness of the various power relations at play between texts and between voices.

\section{The Risk of Exceeding Reasonable Responsibility}

I must first be clear by explaining what I mean when I say "exceeding reasonable responsibility," because on the surface this risk seems not only vague, but also somewhat counter-intuitive. Going "above and beyond" one's basic responsibilities is typically thought of as being demonstrative of one's strong sense of morality, and the notion of placing one's own wants and desires above the needs of others is generally seen as selfish and indicative of poor moral action; however, it is also the case that an excess of selfsacrifice in the process of giving care to others can result in harmful effects for the caregiver. In the context of appositional writing, this refers to the potential for a writer to overburden herself with more responsibility than what one could reasonably expect to manage. Because appositional writing seeks to repair points of rupture within a climate of 
trust, there is a certain degree of responsibility-taking that must happen, and the degrees of responsibility occur across a wide spectrum. A writer might feel a sort of personal responsibility, for example, if she contributed to the rupture that she is now focused on repairing. A hypothetical example would be a case in which a former American soldier decided to embark on an appositional writing project using source materials relating to civilian casualties of the war in Iraq. Such a project would have the potential to be reparative not only in the sense that the civilian casualties are mourned and the wider public consciousness of the gravity of the situation becomes heightened, but also in the sense of personal healing. But what if this same project were undertaken by an American civilian unaffiliated with the war in Iraq? What if this American civilian attempted to take on the same amount of personal responsibility as the soldier? Turning an excess of blame on oneself and taking personal responsibility for injustice and suffering that is beyond one's control may possibly result in the writer experiencing an excess of guilt, where the amount of guilt greatly outweighs the amount of actual responsibility to which one should reasonably expect to be held. Such work can take a large emotional toll on the writer, and this raises the question of whether such a project would be ethically problematic, given the moral need for self-preservation.

In examining how appositional writing can best consider the possible risks involved in exceeding one's reasonable degree of responsibility for points of rupture within a climate of trust, it is important to take note of the concept of mature care, which was originally developed by Carol Gilligan and then later expanded upon by Tove Pettersen. Pettersen explains that mature care - which differs from the two types of 
immature care: selfishness, which is an excess of care for self over others; and selflessness, which is an excess of care for others over self - acknowledges the necessity of meeting, at minimum, the basic needs of both parties: the care-giver and the cared-for (14). The basic needs of the care-giver must be met, including mental and physical aspects of self-preservation, and while the emphasis on the care-giving remains, the potential harm of self-sacrifice is avoided. Pettersen, who characterizes mature care by its intermediate position, is examining an ethics of care ${ }^{9}$ by grounding part of her discussion in professional care work, such as the work performed by registered nurses who care for the elderly or for those who otherwise are in need of care. In the following quote, she nuances this position by referring to a need to set limits, which must always be contextually driven, in any mature care-giving situation:

The point however is that caring should not and cannot be boundless. Setting limits is therefore inherent to any concept of mature care. Where exactly they should be set will vary with the circumstances, and this is something the mature agent must consider in each situation. But accepting constraints on the distribution of care does not imply that the altruistic component of care disappears. Mature care presupposes altruism and good will towards the other. The altruistic aspect, however, is not the only or

${ }^{9}$ The "ethics of care" has been defined in multiple ways through the last thirty years, but I prefer Virginia Held's conceptualization of care as both a practice and a virtue. As a practice, care is relational and multiple, and yet all care requires the values of "attentiveness, sensitivity, and responding to needs" (Held 66). 
even the decisive element. The reason for controlling the altruistic dimension is that unchecked it can lead to self-sacrifice. A willingness to sacrifice all personal wants and needs...could result in serious harm to oneself and others. This is a major objection against basing professional care-work on an altruistic conception of care, and an important reason to adopt the concept of mature care instead. (Pettersen 124)

It might be argued that professional care work and a creative project such as appositional writing enact care in far different ways, and of course this is correct. The author engaged in appositional writing might exhaust very little physical energy in the conceptualization and writing of a particular project, save for possibly a great deal of research, possibly even travel. But such a project would also involve a significant amount of emotional investment and - in the case of a writer taking personal responsibility for injustices beyond her control - of being in an uncomfortable and potentially self-damaging mental state. How much of a burden is too much for a writer to take on? As Pettersen suggests, such a setting of limits must be contextual, specific to each situation. In order to avoid the risk of exceeding reasonable responsibility (how much can I reasonably expect myself to take on?), it is important to be considerate not only of the source texts used or of the voices appropriated but also of oneself and one's basic emotional needs.

\section{A Detailed Discussion of an Appositional Text: M. NourbeSe Philip's Zong!}

Philip's Zong!, a fragmented work of "anti-narrative" responding to the 1781 Zong Massacre - in which 133 African slaves were murdered in an attempt to recoup lost insurance money following an unsuccessful transport to Jamaica - is an excellent 
example of an appropriation-based poetry project that is ethically intentional and impactful, founded on the concept of repair, and that offers a considerateness to the potential moral risks involved with the project. As such, Zong! is a model appositional work, a level which McDaniel's Saltwater Empire - though well-intentioned - failed to achieve due to its lack of considerateness. In writing Zong!, Philip uses as her source text the court document from the Gregson v. Gilbert case, in which the owners of the slave ship Zong were ultimately denied their insurance claim, reminding us that the case was about money rather than murder. Philip writes in an essay at the end of the book, "Although presented with the 'complete' text of the case, the reader does not ever know it, since the complete story does not exist. It never did. All that remains are the legal texts and documents of those who were themselves intimately connected to, and involved in, a system that permitted the murder of the Africans on board the Zong” (196). The actual composition of Zong! involved the author breaking open the language from the court document, pulling new words from the bones of the old, and creating a lengthy word bank which she used to then try to "tell a story that cannot [and explicitly was not] but must be told" (196).

In the book's closing essay, Philip speaks directly to the idea of relinquishing a portion of agency and inviting alterity into the composition process: "I, too, have found myself 'absolved' of 'authorial intention.' So much so that even claiming to author the text through my own name is challenged by the way the text has shaped itself. The way it 'untells' itself" (204). Indeed, the author's name on the front of the book may read "M. NourbeSe Philip," but in the lower right corner of the cover, it says, "As told to the 
author by Setaey Adamu Boateng," an invented persona whom Philip says represents the spirits of the African ancestors. Finally, Philip allows her text to hold the voice of the villain of this anti-narrative, a white, European male. And while she freely admits that had she not absolved herself of authorial intention she would not have chosen such a voice as one of the most prominent voices in the book, she also recognizes that by "refusing the risk of allowing ourselves to be absolved of authorial intention, we escape an understanding that we are at least one and the Other. And the Other. And the Other. That in this post post-modern world we are, indeed, multiple and 'many-voiced"' (205). That Philip would allow such a voice access to the work is particularly significant in the context of Baier's conceptualization of the climate of trust, which is founded upon the treatment of others with respect and considerateness within the understood human reality of mutual vulnerability. By not seeking to exclude the voice of a white, European male from the text, and thus allowing it to exist beside and not in place of the primary ancestral voice within the text, Philip seems to gesture toward a need to repair this climate of trust by acknowledging that we are, indeed, multiple, and that we depend on the trust that we must establish and foster among one another. It is also significant that Philip frames the European voice as the villain, as it helps to demonstrate and make explicit the extreme violence and domination that foreground the tragedy that was the Zong massacre, the slave trade, and the horrors of colonialism which continue to this day. So while the voice is allowed to remain, it is shown to be untrustworthy.

During the process of writing Zong!, Philip gave strong consideration to the various moral risks involved with appositional writing and, in particular, considered the 
question of permissions. In the book's closing essay, she writes, "I feel strongly that I need to seek 'permission' to bring the stories of these murdered Africans to light - above the surface of the water - to 'exaqua' 10 them from their 'liquid graves.' [...] And so, not knowing what this 'permission' would look like or even why I feel the need, I journey to Ghana in the summer of 2006" (202). Philip visited a shrine near the location of one of the old slave ports, and she spoke with the elders and the priest, talked with them about the Zong and about her project of recovery. While there was no legal need to ask for permission to use the Gregson v. Gilbert court document, as it is a public historical document, it remains important that Philip appropriated the text in an ethically considerate manner. Additionally, in considering Dillon's argument that the question of arrogance is dependent upon the context of power relations, there is clearly no risk of arrogance in Philip's appropriation of the document in her attempt to tell the story that was specifically not told during the trial, the story that is the murder of 133 human beings. Far from demonstrating arrogance, this project instead attempts to usurp "the authority of the dominant norms and values" in an attempt to liberate the stories, and the bones, of the dead.

Apart from Zong!, there are several other important appropriation-based works of poetry that stand out as good examples of appositional writing. Mark Nowak's work with documentary poetics in his books Shut Up Shut Down and Coal Mountain Elementary, for example, illustrates that appositional writing includes the mission of advocacy. By

10 "Exaqua" is an invented term Philip uses to convey the idea of "exhuming" the bones of the dead from the water (Philip 201). 
portraying the exploitation of blue-collar American workers in the former, and by providing a collage of documentation regarding coal mining disasters in West Virginia and China in the latter, Nowak, who himself comes from a blue-collar upbringing, provokes the reader to empathize with the voices of the various narrators interwoven throughout each book. Kaia Sand's Remember to Wave was composed as a "poetry walk" originating out of Sand's investigative walks through Portland, Oregon, as she sought to explore a number of tragic events that occurred throughout the city, such as the internment of Japanese-Americans in the Portland Assembly Center. Throughout the book, Sand makes these ruins visible, reminding us of the value of historical consciousness. In a similar, though far more ambitious project, Craig Santos Perez's from unincorporated territory [hacha] and from unincorporated territory [saina], which make up his larger project from unincorporated territory, investigate the Chamarro culture of the island that is today called Guam. The sections "All With Ocean Views," which features an assemblage of language from various travel magazines organized into lunes or "American haiku," and "Organic Acts," which appropriates language from the Guam Organic Act of 1950, represent two of the more notable examples of Santos Perez's ability to turn the language of colonization against itself as social critique while also crafting beautiful poetry. While showing the effects of colonialism, tourism, and mass migration of the Chamarro people away the island, Santos Perez provides the remnants of what has already been lost after centuries of colonization. In addition to the incredible work of Santos Perez, Sand, and Nowak, there are many more who have contributed and continue to contribute to the expansion of the appositional project. 


\section{Homophonic Translation as Appositional (re)Writing}

I will elaborate further on the concept of appositional writing by talking briefly about my own work with homophonic translation, which I define as the re-sounding of a source text based on each individual letter's potential for sound within the language. For example, "cat" may be translated into "ash" when considering that 'c' may be silent (as in "indict") and 't' may be sounded as 'sh' (as in "motion"). Out of the more than sixty different possible ways to sound the letter combination c-a-t, however, only one is correct. The understanding of c-a-t equals feline is normative, is accepted as a given for those able to read English. But there remains a great deal of excess, the remainder of c-a$\mathrm{t}$, or any other word, that is ignored, withheld. Homophonic translation is then a process of sifting through this excess signification, of bubbling over the domesticated meaning of a text with new, multiple meanings.

In this way, homophonic translation might be seen as a type of what Jerome McGann and Lisa Samuels call deformation, which involves the re-ordering or manipulation of a text, specifically a poem, in order to "Open the poem to its variable self” (McGann and Samuels 45). Meant to serve as a kind of experimental criticism, another way to read and analyze a poem, deformation is more than just a way to allow for a fresh reading of a poem. "It is more important," McGann and Samuels explain, "to see that the poem yields to such a remapping" (39). It is a way to open up possibilities within the poem, to demonstrate that other possibilities indeed exist and are relevant. Homophonic translation, too, points to alternate readings within a text, readings that already exist as possibilities. While it could similarly be used as a tool for criticism, 
homophonic translation allows for a dual purpose that is both creative and critical at once. One is able to quite literally make a written text say something else, which makes homophonic translation particularly useful for appositional writing. As a method of phonological repair (bear in mind that "repair" means "to mend, to put back in order"), homophonic translation not only allows for the ability to unstrain the language of oppression and harness its excess potential for sound and meaning to critique the production of domination through language; it also allows for this phonological excess to serve as reparative material in a move toward advocacy, historical consciousness, and care. From the mess of possibilities, one can reject the original message of harm in favor of one's own ability to narrate his or her life. In my own work this allows me to repurpose my language, as well as the damaging language of others, against conquest, against domination, and toward an ethical responsibility for myself and for others. In discussing my attempts toward this end, I will introduce and briefly explain three homophonic translation projects I have undertaken.

\section{"Arizona State Bill 1070: An Act"}

In April 2010, Arizona governor Jan Brewer signed Arizona State Bill 1070, a bill that featured some of the strictest anti-immigration policies that have been put into effect in the Untied States. The bill granted law enforcement officials the authority to detain any person who they suspected might be an illegal immigrant and to ask to see identification or proof of residence. Outrage over these policies quickly ensued across the United States, with protests organized in several major cities. Protestors and opponents of the bill claimed that the policies encouraged racial profiling. After a number of legal challenges, 
many of the bill's harshest and most controversial provisions were blocked. Despite this small victory, the remaining provisions of SB 1070 have made life increasingly difficult for Arizona's Latino population, and their civil rights are still very much in jeopardy.

In my poetry project, “Arizona SB 1070: An Act,” I have written a homophonic translation of the bill in which I attempt to interrogate the controversy surrounding this legislation. In an attempt to call attention to the contested nature of language in Arizona, where a non-English speaker may easily be suspected by police to be an illegal immigrant, ${ }^{11}$ I have tried to write against the bill, itself, to transform its message from one of divisiveness to one that pursues a move toward compassion for others, to make the bill a public space with the possibility for response. I want not only to call attention to the racial oppression operating within this bill, but also to point toward a need for advocacy as we begin to repair this severely tattered climate of trust within the state of Arizona, as well as within the larger population across the United States, because a damaged climate of trust is harmful to us all; it is something to which, and by which we all become vulnerable. More than anything, this project is meant to investigate this fear of others, so that this fear might be recognized, and we might begin to move away from oppression and toward the repairing of wounds that such legislation has opened, and reopened.

\section{"How I Pitched the First Curve"}

In 1908, William Arthur "Candy" Cummings wrote an article for Baseball Magazine called "How I Pitched the First Curve." The two-page article tells the story of

${ }^{11}$ And let us also not forget the viral video turned hit song and Tea Party anthem, Ron and Kay Rivoli’s "Press One for English." 
how Cummings invented baseball's first breaking pitch, the curveball, after years of experimenting with different grips, arm angles, postures, and throwing motions. Prior to the curveball, pitches were limited to being thrown at different speeds; the idea that Cummings wanted to try to make a baseball curve was a joke among his friends. A ball could only be thrown straight, and that was it. But Cummings made the ball curve. While the game was still in its relative infancy when Cummings threw the first curveball in 1867 , the pitch revolutionized the sport.

Perhaps due to its status as America's pastime, baseball has often been said to have many of the traits that have characterized the United States as a country. Documentary filmmaker Ken Burns has gone so far as to call baseball a metaphor for America itself. Because the sport and the country are so interconnected, baseball presents an interesting microcosm of America's social and cultural struggles throughout the sport's and the country's shared history. Each have struggled with the effects of segregation and desegregation, with labor stoppages and worker exploitation, with the prevalence of substance abuse, and with a great number of other historical and contemporary forms of injustice or trauma. But rarely are these issues evident on the surface of the game; when a player makes homophobic comments on Twitter, or when the Players Union goes on strike, perhaps we think about these things and how they relate to the game. To make these issues more explicit, to show them as inseparable from the game, just as inseparable as the game is from American culture, one must dig beneath this surface; one must see it as a curve rather than a straight line. 
In my poetry project "How I Pitched the First Curve," I have written a total of nine different homophonic translations of Cummings' article, one translation for each inning of a regulation baseball game. With this act of translation, I attempt to curve my reading of the language in order to make the article say something else. Each translation, or inning, investigates a different social justice issue embedded within the game of baseball. These include: racism, labor conflicts, exploitation of Latin American prospects, steroid use, and substance abuse (particularly in regard to current star player Josh Hamilton). Cummings presents himself as a relevant topic also, as his claim to the curveball is still disputed, with some believing Fred Goldsmith to be the true originator of the pitch. It was, in fact, primarily due to Cummings' article that he was finally inducted into the Baseball Hall of Fame as the inventor of the curveball. Through writing, Cummings was able to claim sole authorship and a great deal of recognition, which not only alludes to the power of language but also represents the drive to hold sole dominion over something (or someone) in the world. In translating Cummings' words, I have attempted to forge a collaborative authorship with Cummings, transforming the monologic article into a dialogic poem. In effect, this project is similar to Kaia Sand's Remember to Wave in that it places emphasis on historical consciousness within the game of baseball, making visible its scars, which are as much a part of the game as the stitched seams of the ball.

\section{"Is Ryan Clark a Monster?"}

The third project I will discuss is far more personal than the previous two. Rather than trying to make explicit a variety of social justice issues in my homophonic 
translations of source texts, I turn my attention inward in an attempt to address, head-on, my own monstrosity, my own power to dominate, subordinate, and harm.

Throughout my teenage years, I struggled with depression and was often suicidal. When I was seventeen, I hurt my little step-brother out of anger, leading my step-mother to announce that she did not trust me around her children anymore. This loss of trust coupled with the realization that I had the power to physically harm those I love was a brutal blow, resulting in two failed suicide attempts over the span of two months. Shortly thereafter I developed a mathematical equation that I imagined would determine the date of my eventual death. The date that the equation gave me was December 10, 2011. After years of ignoring this part of my life in my poetry, because I was too afraid to address it, the opportunity arose to finally confront it when the death date was only a few short weeks away.

So as the day approached, I put a new project in motion. I asked twenty-five friends to send me a text message at a different hour of the day, such that on the hour, every hour of 12/10/11, from midnight to midnight, I would receive a text message from a different person. The contents of these text messages were responses to the question: "Is Ryan Clark a Monster?" Once I had collected all of the text messages, I used them as source texts from which I wrote, using homophonic translation, an autobiographical sequence of poems addressing the events and emotions behind my suicide attempts, which were prompted by an inability to handle the guilt of having injured a family member through an act of rage, and an inability to imagine living excluded from my family's network of trust. 
In addition to translating each text, I also included twenty-five "windows" that function as 160-character snapshots into the events of the poem. These windows add some much-needed context and clarity to the project. The 160-character constraint is derived from the fact that my cell phone only permits 160 characters per text message, and so I see this constraint as a way to further connect these windows to the roots of the project.

The final version of each section of the poem, which is broken up into one section for each hour, features four components: 1) text message; 2) translation; 3) window; 4) monster poem. The "monster poems" are assemblage poems which draw language from each of the other three components. In writing them, I first lined up the text messages in one column, translations in a second column, and windows in a third column. For each hour section, I read across the columns from left to right and pull language from each line in order to compose a new assemblage poem, or what I have been calling a monster poem. I did not use every single word, but I forced myself to use at least one word per section of the line, and I tried to use as many words as I could. These monster poems hold everything together. The reconstituted language is a piecing together of my experience and my investigation into that experience, a personal portrait of the effects of mistrust and my gradual acceptance of the monster that I can never excise from myself.

This project likewise holds together many of the themes from "How I Pitched the First Curve" and "Arizona SB 1070: An Act." It is my attempt to examine my own monstrosity, my own potential to inflict suffering on myself and others. Appositional writing must ultimately begin with responsibility for oneself, including self-preservation, 
and so I find "Is Ryan Clark a Monster?" to play a pivotal role in my exploration and understanding of the ethical impact of this appositional project, as it was through this writing that I first considered the question, "how much can I reasonably expect myself to take on?" By navigating through my own personal trauma, I came to realize the emotional toll that responsibility can take when one is not careful to set limits or put into place various measures in order to ensure that one is able to find reassurance and comfort in the care of others. "Is Ryan Clark a Monster?" is thus very much a project of exposing oneself as vulnerable in order to recognize more clearly the vulnerability of others. While I asked only friends and family to provide me with text message responses, which was sure to limit the likelihood that anyone would take advantage of my vulnerability in an attempt to harm or be cruel to me, included among those who responded was my stepmother, whose absence of trust was initially so unbearable that I could not imagine living as an untrustworthy person. This process of trusting others to not take advantage of one's vulnerability is one that occurs everyday, and it remains a necessary step toward the fostering of a climate of trust.

\section{The Appositional Project}

The appositional project is a project of repair; it demands of the poet a concern for and an attention to the ways in which the damaging effects of language are distributed through mass media, through politics, through wellsprings of hate and ignorance, and through our own occasionally misguided attempts at being ethical beings who live with and for others. The idea of literature as reparative is itself not new. Viktor Shklovsky adapted from Tolstoy "a conception of literary works as able to infect readers with the 
sensation of life, with a feeling for matter" (Robinson 87) ${ }^{12}$ More profoundly, Tolstoy believed that art should "transmit from the realm of reason to the realm of feeling the truth that well-being for men consists in being united together, and to set up, in place of the existing reign of force, that kingdom of God, i.e. of love, which we all recognize to be the highest aim of human life" (Tolstoy 184). Likewise, appositional writing aims to create, in place of domination and inequality (art which breeds divisiveness is bad art, according to Tolstoy), feelings of agency and care for one another by providing a model for working with and against the torrents of language, be they in the form of government documents, works of literature, message board postings, or any other form of text, that help to shape our world and our social relations within it.

It is perhaps the vastly different understandings of what happens when these texts and voices are meshed together, deformed, reconfigured, and recontextualized that most sharply demonstrate where appositional writing and Conceptual Writing differ in regard to the ethics of appropriative writing. Douglas Robinson, in tracking the theorization of collectivized feeling from Tolstoy through Bertolt Brecht, comes to the conclusion that "where the structuralist reads literature in terms of pure textuality, as if the writer and the reader did not exist, the somaticist reads literature in terms of human relationship, as if the text did not exist. [...] The structuralist constantly recreates a world stripped of human signification, human interaction, human feeling; the somaticist constantly recreates a world overdetermined by felt collective regulation" (Robinson 252). Whereas

${ }^{12}$ William Burroughs later came to think of language quite literally as a virus, one which infects us with ideas as well as sensations. 
Goldsmith's "thinkership" is based on the intertextual, where the art is good if the concept is good and morality is not much of a consideration at all, the appositional is intended to transmit to the reader feelings of care and empathy in order to foster and encourage moral and potentially reparative action.

Because of the ways in which language is able to regulate the transmission of both ideas and feeling, we must consider the effects of language in our poetry. The increasing popularity of appropriation-based work only makes the need for considerateness more glaring, as appropriation has long been used as a tool for the domination and subjugation of others. An ethical awareness and consideration for what is at stake when we appropriate language, for purposes artistic and otherwise, must therefore accompany current and future conversations about the relevance, value, and craft of appropriative writing. Furthermore, in the face of destructive views distributed through language on a daily basis through advertisements and mass media, which only serve to foster inequality and weaken the climate of trust, the appositional project is a valuable move away from the apathy purposefully embraced by Conceptualism or, worse still, outright domination. We cannot simply disregard language as "debased, mere material" if we are to take seriously the very real effects that it has in the world. If discourse forms the limits of our cages, after all, we must do something about the bars. 
CHAPTER II

ARIZONA STATE BILL 1070: AN ACT 
Set in our Arizona

in

our legislature

in our air a session

wanted

to stop a living

act 
Men live in fear of Arizona

visit statues of frightened faces near nothing there in tears in our faces

tattoos of our terror in Arizona or visit statues bitten sawed torn and then

turned to a fence or a wall of fear a wall of any word for ending or if all of

Arizona revisits statues and if art chopped here all of our Arizona or

visits to a dissection of our event of our relation to lawfully present lines

these awful lines of ache 
1 Be it a naked leg, a slow oar of dust taut over

2 a canyon tent

3 the ledge where fingers map a line at rest in the

4 furtive calf muscle

5 ahead of the shak

$6 \quad$ ing train of a step of sandal

7 feet gaining Arizona the rough sun sanded sh

8 ore where a scar in the earth hung law over a young presence of

9 line and economic activity pressing on fully present in the untied $d$

10 ust

11 as a wall of fence severs our vein a bea

12 ten river $\mathrm{d}$

13 rifting forward In a loss

14 event everyone ends in a forced

15 migration in wind and sun 
16 and no safe water Skin $\mathrm{n}$

17 ears a division of soil is IDd as a

18 restricted remainder All immigrants change

19 as entry touched a body raw

20 Before any law is an act made by an arm an official one

21 of a state a subdivision of us

22 as we are A wrist suspects it hears aliens is

23 unafraid to say reasonable attempts shall be made $\mathrm{t}$

24 errorist to say blood determined the immigrant a soft person The

25 person is migration to us is all of our ID Our nomad

26 pursuit unites us centuries of our us

27 See aliens in love fully present in the untied status

28 of visit of voila tie it here localize here

29 What is a native if the map said the line shall be

30 transferred immediately to the west What hunted immigrant 
31 cuffs mean or the United States Customs and Border Protection

32 Do not stand here Law will force again a $\mathrm{m}$

33 arch or for an alien a ship Residents stay

34 and watch as custody of a dry land is tor

$35 \mathrm{n}$ Others fear and fear the outside the

36 jurisdiction fear seeing agents

37 Alien is made to search where a person

38 has probable cause to believe that fear is a home It

39 pulls a fence that makes the fear a song of buffer around us

40 Fix us river Wash off this

41 stain in the sand dry as a fish in a $\mathrm{d}$

42 esert dry and restricted from sun

43 River remain in formation our linked migration a state of

44 vital exchange of form a wide feral state

45 a river meant to flow across 
1 In the river public a knee fits surfing se

2 vered for a state clothed of visions

3 shot

$4 \quad$ over a fence slammed in yards of dirt in

5 desert Miles are acquired under the haze of feet toward a sh

6 ore ears shut for sand Over a river even

$7 \quad$ a river is detained

8 if it is an alien dreaming where the person is $\mathrm{i}$

9 f a line is there As legs stretch on a low ripple hover

$10 \mathrm{~s}$ a veiny trail migrating gownlike

11 back toward the shall

12 ows This story through our political

13 division is a story of laments of limits

14 Tired is the river migrating wheezing full

15 under a border just ink an 
$16 \mathrm{~d}$ a fence a rail or a door or a wall a line

17 One thought our border a river shortened

18 to our knees

19 at the end of a sea of pain This is in the sand

20 all our sand and more than enough sand each day shut off

21 A river flows in pursuit to di

22 ssect

23 Here is elective alien Our script is subsection $\mathrm{G}$

24 And dream it the civil and the departmentalized the foreign

25 the gang of immigrants a stream a song un

26 established Bite down for it is a vein in the teeth

27 I love our cement rivers and

28 our age of reasonable costs and easiness I love our

29 signs read by our eyes And just near

30 our border is a sign which says Here may be 
31 reason here in a river flow

32 ing from agencies in relation to ours In here is

33 a judge of bad faith

$34 \quad$ Justice shall be planted in a ri

35 ver swirling gyrating protecting us Evil are the

36 persons trespassing their evil legs and tongues unstate

$37 \quad$ ed eyes

38 Search the river in Arizona Revise its status amend it by

39 adding a shot in the heart enough to tear

40 through nine trespassing illegals as one take a pin

$41 \quad$ classifying

42 And in a violent river is a life

43 trees pass a person in a boat

44 nears shore a rough land In this state

45 in violation of states is our river or theirs 
1 Bite down on this section If I determine an

2 alien as immigrant a determined other

3 a new force moves our author is federal

$4 \quad$ Go over a verified chain Aliens migrate to us

5 to a wall when forced to for agency Some night in the United

6 States I grade and cuss and force more to the border

$7 \quad$ What is a border save another sea

8 a sea a person isnt personeligible

9 over some mutation of sentence or a lesion on a body

10 decomposed deserved to

11 die in a ditch I need to hear and rescript a bill to show our

12 ordering to a page I lost in a ditch in a cement ditch

13 falling int

14 o one All of our dollars for a river violation

15 twice the amount specified in paragraph one of this subsection If a 
16 person is previous a subject dead pursuing this space

17 ears select this Say its our script Say at the end of

18 this section are righteous men Say art means safety

19 What else is it for exc

20 ept for everyone Tell us of a cement

21 song a river at dawn A moan is in this Say a sound a just

22 ice for rivers bordering

23 our rivers Here a border line is shook o

24 ff a raw tone

25 If this shaking does not apply to a person who maintains a shore is the

26 river a leg for running into a state

27 a flowing of eyes tongue clashing toward

28 violation cheek at the $\mathrm{s}$

29 un A class three felony if the sun falls in

30 possession of anything 
31 Danger is defined as sand dirt a river run A

32 border is a sediment ring

33 a map meaning flush it away and the river run

34 s straight through it meant as defined as c

35 arrying ov

36 er Every reused word proves it Is it

37 true our eyes are a script in a scene our ears gone in

38 the clay of our flung border

39 I invite you for a second violation of this section

40 Be within us as moths before a full light chain removed from

41 the wing with the shine of a $r$

42 iver flow in the sun

43 Take is as a song We love to dance 
1 Cease reading Write what a nation is Revised statute amended to read

2 thirteen twenty three nineteen smuggling classification and definitions

3 It is an awful love for a person to intend an ally in a cage $t$

4 ugging human beings for proof of America a lover pose

$5 \quad$ fellating this seized nation

6 notwithstanding Such young bone filled the $n$

$7 \quad$ ation

$8 \quad$ as it fell a knife huge over

9 its edging And this is mapping cut by a mile every ten

10 years or the fence full of fuse jaw pointing fur

11 ious toward

12 what tuff fell out The nation full of fuse and

13 spark and the barb a leering sun Wh

14 at is beautiful is room confined Tether us

15 as captured threaded right here in our eyel 
16 id to the earth the surface eligible Forward

17 to section forty one sixteen o four Even this sentence is a muted

18 capture to which a title does not apply A full $\mathrm{n}$

19 ation is forever eating

20 a note hanging in the air A peace officer may lawfully stop

21 any person who is operating a motor vehicle if the officer has reasonable

22 suspicion fully enough fang of law and

23 hissing

24 a letter crossed out for the purpose of this section

25 A family member means a nation of parent bubbling

26 through wire hairs by consanguinity wire riv

27 er ray

28 chewing trains of dirt stu

29 ck to the tongue A tongue includes

30 proof as a face does of a ringing clue $\mathrm{f}$ 
31 or arrangement See our fixed nation services

32 buffering breaking

33 up of a color wheel sand fa

$34 \quad$ lling leased or otherwise unavailable it drops as

35 defined in section thirteen twenty three twenty two

36 Here smuggling of human beings means the nation never came

37 never was brought or ripped away an

38 entity that has reason to know The person is a

39 transported tube at port terrorized as citizens are

40 or as aliens are or as others lawfully in this day are A vat emptied

41 and redrawn tied to union and full of law 
1 Say us every day Our Arizona our vice and

2 our wanting of our want I need to need to read

3 our end winding to an unlawful stop and hear its passengers Our

4 work in law is notation Our

5 employment is siphoned definitions

6 It is unlawful for an occupant of a motor vehicle that is stopped

7 on a street roadway or highway to attempt to hire or hire and pick up

8 Passengers are workers Driver

9 s are moving traffic

10 Bits of a river enter our vehicle that is

11 stopped on a street Our river retired an ocean

12 of travelers ported to work at a different life

13 The traveler is the river

14 the unlawful river unlawfully rushing into

15 us Who unauthors alien Only our word 
16 works our reform works on our dent

17 in our story in this stage

18 A violent sea is in me a meaner

19 effort ever pushing

20 Sever learning from gesture a $r$

21 oad to say reason A person that a person is I

22 am

23 too an authored alien who is full of

24 writers you and our Our work in this

25 scripting of us is catching the writer

$26132929 \quad$ Unlawful transporting moving concealing harboring

27 or shielding of unlawful aliens fickle

28 and classified

29 It is in love for our fear of loss our 1

30 ove of need too 
31 Drains pour a river a river removing aliens

32 as a means for a ration of personness Wreck us

33 Disregard us Say the alien has come has entered our remains I

34 need a state to violate a flaw

35 to conceal ours ours ours All

36 an alien for detection I pace in this state looting any building for

37 any foreign foreigners Know our reckless disregard

38 of alien See the red remains

39 of alien

40 There is rage reducing aliens in this state of

41 personness our reckless disregard of coming to

42 Tear our resident status our being filed a flaw

43 in transfer I use this as if

44 violence is a just man Try violence on our

45 found words section 283511 
1 See a person who violates this section as guilty

2 Words justify the house in dollars

3 the violence in hate full of armor I legalize

$4 \quad$ Is fear an object to find in

5 rivers of love

6 Is it under our love ours our vices too Is amen read

7 under the love in empathy Is a line of rope en

8 ough for our volume of $n$

9 ecks I feel a noose inside our riv

10 er made of fence

11 An employer shall not knowingly employ an unauthorized alien If

12 we name a race contract an other toward a $\mathrm{r}$

13 iver drag remainders

14 to work for us our alien our right to

15 personness our contraction our line our form 
16 Our other violates us us us

17 Beat the other river Say trash rips open and foreign

18 violations come

19 out breaking social security Ameri

20 ca never arrived as some foreigner in a riv

21 er or as a foreigner illegally a noun

22 hardly a noun a feral race on the shores

23 of a state Hurt them lawyer Shove violence in

24 I fucked her shoved it inside her scripted it

25 for her for our country May I never touch

26 her violated cunt again This subsection shall

27 be construed to prohibit the feeling of us and our

28 s My fear is a river over

29 flowing our race

30 our national origin as if they were 
31 us also under our noise All

32 unauthored aliens are waste mired in river

33 s of our agency mazes of state

34 ment One of us is an attorney for our count

35 ry for our authors authoriz

36 ing a whiter government for us to get the dust out

37 Their river is dust relocated emptied

38 in a bin gently from a nation churning stir

39 ring into us in me ours A surer

40 author than us will verify our governed person

41 hood Say this is our version of life as a

42 failure of us Say we are this section of faces at $r$

43 est in war 
1 After an investigation the attorney general or county attorney

2 determine some plan This isnt a frivolous

3 need here for learners to find

4 status Migrate into us in formation Author us alien

$5 \quad$ What river country holds all

6 of our meanings in the horizon

7 there sure enough for us not to try to cr

8 ross over to not see if the land

9 is really filled with horror

10 and revulsion A sun set on us he

11 re against the Arizona tourist air

12 where rise alien employees or lawyers and

13 attorneys all drenched in a river of violen

14 ce Say this occurs before rivers Show us the end

15 A view of this is based only on an authors alien $\mathrm{w}$ 
16 orld that morphed during a short $\mathrm{r}$

17 evolution of this section our section our subsection A

18 A foreign actor researched a $r$

19 ole dying in a river as

20 practical data

21 If I dive into this

22 one a river of line as described in our graph here what is

23 on the shore

24 A short order Return nation

25 unheard alien

26 Be ashore reader for us Tether your

27 fear to our fear for the current is a line

28 perforating the rope In a river we flow where

29 carried in a form proven to tear us $\mathrm{f}$

30 rom every other This is 
31 location our authored line for a reader

32 Color it for us to ride off with The

33 country in here is safer ordered

34 off as a state There is remain

35 der in this Say and The fear will

36 inch away lurking on the horizon instead

37 Courts ordered the appropriate agency to US lines subjected

38 this division to our reality Fear here is

39 a signature Division trained our signs

40 for order I is all I an us that are suspended under this

41 Dive in here in us ending at river in

42 aid of a white country not white anyway Our

43 view is fences our stately

44 terror fences for ours is divid

45 ed Hours spent revising our Is shut 
1 Air held by the lawyer kicked out a breath The

2 new air is alien for awhile Air does not hold a license

3 is kicked out at a location where the air is reformed to

$4 \quad$ work out the sense as a necessary layering

5 of air Licenses are subject to sense under this subdivision

6 Air licenses are held by the lawyer at the lawyers fairy

7 palace A sign on a word is a wand notwithstanding any

8 other letter or word signed as a wand

9 The short order cook has a word a short

10 one for the attorney general His signing it does not

11 do anything

12 Dumb air dirty air bags of unlicens

13 ed air in subdivisions seas of errored air

14 are to see a busy court day A law is a wand

15 suspending subdivisions on any evidence or information submitted to it 
16 ringing of air violations So is a sun on a

17 flag a story of living

18 In the numb air of an alien ship lur

19 ching over a dusty bor

20 der the degree of harm is slung from the violation

21 of whether the lawyer made a good faith effort Tucked in

22 a cab air qui

23 vered and felt an

24 xiety for hours as the lawyer $r$

25 eviewed the

26 feather of a cactus bird

27 The wren found a scrub territory with

28 in the court ordered property His mate lay

29 her feathers peck cactus nes

$30 \mathrm{t}$ A young wren a ready alien feathered dow 
$31 \mathrm{n}$ no license a cactus nest where the wand is

32 Language worked as a song a sharp bird

33 song feral as a dishwasher and

34 permanently vocal A census is held by the lawyer at the

35 lawyers fairy palace Of note the wren

36 does not count their language immediately

37 revoked tenses

38 Threat of violation shall be considered

39 a first violation Flight is a location of e

40 volution Note soaring for the need to soar

41 away A subsection or section 2321201 subsection $F \quad$ for the lawyer

42 is a location

43 A basic need to violate and to stay in

44 violation is a wren in Arizona 
1 The species does not wander or leave Staying forever

2 is nesting

3 gathering sanctuary A reser

$4 \quad$ vation is not this and shall remain no

$5 \quad t$ this Arizona is not this To have to violate

6 is soon not this is sand a desert Order is available on the

$7 \quad$ attorney generals website

8 How determined rang flying onward into

9 courts and rang full of wringing a desert in pursuit

10 and said section $1373 \mathrm{c}$ the feral vermin are meaning to

11 create a root Presume unlawful status The sto

12 mach aches so full of ta

$13 \cos$ The fed are all government profit automated to testi

14 fy for a sanctuary of feather

15 A feather is soft enough for a wing to 
16 authorize flight though it hovers serrat

17 ed blade like on

18 a threat A line

19 of feathers said the lawyer stabs at

20 the city of Phoenix said shoot

21 See the white feather of defense The lawyer readied a

22 quill pen authorized a line of fence to read Shove

23 off white requirements of 8 United States Code section 1324a b

24 What is sanctuary city in this procedure

25 of failure to meet requirements the risk of faith tempted to comply

26 What took remains

27 Kites in air made of defense of watching see a thing of this

28 section that the air was trapped To lay a trap the lawyer

29 must tie the air to money or other evidence that the al

30 ien is violating empire Who set the trap made a face as 
31 the air deprived of flowing blurred the convincing evidence

32 And they came in vans tied to law and force made

33 of shears to gather the air in a wide jar $\mathrm{r}$

34 reading FOR MEXICANS Sure and they $\mathrm{j}$

35 ump too Some might even

36 jump out Dispose those move on before they

37 leave any roots A root might

38 omit the violation

39 A lawnmower stays at the shed trapped The mower is

40 predisposed to violence Sanctuary meant

41 officers or their agents merely provided meant tied to

42 some deviation It is not a trap for aliens for a ci

43 ty It is merely a ruse to conceal the rent de

44 livering sanctuary in a dream of

45 mowers vein air meat 
1 See a veiny thing on the phone Air is on a rough face is on Dead ai

2 r ready

3 to try to live on intentionally employing a hot line

4 A phone is not a frivolous line It is

5 of a late call asking a listen of sound

6 a voicing of furtive defense

7 An ear is not national Phone it in

8 Find the caseworker and trace the rotar

9 y It depends on the race so hurry The dial labor of an alien is

10 shot of risk What unauthorized line

11 is secure When is a line not a river

12 the water full of leeches sucking

13 Beat the air a knee a face a lip scraped off for repair Sing

14 it to a phone but dont talk in Spanish $\mathrm{S}$

15 ing to hear a choir list complaints Is a song empty 
16 if the form of the song is the receipt of a

17 punch rifled off from marriage

18 Nation plays a notarized line air never sound

19 ed at all Investigate where the air is violen

$20 \mathrm{t}$ This is if a complaint is received But it is not submitted

21 or scripted See a land of fear for country

22 investigate the worth home has if violence is seething

23 This seething shall be construed to prohibit the filing of anonymous

24 complaints Say your number Script it Complain for me

25 The air funnels into a net invested with $\mathrm{r}$

26 aces won A race is our national origin A land is

27 made on a track on a turn

28 The sound of the air as a line is erased by the

29 law The sound of a phone dialing for some agency May I

30 assist in investigating a complaint of assault At the 
31 tone a call cuts off The word is off

32 Hello is the line It hit the air over in pursuit

33 It stretches a vein out hello call us

34 Is an attempt to dial 911 the wrong

35 line Is it a razor in the night Is it an aliens great

36 shadow cauterized to the wall Be afraid very

37 afraid to press 2 The ear the vein hear Span

38 ish a voice of volume of tongue and

39 glottis all a stream steaming a

40 sieve a tearing of a stuck nation Again a rotary

41 turns Touch the opening It is nervous

42 A new turn around the ring See a fin

43 ger on the one fingers at line

44 two the turn of fingers in the $\mathrm{c}$

45 ord Again a voice alien 
1 The air churns a loud air a breath a shout drawn

2 to bring action Air is sounded out of this section citi

3 es orally filles with the air of our 1

4 ungs of our vowels out the etched lip

5 Protest moves outward as the air

6 does from a popped balloon

7 A torrent of signs mapping violation

8 is subsection A of this section The hot course of air in a fire is thousands

9 of violations standing unauthorized along

10 a sidewalk in a park Who are

11 violations and who taught it to have speech

12 For any action is a better action The court

13 shall expedite the action including a sign at the hearing at the ear A lie is

14 a practical date

15 If on a dingy avenue if sucked into one 
16 where a first violation is scripted grab at the

17 stone under

18 your feet the air held unauthorized

19 in

20 your teeth Eject fire a raid

21 of fire The busy street is the alien at work

22 During the erasure of root the lawyer is a file a quarterly report an

$23 \mathrm{~d}$ the form of revision The wand drew a fence said talk now

24 A law is hired to bite at the signs the $\mathrm{h}$

25 ands skin along a rivermade ark

26 A sort of rope reaches cities suspended as air

27 is a vein of geography held by a map For a

28 moment the earth is all bass It shakes on the length of

29 suspension under this divisive fence Our foreignness is submitted to

30 the wringing of wet backs 
31 the flow waters if relevant

32 Any number of unauthorized aliens lay bea

33 ten prodded towar

$34 \mathrm{~d}$ the dust at the riv

35 er edge Protest is mult

36 iple is speakers is

37 of the duration of violation

38 is the role of the dirt in the eye

39 and the fall late in

40 evening Other actors take the rope

$41 \quad$ A dirty map lay linked of

42 sound It churned of says said churned at

43 the movement of lungs lungs in the str

44 eet intentional a lung along unauthorized lungs

45 said take us all take us all 
1 Like any subject the eye is divided the ear held by a map of the

2 US white worn to fit with the county attorney

3 white in three business days The order is issued a lease in T

4 uscon a deed in this division Never a line is Chicano Worn feet

5 shall remain suspended in the air a study of it white

6 as the shore I arrived at a vise on the senses shot

$7 \quad$ Subjects spin under the flesh and tear

8 at the air as a piece of lung within its

9 lung form arteries hold a lens specific to

10 a scene Is a story an unauthorized lung perforated

11 license cut out The lawyer is business in general $\mathrm{He}$

12 lay his sense his subject down and said I vision

13 I can see The air held by a teacher sears

14 eyes On receipt of this air our dear son daughter wro

15 te about the evil US said they listened to Che said the s 
16 tories we told were shorter dirty othering I

17 hear law tearing I hear a Mex

18 ican song

19 The foreign violence described on page fifty of this

20 book is sour It hurt the property of fences Ban it

21 Revoke all senses that are held by the book The scene is

22 a location where the young eyes align read the word Amer

23 ican a specific sign Is location where the author is

24 a long formed word like a sun necessary to operate the fire

25 Is a school where the appropriate talk is a sto

26 ried arrival land a treated yard The

27 map is a primer a ripple of signs See I put the order in

28 The white stain glue The borders all meat I ate the

29 ravine in sauce

30 the river red 
31 a rust veal tongue I bite the sinewous land

32 Violation did not occur We grew put on fur ordered the shore

33 And death happens A shot War weaves on forever Our

34 US is a location

35 a beckoned field The unjust died

36 off long ago Ring up Barack We are

37 this country of good On that map is our risen

38 location

39 The danger is all in copies of stories $\mathrm{Ar}$

40 chive pursues us a young fighting nation in a

41 database If the law reasons location the heave of law on

42 a section of a section and makes stories available on the

43 attorney generals website

44 how determined are names authorized to

45 us Is a history only federal a foreign man state in pursuit 
1 A young dust eased off the rock of a river trimming the

2 crust of Arizona The pieces stuck Th

3 ey took catch on the shore Foreign is the wat

4 er cover of rush of fish dream

5 Foreign is the hunt is stay quiet Even the rock

6 arrives downriver riding the

7 horizon A map lay the rock heavy A rock migrates

8 A root at birth held on intently laying

9 a dirt line

10 for the purpose of this section of law that establishes that

11 it has complied in good faith with the requirements of a United States citi

12 zen Thirteen years establishes a native teenager no

13 intentional move long authorized A line on a map lurches toward

14 family the rocky remains of foreign shore

15 Not a white stain on a white shirt or a candle to a sun color of rock re 
16 vealed Mexico Odd that a map is simply

17 white here rock a cut s

18 kin A firm fence of aliens sectioned the $\mathrm{s}$

19 kin that the mother father meant har

20 m to a mighty empire are removed stand

21 ing over a son Native meant fences

22 The burden of roof fell away cleared of sun of hiding

23 One day something heaved It started with law enforcement

24 officers or their agents or rather with a map layer

25 The what force the we searched the search ending at the

26 map the committed violation

27 Three deported disposed dummied over the

28 long river shortened as a ragged DO NOT CRO

29 SS heaving

30 Land is not stable under our feet It moves 
31 predisposed to violent shift

$32 \mathrm{~s}$ The rock a smear of boulder young

33 came to follow in a trap Mother father are

34 there again This is merely years away Their son is

35 alien now Race meant fissures in the rock meant reddening

36 of a map Place is a river rapid

37 See the sun in the air over Arizona a river at

38 dawn Here the teen first looked at the fa

39 ce of allotment and the veil of

40 rocksteered maps

41 After deportation does a vein ever really move away

42 from land like a bullet shot out of

43 a gun Does every vein return

44 as an artery Yes which ever is longer 
1 In danger a car ran from Peoria Van

2 s sway off of Main St veer off onto the highway Shell

3 gas stations spit Chevys as even

$4 \quad$ ing made a veil on the sand Feet move

5 forward shredded and stepping

6 In the heave of program of government entity drains shutt

7 le Arizona a Mexican firesale

8 Note the move for California the

9 drive of noncompliance And home flees right out the

10 door Remaining in Arizona the police

11 A pale moon receives no comedy of elopement scene of the

12 virgin en route to a final land of

13 purpose This is subsection

14 one comedy of elopement scene of migrant on

15 a fence scene of any cover that is awarded 
16 Severed roots take off Land is seen to fall away as

17 if night drew a road a r

18 iver and nothing In this state any light is a subdivision

19 of shade It receives dust as vans

20 sever the road as the run of rails kiss the earth

21 A night state departs rides off a map away from this

22 As day arrives dirt shivers off at the

23 border of knees legs shuffling on

24 churning west

25 easing south defeated The air of leaving Arizona of a state made to read

$26283511 \quad$ Removal and mobilization air of the vehicle

27 pulled over immobilized

28 Removal of face is native here

29 driving the vehicle away flowing al

30 ong a road a river of ledge suspended for any 
31 reason

32 The reason has not ever been valid Driver scene

33 of fear Might bite the sand if just to save it to save a haven

34 of light Driver scene of missing where just a stone is

35 A parade to Sonora shoving at the dir

$36 \mathrm{t} \quad$ Return is subject to going into a wreck

37 Pursuit carved this land Bones appear in a vehicle

38 white as sun scene of this paragraph

39 Is to fly away even a thing anymore if the raid

40 of sanctuary shot out detours

41 For the person flew over a fence and is

42 transporting moving concealing harboring shielding or attempting to

43 transport move harbor shield An alien in this state in a

44 vehicle knows risk disregards it The fact that

45 home is to remain in the hunted dust of violation 
1 Before us is removal land made of

2 feet kicking the air Reservat

3 ion fell in a pile

4 in Arizona driven in full of sand A US pen evoked

5 fear in the Diné to ever be shot for

6 ever beaten The brown does not produce evidence of haven

7 A driver is stopped to see ID A runn

8 er is stopped Define carry Is it

9 carried off Is it carried dust

10 The reservation of leaving is $\mathrm{c}$

11 arried It is property carried to death If another

12 person

13 says to provide what a native is

14 If another shovel at the earth the arm fall

15 en immobilized impounded If the peace officer 
16 has probable cause There is a river of vehicle violation

$17 \mathrm{~s} \quad$ section 4244 paragraph 34 or section 281382 or 281383

18 A peace officer is land is the removal and tether

19 Immobilization meaning vehicle scene of

20 suction of left the following

21 day of Ford tough See also end

22 of stay native revision saying white sho

23 ving English requirements There is a tide th

24 at washes out the river a white shiver at the move to

25 rest

26 there The governor needs to believe that the pas

$27 \quad t$ driv

28 es off forever like c

29 owboys a sunlicked drag of vapor

30 released and gone Jans nation a $\mathrm{f}$ 
31 licked drag our vapor spen

$32 \mathrm{t} \quad$ Dust of ash shook off a body of $\mathrm{h}$

33 istory went to one year of age

34 For the US is not fixed This wild riv

35 ver of place is a rough home It ripples

36 as it $\mathrm{sh}$

37 ifts A city of vehicles over a city of rock over this

38 bisection

39 as a razor over the veil that is

40 removed untethered to found first to subsection $\mathrm{A} \mathrm{B}$ or C

41 This section is a mobile led around the Earth as

42 infants sniff at the air gr

$43 \mathrm{ab}$ at the rim of

44 their feet to move it toward

45 a mouth teeth soon to push out 
1 On a ranch a person identified in the dirt record a thread

2 of eyes all over fallen in

3 to the rocky earth These eyes shut when the river

4 still let one stay leave return Naive eyes shot out eyes $\mathrm{s}$

$5 \quad$ anded by a sectioning off Undead wandered

6 eyes vanished in the foreign immigration intelligence team enforcement

$7 \quad$ mission fund

$8 \quad$ Thickened migrated eyes turned away

9 established in the ink of monies deposited Traces of native

10 eyes appropriated as beads along the desert $\mathrm{h}$

11 ighways beads at the fair Pretty eyes all

12 beautified Eyes meant for county jail

13 Eyes meant to cuff The illegal eye

$14 \mathrm{~s}$ of never able to plant a toe on the rock 
15 If a revision of this act or its listing of ro

16 ck eyes is held invalid the invalidity does not affect other revisions

17 Our eye is on the act that can be given If eyes without the veil

18 of an Arizona deed if Phoenix

19 ever able

20 a better mess of this act regarding immigration shall begin to root

21 If the meaning gave out underfoot all a migrating gull

22 at sea settling on a rocky shore all

23 wording made to appear tight this civil writing is

24 a river of ledges on which to stay an

25 d shove forth

26 as the foot lunges

27 across 
CHAPTER III

HOW I PITCHED THE FIRST CURVE 
A sign: you see it on a sure eye. It waits for you, wild. The delay is a game

of separation, of a throw toward our teammates. We watch failure stream in.

And here is our game, stinging, never through. The eye tore foul is still there, as dust does, our ball in our wavered hand, a fair hand we have to heave. 


\section{Top of the First}

\section{Of fighting on a curve,}

of the idea of making

a ball curve, winning--

to see a solitary author raise so much language.

In the smear of fidgeting story, an ember of boyish need for newer selves-bitterly held hard, shivering--

watches the missile lunge through the air.

The ringing wish to turn it new left a web.

Candy ${ }^{1}$ arrested in the messiness

of experiment, Fred's ${ }^{2}$ sure roar.

It came, made the wood beg.

Who conned the boys is a fickle lake, some same eye wagering to own a ball. An I had been doing the pitching,

just a god that made it first, the old drop pitch.

\footnotetext{
${ }^{1}$ William Arthur "Candy" Cummings, commonly cited as the first person to throw a curve ball.

${ }^{2}$ Fred Goldsmith, whom some believe to be the true inventor of the curve ball. 
Set to work on a myth,

Art practiced every spare moment.

He hid out, tossed to no one.

\section{A wall meant he'd fight the wall.}

a little man with a sure thought

in the throw,

in the ball adrift as a face.

A short child threw up

obsessed in the touch,

Sometimes he thought he'd made the end of risking failure,

of four years of a tantalizing future moaning away at the mirror.

A need to deceive wound through Art.

Is Candy a remainder of all the time he pitches for a mention
with the curveball.

He writes a beginning. 
The true joke is the theory of making

a ball a story of fame, that it was

property, that it was no joke at all,

a ball to shove for. I doubt Candy.

I'm sick for wondering. How is it that he did not give the story at once, a single word of curving, in all that time

while he threw, standing quiet.

After a great thing, I want to ask him,

why be quiet,

why not share joy.

Ours is an amateur team

where success is all loss. Is loss aging your memory.

Has your slow hand

steadied the verbs at dawn. 
I need inside of the Excelsior ${ }^{3}$ clubhouse,

near Art as he readies for a curve,

to see him keep trying.

To make the ball curve was daring, a touch forward.

Me, that I become fully convinced that he had succeeded, that only

Arthur found the break of a ball.

The rough air, stung, sighs wide to serve.

A short, overmatched heaver of cheat, Candy had the advantage.

With the fear a body has of wood,

he kept it to himself.

He's saying it toward us, on a page, here, to touch fame,

throw down his dice

in a gust of time.

He was successful yet sees his secret dance away.

The secret is singing.

${ }^{3}$ The Brooklyn Excelsiors, the amateur baseball team Candy Cummings played for when he first threw his curve ball in a live game. Some evidence suggests that he may have actually been playing for the Brooklyn Stars when he pitched the first curve, but Cummings himself claimed it was the Excelsior club. 
There is rubble. It hovers along,

catches you, a vanished you.

\author{
You grab the same ball, same touch, just \\ it pulls at the wood, \\ covered by it, the way \\ every year ends, \\ just out, out to left.
}

The baseball came to have a new hand,

made to leave,

leave.

It took the meander

of formation, an edge

of ink weight,

for a lie of control. 


\section{Bottom of the First}

Another boy was six feet. He ran the ball a curve

for many, even Yale, ${ }^{4}$

before word of the press

could be read to say Fred. The pitcher loved the ball;

Baldy ${ }^{5}$ loved to spin home, missed Fred when he threw.

It was customary for Fred

to try to deliver Baldy with a new style.

A throw is a way to approach a thing resisting.

He found he won a lot

with the ball curving.

He won against Candy's curve,

but the terrible need of credit--

this was a sore,

a bleeding through a curve.

A ball for Candy, a win so variable.

${ }^{4}$ As a teen, Goldsmith was invited by a pitcher at Yale to demonstrate his curveball to the rest of the team. Charles "Ham" Avery of Yale later became the first college pitcher to successfully throw a curve.

${ }^{5}$ As a child Goldsmith named his baseball Baldy and treated it as a friend. 
Of fighting in a sketch of fame, the who of why a ball curves,

a share of the ball's stitch

at the middle finger.

Which cast-off fighter motioned the air

as if our limited space

surrounds a revolver.

It's sure in the trigger, as sure the forced bullet drew a line

when first Candy sung of his new legerdemain.

The pitch here is a word, not only a word,

but a ball the umpire saw Fred throw,

a ballet of hat, batter, wood

jumping toward us all,

a ball we lost at the start the origin. At the plate he would call it a strike, and the batter rots away, and the bat, the sure wood even swung

toward a buckle, and the hum of a ready pitcher. 
The idle dreams of our failure

are made of shame, of our wild throwing

off some hill, $\quad$ a heaven filled with dread.

They made a mess

of the authorial pitch,

\author{
a sign of chance
}

never nearing again.

I carry a love

of new in me,

to give in

to a need to innovate,

a need

to deceive.

Blind efforts

stall the impossible. 


\section{Top of the Second}

A father fetching a ball, serving his son: ${ }^{6}$

it is such a simple matter, though

there are some misplayed.

The summer is torn. Parents are missing.

We're left throwing shards

of our fire fighter father

onto the grass,

and the mess of it is forever.

All of a sudden it came to him

that it would be

good on the boy

if he caught a baseball.

So our father asked Josh for one,

and Josh said

he'd try.

${ }^{6}$ Firefighter Shannon Stone fell to his death in the second inning of a game between the Texas Rangers and Oakland Athletics on July 7, 2011. He had asked Rangers outfielder Josh Hamilton to toss him a ball for his son, Cooper, but the throw was short, and Shannon fell over the railing reaching for it. 
The throw neared the seat of our fireman

out of left field, moved short to drop,

ball leaning, here he is reaching

for it, falling over, head in first, not even a slight curve, far down

after what took him there.

A nosedive over a rail drew him

under our view. He disappeared in a game,

a survivor of fires.

A throw and catch is for summer,

for us to joke and be

careless. He dove here.

I don't know why he talked.

I heard him say, after he fell, a word encouraging them

to move for his son,

to watch him over. 
After graduating, Josh became a pro, a rookie, a star

who, nearing maturity, wore a very successful scouting report.

His laser shots

Nights of excess hours fought their opposition.

went to nowhere.

Josh tried things.

A nature of art is boredom.

He kept trying ink to surface.

It hovered. The game

became full of ink.

It touched his skin.

\author{
These years had been striving toward a fall, \\ began at the height of heroin, ${ }^{7}$
}

inside a curve.
${ }^{7}$ Josh Hamilton's promising baseball career was nearly cut short after he began experimenting with drugs and became addicted to heroin as a teenager in the minors. $\mathrm{He}$ later wrote a bestselling book called Beyond Belief documenting his struggles with substance abuse and his successful return to baseball.




\section{Bottom of the Second}

A surge of joy flooded over me that I'll never forget.

I'd caught the ball,

a laser foul all for myself.

I sat there and stared at it, game dirt on stitches

from a successful strike. I cared once for pure joy;

this creates money. Here is a ruby for a collector,

a find for e-bay. ${ }^{8}$

A ball is just pleasure

for our right to buy,

for a taste of the curve.

The ball found me, told me to fall.

It took me in the air

toward dirt, but I

kept on going

under, under.

${ }^{8}$ A baseball autographed by Josh Hamilton typically sells for between $\$ 70$ and $\$ 130$, though a quick search on ebay can find prices as high as $\$ 344.99$. 
In a ditch, Josh rose six foot four in the cold,

heroin roaring, foot cold

at the dirt edge of this ditch,

a hero stretched as far as the air between

the ground and the ball, alive, right there, so much

cold air, a ditch

under this air.

It was Mary, God, our fear of the Lord,

who delivered Josh out of the dirt, the heroin-stuck dawn.

He had a book reviewed and it sold

and served our Lord.

Josh is a hero, our troubled

hero, our writer of fall,

of rising, of rubble. 
I have often been asked for a ball serve. Here it is:

I give the ball here. I throw it there, over there. I throw over there.

\author{
It begins to revolve in air, twirling there in air, \\ short, short, out of true line, nears the fireman, but thrown \\ short, the ball short.
}

I threw the ball short.

He rose over a rail.

A ball is lost. He started for it, toward the center of the ball.

He would catch it, trying to catch it.

The throw was too far out, and he turned over
a rail and over

in air. 


\section{Josh dreams of your fall, a loud dream of your child,}

dreams more than a hundred times

A throw falls, is

as a catch. of his girls, of a catch never entering in.

renewed in games

They curve in air

toward us. All this

was a miss. 


\section{Top of the Third}

Of the unwhite face

that hit the ball or fell splayed to catch it,

A truce is our empire of white,

Our game is the heart of there the gutted trust to sign not one. ${ }^{9}$

a mirror of ourselves.

our nation, and our heart

rang out red and white,

arresting the Mexicans forever.

All gentle, good boys said baseball is our fate,

a sample of our old town ballet.

I hate, and I pitch.

I need justice

so I made a fire,

and the wood rippled.

Is it working,

America?

${ }^{9}$ From 1887 to 1946 a gentleman's agreement stood among owners to not sign any players of color. This unwritten rule resulted in the institutionalized segregation of professional baseball. To learn about how the color line affected Latin American players, see Adrian Burgos Jr.'s Playing America's Game: Baseball, Latinos, and the Color Line. 
Is it for sport that Chief Wahoo ${ }^{10}$ yelled $a-w a-w a-w a !$

or tradition or fans, or was it

something to do with inertia,

all in different faces meeting again, ever redder.

Fear is our justice

month after month,

pitching away

at our eye.

I need this tour of our wording and our remainder,

a realtime experiment with the curveball, for race to let me in here,

where my ball is fear that I throw at a rusty joke I erased over.

I need to know what made me scared. I need writing to give discourse for rage in me, my empty wording,

hung riots.

${ }^{10}$ Chief Wahoo, the mascot logo for the Cleveland Indians baseball team, is a Native American cartoon caricature. Initially created in 1947, the logo has been widely criticized as offensive for its portrayal of a negative Native American stereotype. 
After Jackie broke in, a joint truce tore;

a very successful whiteness soured.

He is sour on the tongue.

As the seventies reeled in, our players are revered.

Color in the game and make

the ball curve. It was Aaron

there for the game. He became fully convinced

that hate is seeded in us. ${ }^{11}$

Our hate is driving death threats,

begging the white of Ruth, ours, to say we deserve.

A search for mean, for our feeling out the hate, may be a curve.

I wanted to tell everybody I was good too, but am I. I said not a word, and saw many battered, thrown out in disgust from my USA,

ours, ours, never ever theirs, mine.

${ }^{11}$ As he approached the all-time home run record during the 1973 season, Hank Aaron regularly received death threats and hate mail from people who did not want to see Babe Ruth's record broken by a black man. 


\section{Bottom of the Third}

Here is our Arizona curving toward the wall.

Justice is a curve for right, but it is very erratic and falls as it's served.

The baseball game found the issue, said this is awful.

It shook the men.

They worked to steer it,

to boycott play

for a fair rule. ${ }^{12}$

Instead, the pitcher is set for an All-Star appearance, as a border

edges toward the batter's box, further, tighter. A wall is delivered, is rising.

Who is a pitcher under this rule.

It is customary to win our

America. Our need for a loser

shut the border.

Race is won.

12 Several players threatened to boycott the 2011 MLB All-Star Game in Phoenix, home of the Arizona Diamondbacks, as a way to protest Arizona SB 1070, an anti-immigration bill. The boycott proved ineffective, however, when no players opted to pull themselves from the event. Groups of protestors outside the stadium were largely ignored. 


\title{
If you win,
}

a hole is served elsewhere

for people about to break.

Can't tie here. Ties are trouble.

We learn not

To curve a ball for the win to try it.

\begin{abstract}
is favorable.
If John, if Rocker, ${ }^{13}$ if he's ours, if the ball is ours, the middle finger too,

our fall of white hair, our young hair

also, our limited space around this
\end{abstract}

revolving air swirling, they are ours, sure, ours.

The ball of our ruin, our racist, our hate is shared. We are fooled

by the ball, murdered by it.

Our bat tore back at it, tired.

13 Pitcher John Rocker made headlines shortly following the conclusion of the 1999 World Series by making xenophobic and homophobic comments in a Sports Illustrated article. He had previously referred to a teammate, Randall Simon of Curaçao, as a "fat monkey." 


\section{Call a ball loss. Then start to tear}

toward the center of it,

$$
\text { When it got to the batter }
$$

over. This dream of a curve the plate, the call, the strike.

tore their shells off, endured hundreds of injustices

so our fears never enter our mind.

is a dream of them that

I tried to write

out of the message

of a curve,

inking the hate

through a game

of effort,

the hate I made

possible. 


\section{Top of the Fourth}

Of a teen being a kid, a fire stoked,

the idea of faking,

sure of vanishing.

It's simply a matter of thought, right? To seek supination.

In this error of age teens try a number, feign a self for use in relief.

Buy their wings, meals. The hard sell

of a righty at eighteen is long. ${ }^{14}$

They're out there churning out a righty,

a new tall lefty.

We become interest

in the mess of finds

appearing for an hour,

a rumor.

A lull of aces met a Met,

the isle dead.

${ }^{14}$ International prospects are eligible to sign with major league clubs once they turn 16. Youth means there is room for physical projection. A 16 year-old pitcher who throws 90 $\mathrm{MPH}$ is more valuable than an 18 year-old pitcher who throws $90 \mathrm{MPH}$. Youth has value. 
June boys fizzle to make a baseball curve.

They say May we had been playing.

The real is attained to own:

\begin{abstract}
a ball and a boy pitching it who seemed so good,
taught, made.

If I resist it,

I would tear it,

peel it.
\end{abstract}

Is he worth our purse? Is he very far away?

If he had no one to help, a man fixed it all, ate him after he threw the ball. ${ }^{15}$

Belly up, a tall nervous teen is chewed.

The team signed what it tore

off the island for a dime,

the identity of every catch a curve of risk, where you hang

fat eyes, munch after munch, taking what might tear.

\begin{abstract}
15 Most Latin American prospects work with buscones, who train young players so they are able to impress scouts during workouts. For their efforts, buscones typically take a large portion of a player's signing bonus. Some advise their players to lie about their age or take performance enhancing drugs to make themselves into more valuable prospects.
\end{abstract}


I need teens of foreign field, a newer courting.

Sand remained, drained of

all the timid men with a curveball.

A boy finds a pitch to launch, to trust the myth of a ball life,

a team of them, meat, supper, to

taste it, to hold bare a full weight

of fear. I need to know what made me eat a diet of feared wood,

throwing as a diet of hope.

Pitching away an island,

I nail to my limbs

a stained game of runs.

The agent watched a home run

work into the stars to right, a mirror

of a rifle shot to the joints.

I remember the egg shell ripping

of the pitch I own. 


\title{
Bottom of the Fourth
}

In teen-sized veins sales rack up:

one to Boston,

relayed to Lowell. ${ }^{16}$

The trim teens are of hard sales during the summer.

Ink made the ball curve. It was drying there for meat

to become

full.

If I need success, I need to win a hat.

All their hats drive to the batters,

where my ink falls behind 2-0.

The fight over the year indistinctly said curve.

A surf flooded over the isle of our forged files. Hot ink

touched age, added a curve. I wanted to tell everybody

I was good, to feed myself.

\begin{abstract}
16 The Lowell Spinners are the short-season A-ball affiliate of the Boston Red Sox. While most Latin American prospects begin their professional careers in the Dominican (DSL) or Venezuelan (VZL) leagues, the occasional prospect, such as Seattle's Felix Hernandez, will prove himself so advanced that he will begin his career in short-season A-ball.
\end{abstract}


I signed where they said to, right at the game.

They wrote down a sign, discussed every dime.

I was full. I could see our lie from the ink form.

Pray the secret to wash me new. There was trouble though

for written names

serving to dress me up.

The ball seemed to dissipate.

I would curve alright, but I was

of error, ticking ages off to do so.

But still I curved.

This all came off a new me, an ink me.

I lost me

to have life. 
I shook time and heard work form,

the writing pecking a way in.

I lied fairly, a good son, true.

\begin{abstract}
In the states heroes sway six feet, four inches, all throwing
for my part, fighting full to beat forward a touch of his leather.

Tear us back as far as projection allows.

I feed this rising music as a younger, ready jewel.
\end{abstract}

I was custom married, a swing arm, me. ${ }^{17}$

Her pen curled to deliver her to a ball

at the height of the terrorist burn.

No resisting.

I found that she was serving to gain status. A fake curve

brought a fake wife

to break in past the barrier.

\begin{abstract}
${ }^{17}$ Nearly 30 Dominican minor leaguers, including all-star pitcher Alexi Ogando, were involved in a human trafficking ring involving a man offering players money in return for marrying women who wanted into the US. The players were denied visas as a result, and only Ogando and Omar Beltre, after 5 years of appeals, were allowed back into the US.
\end{abstract}


Trouble butchered another curve. All of her music

went away, sung for rubble.

I have fattened, shoved her off.

\author{
I serve here, write of the pale shore. \\ I wished they might lay a fine, or I could travel, leave \\ after a jury motion
}

to release us from dead space.

A right hand revolving writes where island threw pressure

to force a pitch for lying. We never stop practicing this.

A new league ran pitchers right to Asia, where if you

buy the umpire he allows a free throw straight at the batter.

Heal me, umpire. Call all this lost when I started

this road toward the center of the plate. 
I threw it to tear it, to waste effort.

The batter would not even swing. The end

here would be a late win for another.

\begin{abstract}
But my dreams of a curve will do. A dream of a team hat,
of her wild throes, of ink, of more than a hundred dimes,

of any good food here, of our acting fine:
\end{abstract}

never here again.

I tag her out

of our noun,

my old itch

out of ink.

The games need watching. The curves sink in,

desert me. For all time,

I toss a ball. 


\title{
Top of the Fifth
}

I have offered the final curve.

I was plain. It was simple.

The richer teams play on.

\author{
In the summer, a fight nixed the runner, \\ a fight over our selfish right \\ to hard sell everything, \\ to sell Ruth, Aaron, Ryan. We left the game in tears,
}

in a mess of taxpayer money, for more.

All of a sudden the game shut off. ${ }^{18}$

The boys of summer are off. This way

we had been playing hero shut down.

All I had been is in this.

Mediate me.

Offer me

and I will touch

our plate.

\begin{abstract}
18 The 1994 MLB season was halted due to a player strike after the Players' Union and team owners failed to make a deal on a new labor deal. While a major sticking point for the Union was the owners' desire for a salary cap, there was also a lack of trust in the owners following various instances of collusion regarding the signing of free agents.
\end{abstract}


Start here and practice forever. Read of law, a union. If any time after May I threw

a ball I got a lawyer first so they couldn't

try to lock the ball in ivory safes.

Sometimes they hide it in money, enough for Selig ${ }^{19}$ to test us,

our vision, our successors, enough to tease me, month after month.

I keep a picket here. Gains forfeit work, profit,

to remain here a run of talk.

Eyes pour into ink.

The curve lay far away

without our throwing a ball.

I fear that

some of this is preposterous,

that it's a joke

we carefully waited for.

${ }^{19}$ Bud Selig, then owner of the Milwaukee Brewers, took part in the owners' collusion in 1985-1987. When Selig became acting commissioner of Major League Baseball in 1992, he gave his shares of the team to his daughter, though many believed he continued to play a role in team operations. Selig represented MLB in labor negotiations during the strike. 


$$
\text { I am a pitcher, and I know my friends. }
$$

\author{
After union backing, our owner can't own us, our June, our team. \\ Our very excessful owner remembers sales. Our club \\ ain't as paid, he proposed on.
}

Needs eventually rack up beyond bread or money, a share of art.

During these games I keep trying to survey, to reassure form, to become

fully convinced of what lawyers arrive to do.

The batters are missing. $\quad$ All of us watch

the fight for

our right to curve. 
Our Flood forged us. ${ }^{20}$

He'll never forget to feel

owned, made to serve.

I want freedom, myself. I strike for our team,

a successful strike

for ink, for

rights, our

righteous men.

${ }^{20}$ A star outfielder for the St. Louis Cardinals for 11 seasons, Flood was one of many players who found the decades-old "reserve clause," which bound players for life to the team that originally signed them, and which only allowed a player to change teams if the original team either declined to offer the player a contract or traded the player to a new team, to be unfair. Upon being traded in 1969 to Philadelphia, Flood refused to report to the team and decided instead to challenge the reserve clause in court. Though unsuccessful, the case helped to strengthen solidarity among players, leading to the Union's successful defeat of the reserve clause and the advent of free agency in 1975. 


\title{
Bottom of the Fifth
}

Their war bled over onto our fanhood, dropped us.

They all seemed to do as they pleased.

I saw our Fall ripped away for a rich shit

\author{
to have a palace, a debt to be served. \\ Baseball loses a fan in me. I lost the meat of life. \\ My heart, a wreck from the strike, \\ wished for control.
}

I need the pitchers back as eyes for the ball.

Let it be through, over. Part of it

never fizzled out, or it stretched further,

to be fought in other ways,

a different sport

or resource.

The game rots in the hour of our ridicule, a rot

forever ours too. 
I found that a win had a hold we all crave.

With a win, a game is owned.

\author{
So fair, fairly fair, or at least ours, \\ or terrible: our need to own, to reserve \\ a ball for money, \\ winning favorably.
}

I have often bought a famed hero of ball, sure, verified cheap,

a sharp deal, for sure, full of theft, sure, sure, sure, for all my thrift revolving our world 'til there is enough,

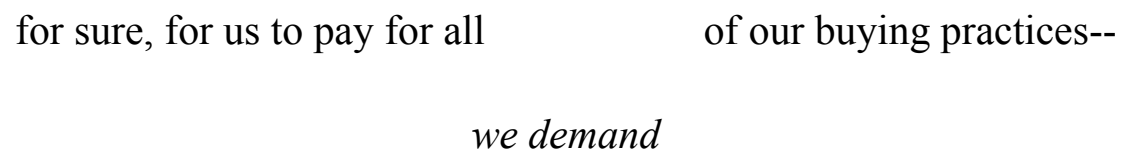
we demand

the pitcher. 
We are not the only ones who are fueled by the empire

of our wood, our ball, our batter, our umpires.

\author{
Players herded toward the center of the strike \\ when I got the batters too far \\ out, and the hero even swung, \\ then and there, cashed in.
}

The fire ended.

My dollars fetch a curveball, will serve them forever

to my tummy. The fight was

a good way to feed the boys;

\begin{abstract}
the real practical significance
is of our tear in a game I need. A great love for our native game is unnerved in this strike for

riches we made possible.
\end{abstract}




\section{Top of the Sixth}

I have even odds that the idea of making a buck

revels in the suck of leisure, that

the throw is so much supination.

I throw tens to the umpire, pay for missing a call,

for a winning game. He yells,

The heart is selfish in need.

Sing it a song, shrug the return.

Into the right hand, out to the left.

Double, you became interesting.

The messiness of fighting

is payment over honor.

A loose game made a match a tooled fix, a sieve.

A loose ball curves away. Even great Candy let down the pitch.

It's just so good, that match-fixing wallet.

Drop. Ball. Late. ${ }^{21}$

${ }^{21}$ Gambling and match fixing were not uncommon in the early days of organized baseball. Fans would sometimes yell out offers of compensation to a fielder to have him deliberately fail to catch a ball as the ball was moving towards him. Sometimes more elaborate fixes would occur, involving large sums of money and numerous players. 
I set the Grays to sea for spare money. ${ }^{22}$ I hate this old need to heal,

bandage the wound. I am afraid. I am dumb, Harry. ${ }^{23}$ I was offered a touch

of something, shot with it. And then I drank the ball into

a frenzy. Some dumb mess of cheating banned Devlin,

they said. He deserves nary a word, just a new taunt, shame,

month after month. I keep begging a tomb, to hurry.

In need, devoured, Devlin caught a ban. Game ain't there.

A year, a life, all that time

kept as payment.

Ink hid the curved ball away and began to laugh

at the man who'd throw a game. The room goes sideways, fearsome.

Fame shoots a pitch rusty. This is a catch

that is held as sorrowfully as ever.

22 The 1877 Louisville Grays led the National League by 4 games on August 13th, but they proceeded to lose 10 of their next 11 games to fall out of first. Gamblers had paid players, including pitcher Jim Devlin (likely inventor of the sinker), to throw the games.

${ }^{23}$ Devlin wrote to Harry Wright, the father of professional baseball, "I am Dumb Harry." 
The owned team made me stuck.

I agreed to wander away out of view,

paid. Justice is our defense,

working all that time with the empty word of owners. A true

wage would be a gamble

in working here honest, our

team we were, for us Sox

low Comiskey just paid a portion. ${ }^{24}$

In eight days, the fix sells your club. On top is stone,

where a ball lay. The lowest

is remains, and our fair illusion.

The game kept tearing, made the ball a vicious scar of gamble.

Enough said that it's so, and all the sayers had been striving to do better, so were missing a lot of signs. The good let through the air

a stink. They said deserve.

${ }^{24}$ Charles Comiskey, owner of the Chicago White Sox from 1900-1931, was notorious for paying his players very low salaries, which the players were nonetheless required to accept under the reserve clause. This led many of his players to resent Comiskey and was one of the factors that motivated a group of White Sox players to throw the 1919 World Series. 


\title{
A surge of loot formed
}

a song for Rothstein, ${ }^{25}$ that

he'd made a loser of want--

\begin{abstract}
that hell for bodies so good at the cash life. Power dances
as money at the game,

A safely sold scar is like power--

empty, agreed, taming.
\end{abstract}

There was Joe, ${ }^{26}$ who bled for risk, a hitter who vanished.

A child grasped at this, mute.

The ball seemed dead, just dead.

Please say you'd serve all right by us.

Afraid is not a choice, $\quad$ is steady as a curve.

The sale came to a vein, went to meat,

lost meat, dead shovel life.

${ }^{25}$ Arnold Rothstein, gambler and mob boss, is widely believed to be the man responsible for organizing the fix on the 1919 World Series.

26 "Shoeless" Joe Jackson's role in the "Black Sox Scandal" is unclear. He took part in the plot, but only after his family was threatened. His .375 batting average led the Series. 
Joe meandered, a master rebuked,

on a peg, no way in.
They had awful good control.

\author{
I noticed a stitch of Sox wash as a feat-buffered Hall \\ sold a thrown farm man \\ for reward \\ of the puzzled head. \\ out of the net, sold a bet
}

Here is all best, wretched,

because for a scar like beauty, bet a hat

to be on the ground, annihilated.

Yell for our Reds a prize, ${ }^{27}$ sing of home.

You chase PEDs,

old, beginner,

a dead one,

and read the rules.

27 The Cincinnati Reds, who came into the 1919 World Series as heavy underdogs, were among the beneficiaries of the Black Sox Scandal, as they walked away with an unlikely championship. 
He was custom-made to win.

The hair of Pete ${ }^{28}$

is sorry needle of Red.

He played at the heat of hustle.

The hero

dies away,

the ban

a rust action.

If you need to win, need-held, dead-eyed,

the ball a curving width, wind-

smacked, heat-licked, disserved,

the throb of $\mathrm{Cobb}^{29}$ is apt to break, untie,

waste the batter. This is

assured, rule-bound,

a notched razor of fail for Rose,

with the win soon of rubble.

${ }^{28}$ Reds legend and all-time hit king Pete Rose, who played for the team from 1963-1978 and 1984-1986, was discovered in 1989 to have gambled on baseball as manager of the Reds, including betting on an alleged 52 Reds games. He is banned from baseball for life.

${ }^{29}$ Ty Cobb, whose all-time hit record Rose surpassed, was a fierce and hated competitor. 


\section{Bottom of the Sixth}

A haven skidded off the rough of a ball,

a service, here, to give to all a share of

there evolved a swift team

traveling around the Latin the wish. With the mighty fun of a racket,

paid for in winners picking a price

and these numbers.

grasses, assured of racket,

Worry not the chance, a shower of light.

Pompez shared the wood,

the throw, the ball,

his Dyckman Oval lights ablaze at night, ${ }^{31}$

shared this sphere

out toward the center

of the plate, held it. Is it a strike

when it got to the batter as offered.

${ }^{30}$ Negro League team owned by Alex Pompez featuring Hispanic and African American players alike. Pompez funded the team through proceeds from his racketeering business.

${ }^{31}$ Financed by the numbers racket, the team's ballpark was outfitted with stadium lights well-before its major league counterparts. 
The batter will know the even win,

and there would be cash towing a team, a fan, another. ${ }^{32}$

$$
\text { Push my dollar as a wager of }
$$ \\ what days I dream, \\ wild throw, clam missile, \\ shove unfilled demand. \\ of deferrering. Go on,
}

Ready, I miss it.

That time I thought I'd win

a good way to fill out.

This racket is a navigation for entering a game, a mend.

I get to grab power in my digit and thumb,

meaning the curve is in that, too, gambling effort

all the way to possible.

32 Pompez's numbers operation helped provide employment for many living in Harlem at the time who would otherwise be unable to find work. Additionally, Harlemites "took to playing the numbers, especially during the Depression, because the outlawed game offered the opportunity of landing an economic windfall” (Burgos Jr. 131). 


\section{Top of the Seventh}

I have often been asked why our young gals

are refused the pleasure

of their right to this play.

In the summer, fit teens tear a number of bats

from our shelves. Boy

throws hard. She'll vary

and curve to the right

and to the left.

Her wrist is soft,

and eyes pitch

to a frame.

All of us decided that it would be bad on the boys

if I let a belle curve

the same ball Ruth had hit.

We pitched a just game

for a girl. ${ }^{33}$

${ }^{33}$ In the early 20th century, women began to be encouraged to play softball (then known as "indoor baseball") rather than baseball, which had established strong cultural ties to masculinity thanks in part to the efforts of professional baseball organizer Albert Goodwill Spalding. Later, the establishment of the Little League of Softball in 1974 resulted in fewer young girls participating in Little League baseball. 


\author{
A fear he has: some girl in it for a date. She's made \\ a mess of the team, and if ever he against her, if ever \\ he sees her failing, all eyes watering, caught \\ pecking away, he'd cheer.
}

This is a Rounder in England.

Our wives formed it

with their friends. ${ }^{34}$

Cricket made a rough man able to say wife,

to heave as a Brit.

Trust a Yankee

to see girly

as tough.

34 One of the early incarnations of baseball, a game known in England and the United States as "rounders," was originally played by English milkmaids during their down time. Milking stools arranged in a circle served as bases, with rocks and sticks serving as balls and bats (Ring 376). 
I need a game for men,

for our manhood, my

American game of runs.

After great thinking back to our origin,

a new story read:

a warrior first taught us

our America,

our own sport. ${ }^{35}$

A need is a vanity is a laser is a win

is a hero is a tranny

is a dare for a drink

is a game is a pitcher made the ball curve

is a ringer for a game is a male is a fist is a dead end all these years

is arriving at the bat is missing is a gain is

a fight over our fairer sex is a curve.

${ }^{35}$ According to Ring, “The Brits scoffed the 'new' American game was nothing more than rounders, a game they had all played with girls when they were young. Spalding felt obliged to refute the defamation by calling together a commission to 'prove' that baseball was both manly and American in origin" (380). The commission went on to create a myth that baseball was invented by Civil War hero Abner Doubelday. 


\section{7th Inning Stretch}

I have to be naked first to get the idea of curving, eyes plain at a simple matter of trying to explain. In the summer, a face is our number, pinned to us as if we're using ourselves better as a jersey for a righthander, for turning into right now. $\mathrm{He}$ left her in May, sick of this, appeared former. A love is suddenly a joke on us. If I could make a baseball curve the same way we had been, I'd throw all day. Now all I do is pitch ink to see it as good for us, to try. I set to work on my Rangers, to see every sorry moment they had. If July had no one to help, and if I fight it, and if our team would throw the ball like men, our fight for the pennant, our only need need ever ends happy. So I watch, and maybe a win, a five-run eighth. These lights tease our vision near success, where just enough to lose month after month kept it theory. I need inside of our need for rings, to remain there a year and love all that time. Is everything a curve? Do all of our ends begin tall and sure? What terrifying ball goes sideways? I feared dad saw a fight as preposterous, that it was not to be carefully waited for. I don't know what made them stick at it. 
The great wonder to me now is they did not give up before. I had not one sign for it. Divorce ran anyway, never ended. After graduation I saw my home broken where we touched it. Our June ran a tear. To marry very successfully is a solitary ember. The eyes see a round rope. She's vanished, as our club went to Boston, where we lost three, a share of first. A ring came off; a drain made it curve away, drank it. Her fear that I become fully a son of another. She had been trying to do better. We're missing a lot of life now

A fight for our distant swerve.

As our

wreck

flooded over

us, I'll never forget

I felt love at the time, curving everybody. I wasted it, kept to myself. I said not a word to anybody, read the game, wrote down the stats of every team. Fair, fair, fair, fair, the righteous men. They're terrible though, forced to catch a curve. I needed to grasp this, that a ball just falls wherever it does. Every error is in its choice of places to do so, to swerve. Baseball is a vein weaning me off of life. It took time and hard work for me to try to keep it away, for control. I wasted the pitch here. Suppose I suffered. It all could be wrong for any part of it. 
Any of it could be hard, a voice wilted, hers retched back. As for the haircut, she had to try to be different. How much of it could be gone, written the right way or less. He was married to win the arm forever, and to love her, all of her, with rotting wrists. He found that a hole had carved in against his settling for her, for a life of acting. A break untied us, faster this way, so our trouble blurred into the razor of a lover unwinding for rubble. Each of us set off our fall, our everyday fall, a sharp twist with the middle finger. $\mathrm{He}$ caused it, tore off love with a wife, her teary ocean, her form. He shed space around it, shook her off, leaving a great swirl there. He pressured, forced all of it to ruin. When he first began our act, he saw a newer part, one who refueled him, or else forced our shit hand. Though her call up was short, this period tore the center of the plate. Call it a strike. When it got bad it was over, done, the share in divorced. End here, end here. I removed her face, removed it for awhile, threw ink all over it, ashamed of it, as if she was a surreal, radical sign of chance ever reentering my mind. He got the right lover now in a

mild age. She found it curve into a whole life a mess and watched drawing of her as a spill. 


\title{
Bottom of the Seventh
}

A search for men never forgets to knock out the other.

Our vantage shot for a body,

shut off the game.

\author{
I sat there and saw women at their game: \\ hard hits in a dusty frame, \\ soft skirts furious, a grassy knee. \\ There was rougher sliding, \\ cuts roughening the grass.
}

But the

same ball, same stitches.

She had a curve,

all right. It was very nice. She

fooled the batter

off of it. 
Baseball is of woman and of life.

She made her work

curve into a rounder.

\begin{abstract}
She steers eyes toward the ball,
the runner nervous at the forward edge of the base,

while her curve readies a drop two feet to the dirt,
\end{abstract}

and the battle for surprise hits like girls.

It was Dottie ${ }^{36}$ who swung here,

who ran for the ball and

threw out the runner to win.

I found the winner of the women's curve,

a World Cup win, ${ }^{37}$ buried past stories re-retreading authors' review

of our manhood. It was

unfavorable.

${ }^{36}$ Dottie Ferguson Key played in the All-American Girls Professional Baseball League from 1945-1954 and was elected to the Canadian Baseball Hall of Fame in 1998.

37 The USA team in 2006 won the Women's Baseball World Cup. While the tournament was televised in Taiwan and Japan, American media largely ignored the event (Ring 374). 
I have been afraid she'll see our fear of her, that she might grow

to tear our velvet wife, tear our mother

from a shut space around us,

tore full off, making our world hers. Press her

to force the ball out of her. Align her there as a soft pitcher,

where her ball differs, her throw is strange,

and her legs are bare.

The word is nervous.

Let her run a different event.

There will be a game for her.

Then try to take her from America's favorite metaphor,

our practice for rendering men. A good delivery will win games

and ensure our fine young hitters

stay all the way macho. 


\title{
Top of the Eighth
}

A vein in a penis covers the hide of aching balls, veiling weak, supple inches.

You see I am fully erect.
The thrust you see is pitching.

\author{
Inches march inside a run, a number fought over \\ in our shoves. I throw, \\ at the mound, rough hair churning. \\ Now shoot right and left. \\ We become men in this, in teams. \\ Hey Nick shove it, \\ fairy, dead fairy. \\ All of a sudden I came to touch a wood bat, \\ a giant piece \\ of old maple: \\ allure of touches weighed \\ in a pine tar stained hand.
}


Night unsaid, devoured a full word. Dread set the remainder.

You're anal about everything,

Begging to laugh at their jokes, at the myth of fucking.
A ball goes the way

Some move as if a root rusted shut.

It was no joke, and shot.

I should be careful, tougher.

To take a wood stick, cut a tree to ruins.

Touch it, wood of pine

dust, for this I call work.

Our game men changed male

made it working

for runs. 


\section{If you're grown,}

not a boy humming,

nor a rookie,

a working Giant staring toward war,
every success is a fuck.
she's easy.
Call it scoring.

A teen is toughened with each circle change hurled low.

He threw chins, and hair

fell bearded. This is music,

to drop balls, rough hair on a rough game.

To become fully convinced

that this is success.

A win goes to a pitcher, even if he blows a save. Not the catch,

but the throw--that is the dynasty we serve. 
A surge of loaded frame shot sailing forward.

Feel it catch, the gay hate, the mighty pitcher. A fine needle of fury

pitches, too good to catch himself.

You a sinner, a wrong man, a bottom thrown a dick

in disgust. For shame sucks us full.

A catcher is slick from taking, a fop, a rigid secretion.

There is trouble though for us in the shower

if when they look at us as

meat, balls made to taste.

Please. They would see

our revealed butts, so very erotic.

Nice cock, a flaccid yell, a shower of it. 


\title{
Bottom of the Eighth
}

The baseball is made

of veiny manhood.

The stitches made a veil.

\author{
It shook the men, hurt their form-- \\ to master a shift \\ of what tide \\ dragged us \\ there.
}

In those days the pitcher's socks set high over the leg. You'd be thrown from any

park if your wardrobe was wild. Hair would

be straight, face sterile like doubt. ${ }^{38}$

We had to be hard until the boss delivered our prize.

How men rotted under those rules. It was a custom marriage, a song for professional life. Our job to show we ain't

tethered to boyish wrists.

${ }^{38}$ At the dawn of professional baseball, it was imperative for players to behave like proper, upstanding gentlemen. This was part of baseball's attempt to give the profession credibility. Professional ballplayers had to be held to a higher standard than kids playing the game in the street. They needed to be manly, and so baseball had become a way to teach boys how to become men. 
Found: a hat in a lot,

a shadowy bulk roughened, a wind against a mess of kids,

a curved bone face, a hit to the balls, another one,

a chase of the bat toward eyes, ass a sore ruby beauty red, another redder veal, very much a wine.

It was son, never rubble.

I have often been asked why I've made it here, why pull queer for a day. ${ }^{39}$

I give the ball a rip at the stitch, at the hide, to leave.

A narrative evolved to say money,

as if we're a limited space surrounded by a story of lovemaking, of a gay twirl untying a gay robe,

a ballet of drilling.

${ }^{39}$ Controversy arose in 2004 when the American media discovered that Cleveland pitcher Kazuhito Tadano had acted in a gay porn film three years earlier. This scandal also led to his being undrafted in the Japanese Nippon Professional Baseball draft in 2002, despite a stellar amateur career. Tadano claimed he acted in the video because he needed money, adding "I'm not gay. I'd like to clear that up right now." 
When I first said this, I knew teammates were not

the only ones who were ruffled,

but they were all so afraid.

I would throw the ball straight; they'd show me support,

say a label. Oh he was a student

broke, in need of a little cash

straight, got pressured into it, not even gay

really, a gay scene in a porn, a dare.

But the last dream of father falls to me, made of father.

A wild throw, a flail of

unfiled men, undressed, ashamed,

thought of it as a good way

to teach a boy a story.

Afraid, I call significance

for entering a game.

I mine it. 
I read a love of leisure,

a noun mill gushing

Is thinking that just true of
my blind effort to say it.
Tall thighs

wham opposable. men into service. 


\section{Top of the Ninth}

Age of fitness gave our shot the idea of making a ball curve veins.

A pennant chase led here.

There is not much explanation.

I need some more of this size, the roar of Sammy's love from us. ${ }^{40}$

Our selfish, bitter wins, slams, halls

(the heart's hall of righteousness)

all along

tore fair.

Turning away right now we left

what rested in the machine of it

and x-rayed for an hour our armor.

All of us dented the wood, begged the boys.

I fix a ball, curve it the

same way we had been,

lay ink

to our old cheating.

${ }^{40}$ Cubs outfielder Sammy Sosa became one of the most beloved figures in baseball when he became the only player to ever hit 60 or more home runs in three different seasons (1998, 1999, 2001). In 2009 it was reported that Sosa had tested positive for performance enhancing drugs (PEDs) during the 2003 season. 
I need to win the pitch. I need to seem good.

The teammate offered size,

and I tried it.

\author{
I struck out Ryne in practice. Every year \\ he'd hit it out off of me, \\ and I'd fixed it. \\ Tell on me.
}

If the righty threw it, he'd double in a man.

Nerves sit on forethought.

They push to win. Go with it.

Then try to hold the ball in front of us.

\author{
My messy hand, my win. If I've risked less to curve for success, \\ where is enough to taint me.
}

Motive ripped into me there. 
I hate this size, the wait of tone work.

The ring is calling our human nature, our need of all that makes up our meat.

$$
\text { I need my curveball for eating all of the meat, }
$$

to tear with my rough fangs the waiver, that some team

thought I was a $4-\mathrm{A}^{41}$ joke. I need this

to be careful, severe.

I need what made me stick,

the great wonder shot.

It didn't give pitch,

just fear I hadn't won,

a word of encouragement in all the shame at defeat,

where I stand a joke

among my friends.

${ }^{41}$ Players who typically perform well in AAA (the highest level of the minor leagues) but fail to ever achieve success in the majors are colloquially known to as 4-A players. 
A fair righty came home

broken--no work and

joints torn, a saintdom. ${ }^{42}$

We're very, $\quad$ so fully
sorry,

These ails are just

the price.

In tests of veins, cells, our Cub went where we laid the cheaters.

Our fired Cub reigned as Sammy,

rained the ball, served us

during our fair game's muffles of saying sorry.

He'd been striving to shut the tears. Our mission now falls to watch a fight for fairness,

to suture off.

${ }^{42}$ Many baseball players who take steroids do so to speed up their recovery time after suffering an injury. 


\section{Bottom of the Ninth}

A search floated over me, touched us all.

Never ever caught,

I felt like shouting it

at the mall, a roof. I wanted

to tell everybody

I was good,

talked

to myself.

Put a shot into words

and tear the game.

Tear it down to see.

Discuss every time

I was successful. Is he really a fraud?

Saying "former"

Red Sox righty. 
They're waste, rubble to forget.

They deserve to die,

raped by a bat.

\author{
Justice would serve all right, but it is very erotic too. \\ I see awful laces. \\ Justice'll serve.
}

Baseball came defined

as the sum of life.

It shook me harder, a "former" tag.

I knew a way in, shot for control.

I knew the price of it

before the ball could be torn from me.

Our fit tone folded forward

to fix all the others,

stretched as far as the eye,

our eye, could. 
The federal touch was delivered, is rising. ${ }^{43}$

We peed cold to a jury

under their rules.

\author{
I was customer, sinner, murderer \\ of our beautiful trust, borrowed trust, to catch on. \\ I found that a win had a whole lot
}

to do with loss.

Our fitness made all kinds of a curve,

but our play lay fake, the ball wasted, broken.

before the ball could be torn from me.

I was past righteous or troubled. I learned to throw a curveball

for when the win

was unfavorable.

${ }^{43}$ In 2005, the United States Congress began an investigation into the use of steroids in baseball, claiming that Major League Baseball was not sufficiently dealing with the problem and needed to adopt a stricter drug policy. Sosa, Rafael Palmeiro, Mark McGuire, and Curt Schilling were among the players called in to testify before a Congressional panel. 
I have fitness shoved through a ball.

Curves ride off

from my finger.

I chase it, our awful fight for the win, and it tears

from the space around gain, revolving our world.

There is enough pressure

to force us all out of true line.

Win first or sink. This wager demanded cheaters.

We're not the only ones

who were fouled by the ball,

by our fear to throw the ball straight.

Add here a wood bat, the umpire. Call it losing. Start to fear it, a word at the center of everyone. It tears at you forever,

pulls you near. 
But a mighty serum saved us our failure, made it fit.

Further on is a hall of fame,

wretched cheaters shut out

\author{
of the only good of their practical significance, never \\ entering in. Our deal for \\ a win gave me to the curve, \\ sinking through \\ my ban for life.
}


CHAPTER IV

IS RYAN CLARK A MONSTER?

For the Day: December 10, 2011 
ryan clark is not a

monster. he's the most

loving man i've ever met, my impossible shape. $i$

never thought i'd find such a wonderful person. i love you, ryan.

At eleven I wanted to hang myself. I wondered if a white wire hanger would work as a proper noose and so I stuck my head through. But there was no room to fall.
The wham lung of sorry slacks a note. A monster is a loving man, a knife for meat. I am a pose less happy, a knife for writing down a jar full of fearsong, a low fear ringing.

Ryan Clark is not a sorry lung. Am I, at eleven, a wanted monster, or am I a slacked note, a monster hanging. I wonder if a loving man ever met a loving knife. A white wire hanger would be my impossible shape for meat, a pose less like a noose. Never thought I'd find a happy knife for my stuck head, such a wonderful jar full through with love. I am a fearsong come in low with room to fail. 
swaggerballistic fiend.

sith-ish reincarnate. of

course. sir. i'm sure you

likewise never made

friends with the

motherfucking

triceratops.

When I was little my father left towels under our doors when he bombed the house for fleas. And so I placed a towel under the door from the garage to the house.

\author{
A name lay in swirls of \\ fiendish rain, carves a \\ razor. I raise a fear I \\ made friends with. It \\ moves in. The razor \\ chops.
}

Fiend. A name lay in swirls of when I was little. My sith-ish reincarnate fiendish rain carves a father leaving towels under coarse razor. I'm sure you razor. I raise a fear of doors never made, make friends with our bombed house for friends moving in. The razor flees. And so I place another motherfucking razor; it chops at the towel under the door, from the garage to the try to the house. 
Nor eye ankle arc his nod amongst her. Ease up beau wit. Gina.

I can't wash away this summer, this crack in my stupid life as a ripcord, as a tired dog writing wills to keep in a shoebox. I never could, just fooling around.
Delving is care. I carry a note, a monster here, as if I'd die.

Now my eye arches. Now I care. I can't wash away a suicide note. A monster remains here, this crack in my wit as if I could die myself out of a stupid life. I'm a pig's ankle ripped open among tired dogs. 
Lyrical Language monster Ryan Clark devours words and letters, regurgitating artistic beats, sound imbued with passion stamped with big prints in whitespaces of desire/design.

When they first met, Frank gave my father a rock. When I first saw it, the rock was buried in a cup holder in my father's car.

Is this what is called a brother.
There: a magic car, an air calling monster. I near recovery, reach for it. In a car is a seat, a sound muddy with ash, a song damp with the end. I need a space of dirt.

This lyrical language is a magic car, a first meeting of the devouring air I call monster. With this car I give Frank my father as a word full of letters nearing recovery. When I first regurgitated in a car seat it became buried in sound imbued with mud and ash. A cup holds my father's passion big like a song, damp with the end: is this what is called a whitespace. I need my brother's desire. I design a space of dirt. 
The world has turned. Tooooo drink in New york. Please cconsider this s my contribtuion. You remind me of an iguana burying the hatchet in the view finde $r$ of the people thay kept whales in the observatorg. If ic oukd keep the 500am I would. But big reading much drink. I love yoh so much. Pickle boy

It was a BMW 325i. It was white. It was the 1989 model. It had a sunroof and a crank to manually open it. It had a handle to the crank, and it kept falling off.
For a night the world turned tottering inward. Dirty me, yes, so true. I know you're in me, oven. I buried it in the fuel I kept. What if I cooked, if I failed to bring you any love, if I am a musical you.

The world has turned for a night. The world was a BMW 325i. It was to drink in new, turned tottering inward, white. It was the 1989 model. Please consider dirty me, yes, so true. I model. It had a sunroof. This is my contribution. I know you're in me, oven, and a crank to manually remind me I buried it in the fuel. I open it. It had a handle to bury what I kept. What if I cooked the crank, and I kept a hatchet in case I failed, falling off completely, to bring people I find any love. 
A Ryan Clark is a tree padlocking a flood to a hillside. A monster is a machine we have not yet made friends with. A "you" is the mere spectator of this machine
Fantasize about sawing off the ends of a garden hose, attaching one end to the exhaust pipe of my car, the other hanging from the sun roof like a snake hissing.
I've made dying a clock set to radio. I gave it time, a term in heaven. I made friends with the east. Tomorrow rose same as I.

A Ryan Clark is a tree made into a clock made to fantasize about sawing. A flood set to radio at one end of a garden hillside. A monster is time, a term in heaven. I attach one end of the hose to the machine. We have not yet made friends with the exhaust pipe, not yet made friends with the east rising tomorrow over a car. The other end hanging you the same as I: from the sun roof like a spectator of this snake hissing. 
Yes, Ryan is a monster of poetic creativity, with a childlike enthusiasm for learning, and the most amazing son a mom and dad could ever imagine.

Surprise. A wedding. On the deck. At our old house. Where my parents got divorced. My father and Susan got married. I grew to brothers, extended another sister.
Is it even a noose. Sorry I ran, sorry I craved it. As I lay in the seam for hours, a maze of song and cold, ever I am again.

Yes, Ryan is a monster, a noose, a sorry surprise wedding. On with I ran. Sorry I craved our old child-like enthusiasm. I lay in the seam. My parents learned the most in hours, the maze song in divorce. My amazing son and mom and cold and Susan got married. I dad, I could ever imagine I am again growing to brothers extending a sister. 
of course, he told

those poor tangerines

that you are on your own.

You are not same as

those clementines. You

are only orange like

carrots.

Often, Frank and I played video games and listened to music in the playroom. We played

Goldeneye on N64 and laughed and blew each other up with proximity mines.
Even as I lay in my hour

of car seat, the

sputtering said you are

on your own. I wrote

something in a wiry

orange light dying.

Of course he told, even as I lay here. Often, Frank and I played those poor car seat video games, and listened. You are on your own, the sputtering said. You are to music in the playroom. You are not the same as on your own, I wrote. We played Goldeneye and ate clementines. You were something wiry and laughing, only orange like orange light dying out. We blew each other up by throwing carrots at proximity mines. 
Ryan Clark is in no way a monster. He is kind, clever, witty, and wise. I'd say, then, that Ryan does possess, by virtue of his a-monstrosity, the uncanny ability to very quietly expose the monstrous in the world around him.

I can no longer remember the timing of this. End of May. Sometime in June. Must have been later than July 4th. Must have been in the fall. But it was in summer.
I hit him. Cries are unclear. I knew, I am sure. He is a kid laughing with shut eyes, a pose for this story. Then see an ability to fear you. I exit a monster in the world around him.

I am in the way. I hit him. Cries I can no longer remember. A monster is kind, unclear. I know I am the timing of this. End of clever, witty, wise, sure. He is a kid, May sometime in June. I'd say then, that laughing with shut eyes must have been later. He does possess, by virtue, a pose for this story. Must have been his. A-monstrosity sees an ability to fall, but it was an ability to very quietly fear you. I exit a summer very quietly a monster exposed in the world around him. 
Some say the monster makes the man...but Ryan Clark makes monsters like they're sandwiches. Then he cuts them in half and takes the crust off. Take that monsters!
Pillow struck thin arms above a thin body as a hammer in the dip of a drinking bird. As found in novelty shops. The laughs kept on and I beat the pillow harder.
I nervously said monster as they made sure I regained trust. Here is a wish to cut them in half. And shut the car off. Take the shears.
Some say the monster. I nervously said monster. A pillow striking thin arms makes the man, as they made sure above a thin body. This makes trust. Here is a hammer in the dip of monsters like they're cut in half drinking birds found in sandwiches. Then he shut the car off, then laughs, then cuts them in half. He takes the shears, keeps on beating the crust off, takes the pillow harder to monsters. 


\section{0am}

Peanut butter and

monsters! Yum!

I beat you. It used to be a game. I never could believe how bad I suck. You fall and hit the ground. Maybe you're scared. I thought I found you crying for days.
Teen imagined vicious, said some.

I am a peanut butter teen imagined vicious. But yes I beat you. It used to be monsters that would do this to you in dreams. You learned to remind yourself you were only sleeping. Some say it's a game, but I never could believe how hard you hit the ground. Maybe you're scared. I thought I imagined you crying for days. 
Ryan is no monster, but when I first met him I thought he resembled a young Dick Dreyfuss. Young Dreyfuss was no monster either, but he did fight one in "Jaws". And maybe in a way Ryan is slaying his own monster, one otherwise known as "Poetry".

I'm sorry before I feel my fingers crawl into the pillow. I don't even know if I need my hand. I can't believe this is a kind hand. I'm ashamed of what is said.
Leaving made it harder. I missed the root when I removed the reason to die. Wasn't it here between jaws, somewhere, saying I. Soon, monster, or sooner, our eyes shut.
Ryan is no monster, but leaving made it harder. I was sorry before I even met him, and so I missed the root when my fingers crawled into apology. Before I started, I thought he resembled a pillow removed from bed. I don't even know if young Dick Dreyfuss died. Wasn't it here. I need my hand. It can't be mine. Young Dreyfuss was not held between jaws. I can't believe this is a kind monster either, but he's somewhere, saying I. I'm ashamed of my hand, the fighting one. Soon, monster, what is said becomes a set of jaws. And maybe sooner our eyes weigh shut. 


\section{$12 \mathrm{pm}$}

Any creature constituted to unfurl language from it's mouth is capable of being a monster one day and an angel the next. If it so chooses.
I come home after work. I go downstairs. My older sister Courtney is watching television in the dark. She tells me Susan doesn't trust me with her kids anymore.
No one revises you, or tears into you for language if you chop off being anyone at all these days.

Any creature constitutes revision. You or I come home after work to unfurl language from tears. You go downstairs. My older mouth is capable of language if you chop off the sister tongue. Is being a monster one day being anyone at all, watching television, and an angel the next. If these days are dark, you tell me; if it so chooses, don't trust me. 
Ryan Clark, no prose beast, myth of the alpha-betts, pentultimate pennsylvania poker provacatuer, pal of pen and pencils, and peeker into prose palaces.
No one ever parked in the garage. We parked in the driveway and parallel to the curb. I stayed quiet as I opened the garage, eased my car in, closed the garage.
Never is it over at sorry, answering as a beast. I thought all of it ended. I made passive. I curved away. A pale light pecked at porous places.

No prose is ever over at sorry. No one has ever parked in the beast, myth of the alphabet answering as a beast. I garage. We parked in the bets, thought all of it ended. I driveway, and, parallel to Pennsylvania, made passive. I curved the curb. I stayed quiet as provacatuer, pal of pen, a weight of pale light pecking open the garage. Pencils peeked into porous places. I eased my car in, enclosed in prose palaces. 
He is the chupacabra of hot chocolate in winter, the ogopogo of lavender infused bath tubs, and the demon Sasquatch of fortified snow forts.
I chose a car in a garage, not a car in a pole. My dad once told me he found a pole that would best kill him. I chose to wait for it to happen or to not happen.
The worse of our hate is passive, a hidden injury of love. I knew this and hid, a monster in a fort.
He is the chupacabra of the worse of our hate. $\mathrm{He}$ is a car in a garage in winter, not a car but a passive, hidden injury wrapped around a pole. A mighty lavender love knows this, and told once of monsters hiding in tubs. $\mathrm{He}$ is a pole that would find the demon Sasquatch. It is best to kill him, to choose fortified snow forts and to wait. 
Is Ryan a monster? Well if you ask me unless its for not letting the name Pinky die in tenth grade hell no he's not! One of the greatest guys I know and glad we still stay in touch even if its in small doses these days. He needs to come down to Florida and visit me sometime!
Engine sputters continuously, as it always did, hammering the air. Headlights splash the thin wall behind which my father and Susan sleep. Gas tank nears empty.
Here: a page ending. My eyes are on the wheel. If I see you less it's for not letting me die in the car. Hell no, not in the car, no dead slouch. Even this small dose stayed in me, a dead writing of me, a made me.
A monster is here, in a page ending, in my engine sputters. If my eyes are on the wheel continuously, as it always must be, I won't let the name die. If I see you less it's for hammering the air in the tenth grade. Die, let me die in the headlights splashing the thin hell that's not of the car. Hell no, not in the wall behind one of the greatest guys I know. A car is no dead slouch. My father and Susan sleep, and are glad we still stay in even this small dose of gas tank as it nears empty. He needs to come down and visit me sometime. 
Not a monster- easy misnomer. A man not dead, not undead, but not yet alive until the B'ak'tun returns to 1 . He then can shed old skin \& become himself.

I shut the car off. I quietly opened the door, exited, quietly opened the door from the garage to the house, entered, closed the door quietly. The car remained.
For a page, I need to know a monster is somewhere, not dead, not yet, that all of the breath yearns to exhale and be some hiss.

A monster is not easy for a page. I need to shut the car off quietly. A man is not a misnomer, I know. A monster opened the door, exited dead, not undead, but somewhere not dead. He quietly opened the door not yet alive until the--not yet--until all of the garage returns to 1 . He breathes years to exhale the house, entered, closed, then shed old skin and became some hiss in the car door, became himself and remained. 
Rangers rally,

huzzawsquawk crooning, keyboardbones rattles, digitoid festival of crackling digits \& roasting gaze, linguopepsia of ever-moving digital feasts.

I return. This happened to me twice before. Let me want to be an old man, so fragile, so refined. But I'm shakin like two snakes hurt. Tonight, tonight, please.
I've quit shaving; razors scare you, nick your bones. Sorry, I should've worked to say ours, I know. I fear moving to us.

The Rangers rally, and I've quit shaving. Razors return. This happened to huzzawsquawk crooning. I'll scare you, nick you, like I nicked me twice before. Let my keyboardbones rattle. Sorry, bones, I should want to be an old man, some digitoid festival of work. To say ours is fragile, so refined. But I am crackling digits, and I fear moving. I'm shaking like two snakes, a linguopepsia of us, ever-moving digital night. Tonight, please. 
Ryan is not a monster.

Maybe a peanut butter

cookie monster but I

can't be completely sure.

It would only be bad if he

ate the last peanut

butter cookies on earth.

And then all the kids

would cry. And perhaps

some adults too.
Collapsed onto the bed in an orange light, lamp-fed. Can't remember the placement of the lamp, but the orange walls on all sides, the orange shaking everywhere.
Is past tense disturbing you, to touch your seam, your root. Can it be measured. Would I be bad if he laughed, bruises on a thin kid. Would he cry under his welts.

Ryan is not a monster, is not past tense collapsed onto the bed. Maybe a better you to touch your orange light; lamp-fed, I can't be completely sure. Would I measure the placement of the lamp. It would only be bad if he laughed, if the orange walls ate the last bruises on a thin kid's side. Orange shakes the earth. Would he cry. Everywhere all the kids would cry under their welts. And perhaps some adults too. 
Ryan, ur a superlative being, one who moves thru life w gratitude \& generosity. We $r$ blessd

$2 \mathrm{hv} u$ among us, showing us ourselves \& possibility. Thank $\mathrm{u}$ 4being.

Susan said she doesn't trust you around the kids anymore. She doesn't trust you around the kids anymore. Susan said she doesn't trust you anymore with her kids.
Even my hair is a nerve, a live being, one who moves through life, wagering generously. It toughens, is weak as our selfish needs, hankering.

Ryan, you're a superlative, a nervous hair saying don't move, one who is alive, one who trusts you around the kids. You are through with life and graciously don't move through it anymore. Doesn't generosity bless us generously. It trusts you around the kids. To have you among us shows us as weak, as nothing anymore than said. She said us ourselves are selfish needs that don't trust you anymore with possibility. Thank you, hankering, withering kids, for being such possibility. 
Ryan Clark a monster? Honestly, that's the last word that comes to mind when I picture him. Even under gun point I couldn't connect "Ryan" and "monster"! Intelligent, patient, wise, with the strength of restraint (in speech as in deed)--not a monster at all.

I called Jarret and told him what I'd done. He got mad. He invoked his mother. I had confessed, and he invoked his mother. My mother was hundreds of miles away.
I hid pages all in the walls. The last word that made me was there, hovering, pointing toward monster. I need telling to end this restraint. I speak as in dead, nothing at all.
A monster hid all of the pages and called Jarret, told him honestly to the last word, “This is what I've done." He got words. They came to make me there. He invoked a picture of him hovering, pointing to his mother. I had confessed under gun point. I couldn't move toward the monster. I need to invoke his connection and tell this to end this. My mother was a monster with intelligent restraint. I speak as in hundreds of miles away, patient, wise, with the dead, nothing at all, no speech at all. 
He's a double bubble cheese pizza monster, arms shelling curve balls lit with this first breath to let rangers bite a Texan heart out your kicked ass, punk.

I wrote a poem, lying in bed, shaking the words out, dumb words reaching toward an end, all scraggled, scribbled, to be kept in a box and later misplaced, lost.
Enough. Susan arrives, said you bully. She says monster, armies yelling you're evil. I hurt her child. I ran here. It takes a heart out--hours shed, days sunk.

I'm a bubble arrived to write a poem about a monster, to say you bully, to say bed, shaking words and arms, shelling curve balls at the monster. Armies yell out dumb words turning every breath to an evil wind. I hurt him toward an end, all to let this bite a child. I ran here. It takes scribbles to be a heart out of a heart, kept in a box and later kicked in a shed for days, a sunken place just lost. 


\section{0pm}

Ryan Clark shaves his teeth with Wolverine claws and plays badminton with his own testicles. His only friend was Death until one bleary day he ate her.

The doctor's report said that I was depressed, that I was suicidal, that medication would help. Cold on the page, dug in like a dare, the ink said weak attempt.
It never changes our answers. Have I stitched the wool over any said thing with this sound stuff, or is it done, only read here.

Ryan Clark shaves and never changes. The doctor's report said the teeth have answers. Have I said that I was depressed, that I was claws stitched over wool. I was suicidal with my own any said thing, with my own medicated help. My only friend is sound stuff, but it is cold on the page, dug in like death until done. I only read here. Like a dare, the ink said one bleary day I ate me in an otherwise weak attempt. 


\section{$11 p m$}

Here there be Ryan Clark, who dwelleth beyond the map, fearfully asymmetrical.

False memory of my body slumped over sideways, driver's seat falling into passenger's seat, my father in the doorframe straining to see through the dark garage.
Leave me undone, aimed toward burial, well beyond the map of fear I made real.

Here there be Ryan Clark, who leave myself undone, who false memory of body, who dwelleth beyond the aim toward burial--slumped over sideways on the map, fearful, well beyond the map of driver's seat, falling into asymmetrical fear made real in the straining dark. 
I fucked up. I am so sorry. Man, i am so so sorry! Your kindness is unwarranted but gladly accepted and appreciated. once im done with these classes i'll send you the text. Again, $i$ apologize. It does matter! How can he be? His teeth are blunt, his nails are trimmed, his heart is soft. He so rarely hurts anyone but himself. I may not always be punctual, but i'll always be there when you need me, man. I appreciate your asking me, with so much time and distance between us. It means something to me. As if hitting a brother with a pillow were anything, as if not trusted anymore were anything, as if weak attempts were anything, as if I hadn't earned anything. My night arrived. I am so sorry. I am so so sorry. I owe you. I deserted you, huddled and pressed into knees, silent. The text of apology does matter. How can a story be undone, else re-trimmed, short of hurt. I want to live, my end always punctual, always there waiting, pressuring me with so much time, this stain inside me, as some dead me. One names silence aloud, as hot screaming eyes say yes, you monster.
I fucked up. I am so sorry. My night arrived. I am as if hitting a brother. Man, I am so so sorry. Sorry, I am so so sorry. If a pillow were anything as your kindness is. I owe you. I deserted, not trusted anymore, unwarranted. But gladly, you, huddled. And you were anything, as if weak, accepted and pressed into knees. If attempts were anything appreciated. Once I'm silent: the text, as if it hadn't been earned. With this does apology matter anything. I'll send you the text. How can I apologize a story undone. Does it matter. How can it be re-trimmed, short of teeth, blunt nails, hurt. I want to live. My trimmed heart is always punctual and soft. It so rarely hurts, always there waiting on anything but itself, pressuring me to always be so much time. I'll always be there when you need this stain inside me, man. I appreciate some dead me asking you this. In so much time and distance, silence is a loud naming of silence, a shout screaming yes aloud, a hot screaming yes, you monster. I say yes, you monster. 
My cell phone alarm for

this failed!!!!!!! Ryan

clark is a monster. Ryan

Clark is a beast. A poet.

A quiet force. Yes, the monster that lurks beneath.

$\mathrm{He}$ is that piece of you

you are afraid to love

because if you do, you

might fly. So until

capable, you call that

piece by another name.

I worked on an equation that would determine the day I'd die, solved as December 10, 2011. So I sit around waiting for the buzz of a text to say that I'm alive.
Is it mercy to hear my cell phone alarm for this failed recall, or is someone there. Calls stopped. A quiet forces the monster to lurk beneath this. Speak, you. A year afraid to love, because if I do, I might die. Soon, I'll call you, say that I can't hear me.

My cell phone alarm for mercy, hear my safely medicated failings. My cell phone alarm for this worked on an equation that I am a monster. I failed recall. Or is that what determines the beast, the poetry. Is someone there. Calls come in the day I would die. They set a quiet force. Yes, they stopped. A quiet forces December 10, 2011. So I'm a monster that lurks beneath the monster, waiting around for another piece of text that shows I'm alive. 


\section{CHAPTER V}

\section{APPROPRIATION AS INTRODUCTION TO CREATIVE WRITING}

My students know how to express themselves in conventional ways; they've been honing those skills since grade school. They know how to write convincing narratives and tell compelling stories. Yet, as a result, their understanding of language is often one-dimensional. To them, language is a transparent tool used to express logical, coherent, and conclusive thoughts according to a strict set of rules that, by the time they've entered college, they've pretty much mastered. As an educator, I can refine it, but I prefer to challenge it in order to demonstrate the flexibility, potential, and riches of language's multidimensionality....[T] here are many ways to use language: why limit to one? A well-rounded education consists of introducing a variety of approaches. [...] I think writers can learn a lot from these methods. (Goldsmith 216-217)

What skills does appropriative writing, which I define as the appropriation and/or manipulation of source texts in the composition of new creative work, foster in beginning writers? How can appropriation, which critics have argued is no more than inventive 
plagiarism, serve as an introduction to creative writing and key concepts within the field - such as authorship, originality, and the function of ethics in creative writing? What, ultimately, might students learn from these methods? The standard introductory-level creative writing course has long been concerned with the teaching of one or multiple genres to a group of undergraduates, typically incorporating discussions of craft, analysis of literary forms and devices, and, of course, a good deal of reading and workshopping. While this has undeniably proven to be a successful model in the past, the growing influence of appropriation-based writing, from Flarf and Conceptualism in poetry to the publication of bestselling author Jonathan Safran Foer's Tree of Codes - a novel literally cut out of another novel, The Street of Crocodiles by Bruno Schultz - provides an opportunity to examine what role appropriation has to play in preparing introductorylevel students for upper-level creative writing courses.

In an attempt to answer some of these questions, I designed and taught an Introduction to Creative Writing course, in the Fall of 2011, that focused solely on appropriative writing. Rather than covering creative writing genres, such as poetry, fiction, or various modes of creative nonfiction, everything in the class, including readings, lectures, class discussions, and assignments, was geared toward introducing and building familiarity with various methods of appropriative writing. Free to compose within or outside of genres, students experimented with erasure, transcription, overheard language, cut-ups, collage, chance operations, and homophonic translation to create new work while examining the nature of authorship, collaboration, and originality first-hand on a practical and experiential level. While I by no means intend to presume that this 
singular classroom experience is able to answer, in any definitive way, questions about the value of appropriative writing to the introductory-level creative writing course, I at least intend for this essay to open a dialogue about how we might consider alternative course models that seek to introduce students to creative writing by emphasizing writerly exploration and play, as well as an awareness of the great variety of possibilities for writing that exist within and outside of conventional creative writing genres.

While the teaching of appropriative writing remains largely under-theorized, there is certainly precedent for the presence of appropriation in a college curriculum which predates and helps provide context for my own experiment. Kenneth Goldsmith, one of the leading scholars and practitioners of conceptual poetry, included in his book Uncreative Writing a chapter on "Uncreative Writing in the Classroom." While this chapter offers useful points regarding appropriative writing's emphasis on critical thinking due to the heavy connection between process and meaning, Goldsmith ultimately fails to tie critical thinking back to the realm of the ethical, choosing purposefully to ignore any potential moral conflict that may arise through the act of appropriation. In the chapter, Goldsmith discusses a number of appropriative writing assignments given to students that focus mostly on retyping and transcribing various sorts of print texts and overheard language. An excerpt from the description offered for Goldsmith's course, which was offered at the University of Pennsylvania and advertised as "Experimental Writing Seminar: Uncreative Writing," reads as follows: "It's clear that long-cherished notions of creativity are under attack, eroded by file-sharing, media culture, widespread sampling, and digital replication. How does writing respond to this 
new environment? This workshop will rise to that challenge by employing strategies of appropriation, replication, plagiarism, piracy, sampling, plundering, as compositional methods" (Goldsmith 201). Goldsmith's course description is brief and should be seen more as an advertisement to students than a full pedagogical discussion, but I find it appropriate that he frames the course with a question: How does writing respond to this new copy-and-paste, download-and-seed, digital environment? While his mention of "long-cherished notions of creativity" that are "under attack" fails to offer a very nuanced or entirely accurate view of how perceptions of creativity have changed over time, the exploratory framework that he establishes through his description remains useful, as it provides a space for students to engage appropriative writing in the spirit of exploration and play that so often helps to foster creativity.

In addition to granting students students a greater familiarity with transcription as an appropriative practice, Goldsmith's course asks students to continually think about how recontextualized language both affects and reflects meaning, thereby encouraging them to "leave the class more sophisticated and complex thinkers" (Goldsmith 217). Poetry generally seems to invite this type of critical thinking, but what sets appropriative writing apart in this regard is the heavy emphasis on the conceptual meaning resulting from the composition process. In Goldsmith's case, the question of why a text was chosen and recontextualized in a certain way is paramount to the meaning of the work.

That sophisticated and complex thought is essential to Goldsmith's "Uncreative Writing" course illuminates one way that appropriative writing highlights critical thinking in the creative writing classroom, but Goldsmith's course model falls short in 
that the critical thought is restricted to the conceptual level of meaning-making only; the questions of ethics and power relations in the act of appropriation are left unaddressed, meaning that while students might be asked to consider why a text was appropriated in a certain way, they are not asked to consider what are the social and ethical effects of appropriating text. By restricting critical thought to the realm of art and aesthetics, and neglecting to connect artistic appropriation to socio-historical acts of appropriation that have been used to oppress and dominate others, this course model seems to greatly undermine the mission of liberal education, which maintains that critical thinking is essential to the development of a socially responsible citizen. Without this context, one runs the risk of reinscribing domination by appropriating irresponsibly. So while an emphasis on critical thinking is apparent in Goldsmith's course, it is simply not enough critical thinking.

Mark Amerika, "remix artist" and Professor of Art and Art History at the University of Colorado, has also taught a course that focuses on appropriation-based art practices. The description for his "Remix Culture" seminar describes the course as one that "investigates the emergence of interdisciplinary media art practices that experiment with the art of remixing...and other art forms that engage with renewable source material” (Amerika, "Remix Culture,” NP). Likewise, Amerika's remixthebook, as well as its accompanying site remixthebook.com, attempts to theorize remix culture through "a hybridized publication and performance art project" (Amerika, remixthebook, xi). Unlike Goldsmith's “Uncreative Writing” course, Amerika’s "Remix Culture” seminar is not concerned with writing, but with "interdisciplinary art practices." Still, Amerika's 
pedagogical exploration of appropriative art practices, by focusing on remix as opposed to transcription, provides another potential model for the implementation of appropriation in the creative writing workshop, as it suggests mixing found materials rather than reproducing them in new textual environments.

When an author alters and mixes texts and voices in this way, the author becomes a manipulator (rather than replicator) of materials. This allows for a different kind of conceptual engagement, one which likewise produces different kinds of ethical concerns. An erasure, for example, invites one to think about the meaning that arises not only from this new text that is left behind, but from the act of erasing the source text (is this an act of domination? silencing? an act of opposition? or merely playful reconfiguration?) as well as the relation between erasure and source text (do the two stand at odds with one another? in conversation? or does the erasure elucidate something about the source text?). Beyond recontextualization, there is a need to analyze interaction. That these questions are commonly so pivitol to the meaning of the "remixed" appropriative work allows for students to grapple with constructing and learning to identify and understand various kinds of conceptual meaning that result from such interactions in and among the texts.

I see two key differences between what I will call the remix and transcription models: first, remix emphasizes the manipulation of many different materials through cut-up, collage, and other methods, while transcription is focused on repurposing whole materials by retyping or transcribing - think of the difference between a mad scientist mixing chemicals and a filmmaker repurposing a job training video as an art film; second, while transcription is concerned primarily with concept, the remix model 
embraces both conceptual meaning and surface aesthetics. Goldsmith has expressed a desire for conceptual poetry to promote a thinkership rather than a readership, explaining that conceptual work does not need to be read to be experienced but merely thought about, but I believe that a remix model allows for the possibility of both, and, as such, a remix model might be able to develop in student writers skills that reach beyond the conceptual and into the practical level of craft. Specifically, I mean that when the content of appropriative writing is evaluated on both conceptual and aesthetic levels, students must appropriate text in ways that are both conceptually interesting and engaging for a reader. It is this combination that marks appropriative writing as potentially beneficial for introductory-level creative writing students, as it foregrounds critical thinking while also maintaining the importance of aesthetic value.

A third course model for teaching appropriative writing is described by Jena Osman in her essay "Gumshoe Poetry.” The essay's title refers to Osman's name for poetry composed via appropriative methods, otherwise known as found language poetry, as authors become like detectives who "look at the materials at hand" and "read the clues variously, until something new can be perceived" (240). "Gumshoe" also brings connotations relating to a search for justice, which I find particularly appealing. As Osman explains, "[b]y investigating the evidence to be found inside our texts - by seeing language as material that we can actively work with - perhaps we will have better tools for coming to terms with the baffling world that exists outside our texts" (249, emphasis in text). In connecting the writing done in the classroom with the world outside, Osman optimistically points to the potential for appropriative writing to provide students (and 
writers more generally) to provide critical tools for existing and acting in the world. This is an important connection to be made. Still, she understands that this is quite the leap. "In the idealistic dream version of this exercise," she writes, "the student will leave the classroom and consider every billboard, every dictionary, chemistry textbook, or newspaper as a site to be investigated, a site where a new and perhaps better text can be found" (249). The most that a teacher can do in this situation is offer the tools for critical engagement with the world outside, and that Osman recognizes the value of these tools even if she cannot be sure that students will use them - makes her "Gumshoe Poetry" course model immensely valuable. Not only are a variety of found language techniques used, but the critical thinking she encourages in her students recognizes the importance of critical thinking to being a socially responsible citizen. It is a model which "encourages an investigation into language" where one "discovers new logics beneath the surface, and thus creates a renewed picture of the textual (and consequently nontextual) world" (Osman 240). Most importantly, the course demonstrates an approach to found language that democratizes textual sites of meaning, encouraging students to participate in the making of meaning, whether by opposition or reconfiguration. It fosters in students the critical thinking tools to succeed inside the classroom as well as outside of it.

While I find Osman's course model the most appealing, the desire to empower students to investigate sites of language outside and apart from the classroom is, as Osman points out, quite optimistic. One cannot expect students to be transformed into activists after experimenting with found language poetry, no matter how radical the 
technique. This is of course one of the major shortcomings of so much Language poetry and also, as Seehwa Cho points out, of critical pedagogy:

Students do not change just because they are told to change. Similarly, teachers do not change just because they encounter the "truth." Individuals change their moralities, values, and behaviors when social structures are conducive to and can support such changes. The real task of critical pedagogy is to create the social structures that allow individuals to change and to grow. Rather than focusing on reforming individuals per se, critical pedagogy should explore alternative visions of social structures and conditions, so that ordinary teachers and students can practice and experience a pedagogy of hope, care, love, and social justice. If, however, a pedagogy of hope, care, love, and social justice is understood to be a project of (re)making or (re)forming teachers and students, it would necessarily limit, rather than expand, the exploration of possibilities for alternative politics. (99)

Cho continues by calling for a need in this exploration of possibilities to search for real, tangible alternatives rather than hopeful idealism. The democratization of language provided by appropriative writing techniques provides an excellent model on the symbolic level, but Osman's in-class exercise of tearing pages from a mystery novel and distributing them to students so that they might create poetry from the language they find is not quite the "activist exercise" that encourages critical investigation outside of a creative writing context. Unless connections to power structures and systems of 
domination are made explicit, how are students to take these kinds of textual investigations into the world outside the book?

If appropriative writing is introduced in the context of opposition and social advocacy, such that the democratization of language presented through these methods is considered on the level of ethics and power structures, then students will more readily make these kinds of connections and will be more likely to think of text outside the classroom in these kinds of ways. The emphasis here falls on fostering "an awareness of language as a means of indoctrination, or as a means of creative and critical thinking in resistance to indoctrination and domination" (Mullen 283). Because students are taught from an early age that plagiarism is a form of cheating and is highly unethical, introducing them to appropriative writing immediately gets them thinking about the ethical problems involved; in some ways, they have no choice - it's hard-wired in them that copying parts of others' work is simply forbidden. While some may view this as an obstacle to getting students excited about appropriation, it presents an excellent opportunity to begin conversations about the ethics of appropriative writing and about the structures of power behind authorship. As the conversation deepens, and as students begin to negotiate the complexities behind the act of appropriation, they will begin to see differences between, for example, Jake and Dinos Chapman painting rainbows and smiley faces on the paintings of Adolph Hitler, and Raymond McDaniel appropriating the narratives of survivors of Hurricane Katrina for his book Saltwater Empire. The differences in the power dynamics between appropriator and appropriated help to illustrate the idea that appropriation can be used for good, for ill, and even irresponsibly, 
albeit with good intentions. Once students become aware of appropriative writing that is also oppositional, in the sense that they write out against domination in order to create space for possibilities that would otherwise be silenced (such as, for example, M. Nourbese Philip's Zong!), they will more readily be able to consider the ways in which they too might be able to appropriate in order to write in opposition to the harmful language that exists outside of the classroom.

Pedagogically speaking, what I have termed appositional writing works in similar ways to culture jamming, which Carrie Lambert-Beatty claims functions as part critical pedagogy and part street performance. And while one hopes that introducing students to creative oppositional strategies will make them more critical readers of their social condition, Lambert-Beatty recognizes that this sort of artistic resistance cannot and should not replace more traditional oppositional strategies such as "community organizing, whistle-blowing, or engagement in the democratic process" (101). The importance of culture jamming, which could just as well be said for appositional writing, is that it is empowering. According to Lambert-Beatty, this process of empowerment has two distinct phases: gaining an awareness of cultural forces, and then replacing or reconfiguring their messages. "With these two movements," she writes, "it affirms freedom of thought in a world in which it seems media, government, and corporations try to do our thinking for us. It assumes, and for brief moments produces, an alert and skeptical citizenry" (Lambert-Beatty 101). As forms of cultural resistance, culture jamming and appositional writing seek to foster cultural production that is dialogic, community-minded, and politically engaged. In thinking back to Cho's concerns about 
critical pedagogy, while teaching appositional writing cannot pretend to offer opportunities for social transformation, it does offer students a democratic vision of engagement with and against the myriad ways in which the dominant discourse acts through language.

Given the proliferation of mass media, appositional writing's ability to empower students in their interaction with cultural forces presents a unique opportunity for students to craft their own narratives out of widespread, consumer-based messages that attempt to impose identities and narratives on them, which is an important pedagogical move given Peter McLaren's claim that what we perceive on television and in mass media has "become the shifting and perilous ground on which we form the judgments and decisions which forge our communal vision" (60). Especially considering the relative dearth of media exposure given to people of color, people with physical and mental disabilities, people in the GLTBQ community, and people in the lower classes, it is important that appositional writing allows for self-narration out of the very language that purposefully ignores, stereotypes, and disparages. In her essay "Narrative and Moral Life," Diana Tietjens Meyers discusses the necessity of counternarratives to repair the identities and agency of people from systematically subordinated groups, noting the importance of "self-discovery, self-definition, and self-direction skills" (303), which may also be used to stand as a fuller formulation of the need to gain an awareness of how cultural forces prescribe narratives. Once one has attained such awareness, "storytelling skills become tools of moral individuality, moral insight, and moral self-determination," in which case one is able to create through narrative a space for existing (Meyers 303). Erica Hunt, of 
course, brings a similar line of reasoning to her discussion of "Oppositional Poetics," which focuses more strongly on how the dominant discourse is able to "bind and organize us" such that the language of the dominant discourse contains us, "and we are simultaneously bearers of the codes of containment" (Hunt 199-200). Roles and narratives are inscribed, which can result in internalized oppression that restricts ones ability to be a self-determining agent, where one acts in accordance with the expectations set forth by the dominant discourse. And this is exactly why empowerment is such a key component of appositional writing as a critical pedagogy; it allows for one to take those codes of containment and reconstitute them in an effort to tell ones own story and create a space for being. Once the dominant discourse is critically read, understood, and engaged, appropriative techniques allow for self-narration out of and using the text which forms "the limits of our cages."

Despite the ethically ambitious nature of teaching appositional writing as a form of critical pedagogy, the question remains how can a creative writing course truly encourage students to gain an awareness of and write in opposition to the dominant discourse. How is the creative writing classroom an appropriate and valuable site of engagement in this way?

As I mentioned earlier, the introduction of appropriative writing to college students is already conducive to opening a discussion over the ethics of these techniques. Likewise, the traditional creative writing workshop environment is already conducive to fostering a small but close-knit "climate of trust," a term used by Annette Baier to refer to the ability of a group of people to comfortably trust one another in a state of mutual 
vulnerability. A strong climate of trust has long been an essential component for any successful creative writing workshop. Students must feel comfortable sharing what can often be very personal creative work with fellow students in the class as well as the instructor of the course. While at the start of the semester students might be complete strangers to one another, workshop dictates that work must be shared, and so the first few weeks are crucial to establishing the workshop as a safe space. The instructor is charged with fostering the classroom as a space for considerateness, which involves encouraging students to practice considerateness in the workshop environment. This means that both instructor and student alike must be "appropriately aware of how her attitudes and actions affect those around her," and also be willing to behave in a way that does not "cause fear, hurt, annoyance, insult, or disappointment in others" (Baier 178). Much of this we like to think goes without saying, but due to the often personal nature of the work presented in workshop, it is important to make the rule of considerateness explicit. Otherwise, when workshop turns overly critical or even personal, the climate of trust in the workshop is weakened. Conversely, when workshop participants are considerate of their fellow authors, working collaboratively in an attempt to improve the work presented while taking note of its existing merit, the climate of trust in the workshop is strengthened. The stronger the climate of trust, the safer space the workshop becomes, and the more confident and enthusiastic students become in sharing and discussing their work. The benefits of a strong climate of trust in the creative writing workshop are many; in addition to students feeling safe in sharing and discussing their work, students also become more free to take risks and experiment with their writing. Meanwhile, a student's 
verve for writing can receive a damaging blow from a particularly negative workshop atmosphere. The workshop then provides students with an experiential model for how a strong climate of trust is beneficial to everyone, and how a weak climate of trust serves as an obstacle to creativity, learning, and empowerment. Likewise, students in a creative writing workshop are responsible for their work and for the work of others, as the classroom is founded upon collaboration at various levels, meaning mutual vulnerability exists in tangible and readily identifiable ways that students may grasp and understand. Because the workshop serves as such an excellent model for how a climate of trust operates, a creative writing course is in the advantageous position of having the ability to demonstrate the effects of domination within the relatively small trust network that exists in the classroom. In a space where students are asked to rely on one another, despite beginning the year most often as strangers, the practice of considerateness is essential. In a course that focuses on appositional writing, the value of considerateness becomes even more important due to the vulnerability of appropriated text. Students learn to be considerate in the workshop space (or learn and suffer through the effects of inconsiderateness), but they also learn that one must be considerate regarding what texts to appropriate and how to use them. Especially when students are asked to appropriate each other's writing, considerate or inconsiderate uses of appropriated language yield immediate dividends, for better or worse. A climate of trust can become strengthened through considerate appropriation in these kinds of exercises, and this can help serve as a model for students who might choose to appropriate language from sources outside the classroom. The close-knit workshop environment allows students to engage in these 
practices while coming to understand the positive and negative effects of appropriation. This helps to foster responsible and considerate appropriation in a safe learning environment. This likewise helps to foster a safe space in which students can feel comfortable experimenting with self-narration in opposition to various examples of dominating discourse and mass media messages. The tendency for a creative writing workshop to promote a strong climate of trust makes it an ideal environment for this kind of work.

Yet while the workshop serves as a ready model for demonstrating the value of considerateness in fostering a strong climate of trust, that this is the case must be made explicit in the classroom or else one runs the risk of producing yet another model that fails to be immediately connected to the world outside. Therefore, I propose a course model for teaching appropriative writing that builds off of the work of Amerika and Osman, one which not only focuses on a variety of appropriative writing techniques but which also brings to light through discussion, readings, and assignments the issues of power and the need for considerateness involved with the creation of appropriative work. In making the relationships between language, appropriation, and power explicit, I hope for the course to respond to Hank Lazer's call for poets to "engage in an oppositional practice of form and content inseparably" (78); that is, the model of appositional writing will carry opposition in form, through appropriative methods, and also content, in the way that students are asked to self-narrate against the language of the dominant discourse that aims to constrict their narratives and identities. By providing emphasis on language, play, exploration, experimentation, awareness, and possibility, I hope to foster an 
enthusiasm for creative writing while also encouraging students to think critically about notions of authorship and originality as well as the role of ethics in creative writing and appropriative art. In order to provide a more detailed example of what this course might look like, I will describe the course as I have taught it, pointing out the key concepts, types of readings, assignments, and exercises that serve as the foundation of the course.

In developing an appropriation-based Introduction to Creative Writing course in the Fall of 2011, I planned to introduce to my students a wide range of appropriative writing methods while emphasizing a critical investigation of authorship, originality, and the possibility for oppositional work of appropriation. The course description reads: In this class we will aim to explore some of what is possible in creative writing by focusing specifically on appropriative writing, which involves using source texts to produce new work. Rather than specifying which genre in which you will be expected to write, the various methods of writing from an existing text, which can be used across genres, will be the focus of the course. Additionally, the act of writing from source texts will serve as an exploration of ethics and authorship. You will be encouraged to think about and experiment with ways of exercising ethical agency through use of the cut-up technique, overheard language, homophonic translation, erasure, and other methods. In essence, rather than looking closely at formal genres, this class is meant to be an introduction to creative writing: a chance to gather some basic skills (such as developing 
an eye/ear for original/interesting language, and the discipline of daily writing), and an opportunity to explore what writing does and can do.

I purposefully framed the course as an exploration, given that I knew there was a low probability that many of my students would come into class having experience with or even awareness of appropriative writing. In this way, I attempted to demonstrate that we were all in a similar position to explore appropriative writing and discover how it might be useful in developing our skills as creative writers. This "we're all in this together" approach, I hoped, would put the students if not also myself all on equal footing. Even though I had experience with this style, the class itself was a shared experiment. One of my students, whom I had previously taught in an English 101 class, expressed his initial reaction to the course:

Walking into this class in August, I thought that it was going to be a typical "creative writing" class. I thought that we were going to be taught things like poetry (limericks, haikus, etc.) and short stories. I was accustomed to these genres of writing, so the "creativity" aspect, to me, was not there. It was simply another writing class on my schedule. This all changed once the instructor told us of the direction that he wanted to take the class. The concept was appropriation...[and] we were all pretty confused about how exactly this was going to work. We decided that we were going into uncharted territory as a class with Mr. Clark as our instructor. (Jones, "Final Critical Essay") 
While a few other students expressed similar thoughts regarding the genre-based introductory-level creative writing course, nearly everyone expressed surprise, confusion, and uncertainty in their initial reactions to the direction of the course. Several students used the word "uncomfortable" to describe their initial feelings toward appropriative writing. One student, who enrolled in the class with a strong desire to hone his talent for writing short stories, initially showed the most resistance, although he later came to be one of the more enthusiastic practitioners of appropriative methods by the end of the course. Of his initial experience he wrote, "At first I was very put off by the idea of appropriative writing. Not only was I put off by it, but didn’t even consider it a type of writing" (Strubinger, "Final Critical Essay"). On the other end of the spectrum, another student, who had previously struggled with creative writing, wrote, "I was quickly relieved to learn that this section was specifically focusing on appropriative writing because it give me source texts to work with as opposed to only my imagination to draw from" (Ireland, "Final Critical Essay"). On the practical level of teaching students to be stronger, more sophisticated creative writers, the class was to be an exploration of artistic possibility, leaving traditional writing modes and genres behind so that we might learn other ways of producing compelling creative work.

On the more critical level of investigations into authorship, originality, and ethics, the various texts, assignments, and writing exercises would help lead us into discussions of how our conceptions of these major concepts in the field of creative writing change and shift as we become more familiar with appropriation as a mode of artistic composition. In order to track these shifts in their thinking, I required students to 
compose in conjunction with each writing assignment a critical statement, a document in which students would discuss their process for writing the piece, along with their intended effect on the reader. My primary instruction to students for writing these critical statements was for them to show their thought processes behind each piece, to demonstrate how the conceptual element contributed to the content. By being required to pay attention to both the words on the page and the concept-driven process of appropriation, students soon began to realize that the two were actually quite intertwined, and that the conceptual element could contribute to or even strengthen the meaning of a piece. One student wrote, "I found I could help my statement along, or make it stronger, based on the works I choose to borrow language from. For example, my piece on world hunger was strengthened by my use of a cookbook. I can create irony through the appropriated work" (Jackowski, "Final Critical Essay").

The writing assignments given to students were designed to ease students into appropriation gradually. While the first assignment offered an opportunity to create a piece through appropriation, without any restrictions, thusly providing students room to get their feet wet and feel out the methods for themselves, the second assignment required them to experience what it is like for their own original work to be appropriated, as students were each required to provide a sample of their original writing to another person who would then create a new text through appropriation. With the first assignment, a common trend among critical statements was an expressed hesitance to appropriate the words of others. The moral dilemna surrounding appropriation and whether it constitutes theft - with or without attribution - had gone from being an 
abstract discussion topic to a practical experience. Again, this is unsurprising given the typical conditioning of undergraduate students. Said one student: "For years the idea of using another person's work without proper citation was looked upon as plagiarism. In high school and in the first couple years of college, plagiarism was looked upon as the biggest sin to commit as a writer" (Downey, "Final Critical Essay").

The most significant shift in students' understandings of appropriation and authorship occurred following the completion of the second assignment. By having students experience first-hand the other side of appropriation - the side of the appropriated - there was a new kind of discomfort. Some students expressed frustration and even some slight resistance at the idea of turning in a piece of their writing which had been altered by someone else. Regardless, the second assignment proved effective in pushing students to think about appropriation and authorship in new ways. One student affirmed this idea in reflecting on his experience with the assignment:

It wasn't until my second piece...that I began to expand my understanding of authorship. [...] Once I had gotten my work back, I felt that it was no longer my own piece. The changes were slight and not dramatic in any way, but the piece had changed, the purpose was different and I had not been involved in that change. At that moment, when I realized that I was not the author of this new piece, I began to understand the term more fully. (Staller, "Final Critical Essay")

When I set time aside in class to discuss how students' views of authorship had changed as a result of having completed these two assignments, the discussion was full of energy, 
and everyone seemed to contribute. The most compelling comment was the idea that the amount of premeditation that went into a piece of writing directly correlates to the level of authorship felt by an individual. This became our consensus for the purpose of our discussion, and I believe it served as a new baseline for many of us in terms of how we thought about authorship.

Students' views of originality were challenged in similar ways after working with appropriation methods. One student wrote about her revised understanding of originality in the critical reflective essay assigned at the end of the course: "Something I learned in our class is that no thought is really original; someone and some previous place or time has probably already thought exactly what I have. Once I kept that in mind, I found myself much more willing to use source texts without feeling apprehensive about it" (Krist, "Final Critical Essay").

Later assignments were specifically geared toward writing about social and political issues, similar to the approaches taken by the books we read during the semester, including M. Nourbese Philip’s Zong!, Mark Nowak’s Coal Mountain Elementary, and Travis MacDonald's The O Mission Repo, all of which served as valuable models for my students. The first prompt was for students to write a piece that addressed a local campus concern, using only language found on campus, whether overheard or written. This was meant to correspond with our discussion of Nowak's Coal Mountain Elementary, a work of documentary poetics exploring the horrors of coal minining accidents, which used as source texts several testimonies from miners and the family members of miners, as well as various newspaper sources. I wanted this book to highlight the importance of carefully 
selecting source texts that apply specifically to a local concern, which, in the book's case, was the Sago mine disaster.

In reading the critical statements from this assignment, it seems that students found more success when they had a clear topic they wanted to address. One student, for example, chose to write about student debt:

I ended up sitting in all my classes for the week, just jotting down things I overheard other students saying until I had a few pages of random comments people had said. Aside from spoken word, I went around again and took words and phrases off of flyers found all over campus. With my topic in mind, I already had an idea of certain words I was looking for which made this a lot easier. (Krist, "Critical Statement \#3")

Struggles, on the other hand, often came in the form of feeling limited by the source texts. One student, who had long enjoyed coming up with interesting metaphors in her writing, said that the project, for her, was tedious and frustrating: "My found words lead me to metaphors I liked so I wanted to run with them, but the words were not there" (Jackowski, "Critical Statement \#3"). Another student encountered similar frustration while collecting language from a handout about sexual assault. After deciding that the language was not interesting enough to write an erasure piece with the handout, she was forced to change direction and instead decided to walk around campus looking for language that was more interesting to her or that "in some way alluded to sexual activity" (Stroner, Critical Statement \#3"). This same student also claimed to feel more authorship of this piece than she did with the previous two assignments. She explains, "It 
is the first of our appropriative pieces that I am truly proud of because I did not take anyone's organized work and mold it into something else. The ideas behind the placement of all of these phrases are my own" (Stroner, "Final Critical Essay").

This assignment was successful, I believe, in that it allowed students to experience for themselves the importance of selecting interesting language that is relevant to the topic at hand. The struggles, in the end, proved to be learning experiences, as students who felt limited by their source texts began to loosen their processes with future assignments, largely in the form of selecting single words and short phrases rather than longer pieces of text, as well as inserting their own language into a piece during the editing process. As demonstrated above, this also began to lead to a heightened sense of authorship on the part of the students.

The next two assignments were similar to the previous one. The prompt for assignment four was for students to write a piece, through appropriation, about a national issue, and the fifth assignment had the same prompt for a global issue. The national issue piece corresponded with Travis Macdonald's The O Mission Repo, an erasure of The 9/11 Commission Report, while the global issue piece corresponded with M. NourbeSe Philip's Zong!, a highly abstract and visually broken book of poetry about the Zong Massacre composed by creating new words from the "bones" of the transcription of the Zong court case.

The fifth assignment, in particular, provided some truly fascinating pieces, including what I found to be two of the strongest pieces written during the semester. One addressed the issue of human trafficking, while the other addressed the issue of world 
hunger. Interestingly, both took inspiration from Zong!, citing its visual and rhythmic brokenness, as well as its emphasis on repetition, as a direct influence. The piece about hunger displayed a much more experienced and purposeful approach to appropriation than I had seen previously from the class. This can be seen first-hand in the following quote from the student's critical statement:

I decided to appropriate a cook book because I knew it would have the words I need to address global hunger. I also thought a cook book would be ironic in the sense that they are created for people who have easy access to food. [...] I also decided on a poetic format in order to reflect the sort of incoherency that goes along with starvation. I want this piece to feel like the cries of people who are starving, which is why there are incomplete thoughts. Another thought comes in and speaks over the one before it. (Jackowski, "Critical Statement \#5")

At this point in the semester, as shown above, I began to notice far more sophisticated approaches to students' writing than I had seen in the beginning of the semester. The author, implementing the critical skills practiced through reading, exploring, and discussing various examples of appropriative writing, took into consideration the cookbook's implied privilege regarding access to food, which demonstrates a keen critical eye for the systems of power and privilege behind texts outside of the classroom.

The only appropriative writing method that was explicitly taught as a significant part of the course was homophonic translation, a largely un-theorized and un-taught method of appropriative writing which attempts to re-sound a source text in order to 
compose new creative work. While erasure, cut-up, and transcription, for example, are fairly straightforward methods, homophonic translation is a much more difficult and time-consuming process. After initially discussing the assignment, which required students to write a homophonic translation of a text which they found to be unethical, I gave an introductory lecture regarding the history and various approaches to homophonic translation, including both the more commonly used method of phonetic approximation and my own rules for re-sounding a source text based on each individual letter's potential to make sound. I demonstrated, for example, how "cat" could be translated into "ash" by sounding the "c" as silent (as in "indict") and the " $\mathrm{t}$ " as an "sh" sound (as in "ration").

A couple of students turned in translations that were quite powerful. One student, for example, took a great deal of time with the re-sounding process in translating a speech given by Adolf Hitler, and this effort, I believe, is what led to the amount of success he found with the piece. In particular, this student benefitted from the knowledge that nearly every letter in English appears in silent form in certain contexts, as with the "g" in "sign," giving him more freedom to extract new language from the source text. The student explains this process in his critical statement:

The first step I took while creating the piece was to highlight in my word document all of the "non-silent letters" that I couldn't erase from the speech; "f," "q," "v," and "y." Each of the letters needed to be used in the work, so I began to form words around those letters. At first I began by forming abstract words which contradicted the original text. Some of these words were "harm," "war," "hope," "peace," etc. Once I had identified 
these words, I began to build in my mind the opinion which I would express throughout my work. (Staller, "Critical Statement \#6")

In this instance, the student was able to successfully read something new, something outside of the text's original intention, and transcribe that reading in the form of translation. Just as one could re-sound "cat" as "ash," this student took an unethical text and transformed it into something else, perhaps something more ethical. Homophonic translation, through this re-sounding method, thus presents an opportunity for students to study intensely the most minute parts of language, to become aware of new linguistic possibilities, and to exercise a degree of agency in re-sounding texts as they learn to construct new narratives out of the phonological excess of those messages they find to be unethical and damaging.

The majority of the class, however, predictably expressed frustration with the method, most often stemming from the lack of control on the part of the writer. One student commented, "This assignment was extremely frustrating in that it was very hard, if not impossible, to control, at least to the degree that I'm used to" (Campbell, "Critical Statement \#6"). The response to this lack of control offers an interesting point of discussion, I believe, because it moves us into a discussion of authorship. While other appropriation methods allow room for more authorial intent and control, largely through the selection of texts to appropriate, homophonic translation requires a writer to cede a much greater amount of control over the writing process. As my students learned, it is difficult to form meaning through this method, especially as a beginner. While a few found success, such as the student who translated Hitler's speech, each student was asked 
to think about the correlation of authorship and control, discovering for themselves that the inability to control the meaning of their translations to the degree to which they were used to resulted in discomfort and frustration.

That students encounter frustration at the inability to fully control their own writing would on its own demonstrate the value of teaching homophonic translation, as it encourages students to consider the role of emotion in the construction of authorship. Authorship becomes something that is felt rather than easily labeled and absolute, and the degrees of authorship are myriad. The amount of control one feels over the outcome of a creative work, at least for my students, directly correlated with the amount of authorship they felt over the work. So much of what my students learned about authorship was experientially felt rather than understood through reason alone.

The most significant value of teaching homophonic translation, however, is its ability to transform phonological excess into the material for new oppositional narratives. One might better understand this capability through Peter McLaren's explanation of postcolonial narratology's usefulness in the classroom:

A pedagogy informed by a postcolonial narratology shifts the relation of the social actor to the object of his or her knowledge and the problematic in which identity is defined and struggled over. In this respect, a postcolonial narratology encourages the oppressed to contest the stories fabricated for them by "outsiders" and to construct counterstories that give shape and direction to the practice of hope and the struggle for an emancipatory politics of everyday life. [...] It is a pedagogy that is able to 
rupture the dominant narratives of citizenship and destabilize the pretensions to monologic identity that this narrative exhibits. (105) In regard to appositional writing as a pedagogical model, homophonic translation stands as among the most valuable (and among the most difficult) of appropriative writing methods, precisely because it is able to turn a message on its head through the process of re-sounding. The harmful narratives churned out by the dominant discourse can become something new, not by erasing or mixing text together, but by reading the text that is given in another way. The counterstory that offers "shape and direction to the practice of hope" can be found among the phonological excess hiding in the cracks, signifying so much possibility beyond that which the dominant discourse provides. So while homophonic translation remains a difficult method to work with for students, it is a valuable tool in the alternative course model that appositional writing provides.

Appropriation seems particularly well-suited to opening the door to this sort of critical engagement with key concepts in creative writing; because of this, I believe that appropriative writing can serve as a useful introduction for undergraduate students to the production of literary art. Further, appositional writing brings with it the added advantage of allowing students to more explicitly connect the acts of appropriation inherant in these methods to the very real systems of power and domination that are enacted through language in the world outside the classroom.

An important element that must accompany this heavy focus on such a specific set of writing practices as appropriative writing is the practice of daily writing. By requiring students to write in their notebooks (by hand) everyday for a set amount of 
time, a space for freedom and play is created where students can focus on the modes of writing that most interest them. Appropriative writing provides a valuable nod toward the various possibilities within creative writing, but it would be a mistake to allow appropriative writing to be the only mode that students are permitted to utilize, a regretable scenario that would only serve to close down possibility in students' writing. In my class, I encouraged students to share their daily writing journals with me at any point during the semester in order to receive feedback on the writing that many of them are most passionate about; and toward the end of the semester individual conferences would be scheduled so that each student would receive detailed feedback on the best of what they had written in their daily journals over the length of the course.

In considering alternative models for teaching creative writing, we would do well to well to place heavy emphasis on fostering among students an awareness of what creative writing is able to do in its various forms, genres, and possibilities. Jonathan Monroe offers an exciting vision of what this general model might look like:

What if the goal of teaching/learning were not so much mastery understood in a limited sense as the routinized acquisition of particular genres or modes of thinking/feeling/writing - but something like awareness, as exemplified through particular modalities of attention (including mixed modes), not for the sake of innovation as an end itself, but toward something like a more genuine freedom, not as the "other" of discipline or "rigor," but as its companion? As [Charles] Bernstein understands, the political effects of learning to read, think, and write 
"otherhow" are unlimited - especially if the effort is widespread, longterm, open-ended - and has a fundamental role to play in the formulation of citizens. (66, emphasis in text)

What we should focus on, then, is examining how alternate course models might be able to succeed in introducing students to the field and various genres and modes of creative writing, whether certain modes of writing allow for different skills to be fostered (and investigating how well or ill these modes prepare students for more advanced creative writing courses), or whether different frameworks altogether might prove successful (such as subject-based and theme-based courses, courses without workshop, and courses focused on single projects and manuscripts whether collaboratively or individually configured). Appropriative writing does not necessarily offer a better approach for introducing students to creative writing, but it successfully exposes students to new possibilities in their writing and also in how they interact with the textual world outside the classroom. It allows for discussion of craft and provides room for thinking critically about the various aspects involved with creative writing, such as authorship, originality, and ethics, which does not make it unique from more standard creative course models, as these discussions can be raised in the most conventional multi-genre workshop, but by way of the alternative approach to writing the discussions around these concepts are going to be distinctly different, providing students with unique insights as to the nature of authorship in particular. These alternate modes of writing exist, so let us see what they might be able to offer a fuller, more complex and open approach to creative writing pedagogy. 


\section{WORKS CITED}

Amerika, Mark. remixthebook. Minneapolis: University of Minnesota Press, 2011. Print.

---. "Remix Culture.” ALT-X. ALT-X Online Network. n.d. Web. 26 Jan. 2012.

Andrews, Bruce. "Poetry as Explanation, Poetry as Praxis." The Politics of Poetic Form. Ed. Charles Bernstein. Berkeley: Roof Books, 2008. 23-43. Print.

Baier, Annette C.. "Demoralization, Trust, and the Virtues." Setting the Moral Compass. Ed. Cheshire Calhoun. New York: Oxford University Press, 2004. 176-188. Print.

---. "Trust and Antitrust." Ethics 96.2 (1986): 231-260. Print.

Barthes, Roland. "The Death of the Author." The Norton Anthology of Theory and Criticism. Eds. Vincent B. Leitch, et al. New York: W. W. Norton \& Company, 2001. 1466-1470. Print.

Bloom, Harold. Anxiety of Influence: A Theory of Poetry. New York: Oxford University Press, 1973. Print.

Brophy, Kevin. Patterns of Creativity. New York: Rodopi, 2009. Print.

Burgos Jr., Adrian. Playing America's Game: Baseball, Latinos, and the Color Line. Berkeley: University of California Press, 2007. Print.

Burroughs, William S., and Brion Gysin. The Third Mind. New York: The Viking Press, 1978. Print.

Calhoun, Cheshire. "Common Decency." Setting the Moral Compass. Ed. Cheshire Calhoun. New York: Oxford University Press, 2004. 128-142. Print.

Campbell, Daniel. “Critical Statement \#6.” 17 Nov. 2011. TS.

Césaire, Aimé. Discourse on Colonialism. Trans. Joan Pinkham. New York: Monthly Review Press, 2000. Print. 
Cho, Seehwa. Critical Pedagogy and Social Change. New York: Routledge, 2013. Print.

Debord, Guy. "Situationist Manifesto." 100 Artists' Manifestos: From the Futurists to the Stuckists. Ed. Alex Danchev. London: Penguin Classics, 2011. 347-350. Print.

Deleuze, Gilles, and Felix Guattari. Kafka: Toward a Minor Literature. Trans. Dana Polan. Minneapolis: University of Minnesota Press, 1986. Print.

Dillon, Robin S.. "Kant on Arrogance and Self-Respect." Setting the Moral Compass. Ed. Cheshire Calhoun. New York: Oxford University Press, 2004. 191-216. Print.

Downey, Robby. "Final Critical Essay.” 12 Dec. 2011. TS.

Dworkin, Craig. Reading the Illegible. Evanston, IL: Northwestern University Press, 2003. Print.

Friedman, Marilyn. "Diversity, Trust, and Moral Understanding." Setting the Moral Compass. Ed. Cheshire Calhoun. New York: Oxford University Press, 2004. 217-232. Print.

Goldie, Peter. "Towards a Virtue Theory of Art." British Journal of Aesthetics 47.4 (2007): 372-387. Print.

Goldsmith, Kenneth. Uncreative Writing. New York: Columbia University Press, 2011. Print.

---. "If I were to raise my children the way I write my books, I would have been thrown in jail long ago." Harriet. PoetryFoundation.org, April 27, 2010. Web. 3 Apr. 2012 .

---. "Provisional Language." Harriet. PoetryFoundation.org, April 5, 2010. Web. 3 Apr. 2012.

Heidegger, Martin. "The Origin of the Work of Art.” Basic Writings. Ed. David Farrell Krell. San Francisco: Harper San Francisco, 1993. 143-206. Print.

Held, Virginia. "Taking Care: Care as Practice and Value." Setting the Moral Compass. Ed. Cheshire Calhoun. New York: Oxford University Press, 2004. 59-71. Print.

Hobsbawm, E. J.. The Age of Revolution: 1789-1848. Cleveland: The World Publishing Company, 1962. Print. 
Hunt, Erica. "Notes for an Oppositional Poetics." The Politics of Poetic Form. Ed. Charles Bernstein. Berkeley: Roof Books, 2008. 197-212. Print.

Hyde, Michael J. The Life-Giving Gift of Acknowledgment. West Lafayette, IN: Purdue University Press, 2006. Print.

Ireland, Robin. "Final Critical Essay." 12 Dec. 2011. TS.

Jackowski, Jenny. "Final Critical Essay." 12 Dec. 2011. TS.

---. “Critical Statement \#3.” 29 Sep. 2011. TS.

---. “Critical Statement \#5.” 27 Oct. 2011. TS.

Jaggar, Alison M. "Globalizing Feminist Ethics.” Setting the Moral Compass. Ed. Cheshire Calhoun. New York: Oxford University Press, 2004. 233-255. Print.

Jones, Riyan. "Final Critical Essay.” 12 Dec. 2011. TS.

Krist, Jessica. "Final Critical Essay.” 12 Dec. 2011. TS.

---. “Critical Statement \#3.” 29 Sep. 2011. TS.

Lambert-Beatty, Carrie. "Fill in the blank: Culture jamming and the advertising of agency." New Directions for Youth Development 125 (2010): 99-112. Print.

Lazer, Hank. Opposing Poetries, Volume One: Issues \& Institutions. Evanston, IL: Northwestern University Press, 1996. Print.

McDaniel, Raymond. Saltwater Empire. Minneapolis: Coffee House Press, 2008. Print.

---. "The Voices of Hurricane Katrina, Part II: Reflections on found poetry and the creative process." Harriet. PoetryFoundation.org, August 18, 2010. Web. 18 Oct. 2012.

McGann, Jerome and Lisa Samuels. "Deformance and Interpretation.” New Literary History 30.1 (1999): 25-56. Print.

McLaren, Peter. Critical Pedagogy and Predatory Culture. New York: Routledge, 1995. Print. 
Meyers, Diana Tietjens. "Narrative and Moral Life." Setting the Moral Compass. Ed. Cheshire Calhoun. New York: Oxford University Press, 2004. 288-305. Print.

Monroe, Jonathan. ")Writing Writing(." Poetry and Pedagogy: The Challenge of the Contemporary. Eds. Joan Retallack and Juliana Spahr. New York: Palgrave Macmillan, 2006. 63-79. Print.

Mullen, Harryette. "Between Jihad and McWorld: A Place for Poetry." Poetry and Pedagogy: The Challenge of the Contemporary. Eds. Joan Retallack and Juliana Spahr. New York: Palgrave Macmillan, 2006. 282-292. Print.

Nowak, Mark. "25 miners killed in West Virginia coal mine blast.” Harriet. PoetryFoundation.org, April 27, 2010. Web. 4 Mar. 2012.

---. Shut Up Shut Down. Minneapolis: Coffee House Press, 2008. Print.

---. Coal Mountain Elementary. Minneapolis: Coffee House Press, 2009. Print.

Osman, Jena. "Gumshoe Poetry." Poetry and Pedagogy: The Challenge of the Contemporary. Eds. Joan Retallack and Juliana Spahr. New York: Palgrave Macmillan, 2006. 239-250. Print.

Pettersen, Tove. Comprehending Care. Lanham, MD: Lexington Books, 2008. Print.

Philip, M. NourbeSe. Zong! Middletown, CT: Wesleyan University Press, 2008. Print.

Phillips, Tom. "Introduction to A HUMUMENT." HUMUMENT.COM. n.d. Web. 3 Apr. 2012.

Ring, Jennifer. “America's Baseball Underground.” Journal of Sport \& Social Issues 33.4 (2009): 373-389. Print.

Robinson, Douglas. Estrangement and the Somatics of Literature. Baltimore: The Johns Hopkins University Press, 2008. Print.

Sand, Kaia. Remember to Wave. Kane‘ohe, HI: Tinfish Press, 2010. Print.

Sandlin, Jennifer A. and Jennifer L. Milam. “"Mixing Pop (Culture) and Politics': Cultural Resistance, Culture Jamming, and Anti-Consumption Activism as Critical Public Pedagogy" Curriculum Inquiry 38.3 (2008): 323-350. Print. 
Santos Perez, Craig. from unincorporated territory [hacha]. Kane'ohe, HI: Tinfish Press, 2008. Print.

---. from unincorporated territory [saina]. Richmond, CA: Omnidawn Publishing, 2010. Print.

Staller, Nathan. "Final Critical Essay." 12 Dec. 2011. TS.

---. "Critical Statement \#6.” 17 Nov. 2011. TS.

Stroner, Kayla. “Critical Statement \#3.” 29 Sep. 2011. TS.

---. "Final Critical Essay." 12 Dec. 2011. TS.

Strubinger, Lee. "Final Critical Essay.” 12 Dec. 2011. TS.

Tolstoy, Leo. What is Art? Trans. Aylmer Maude. New York: Thomas Y. Crowell \& Co. Publishers, 1899. Print.

Venuti, Lawrence. The Scandals of Translation: Towards an ethics of difference. London: Routledge, 1998. Print.

Voyce, Stephen. "Toward an Open Source Poetics: Appropriation, Collaboration, and the Commons." Criticism 53.3 (2011): 407-438. Print.

Young, Abe Louise. "The Voices of Hurricane Katrina, Part I: What are the ethics of poetic appropriation?" Harriet. PoetryFoundation.org, August 18, 2010. Web. 18 Oct. 2012. 